\title{
Credit Derivatives and the Default Risk of Large Complex Financial Institutions
}

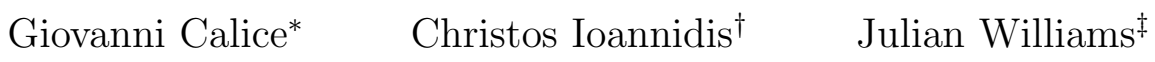

October 19, 2009

\begin{abstract}
This paper addresses the impact of developments in the credit risk transfer market on the viability of a group of systemically important financial institutions. We propose a bank default risk model, in the vein of the classic Merton-type, which utilizes a multi-equation framework to model forward-looking measures of market and credit risk using the credit default swap (CDS) index market as a measure of the global credit environment. In the first step, we establish the existence of significant detrimental volatility spillovers from the CDS market to the banks' equity prices, suggesting a credit shock propagation channel which results in serious deterioration of the valuation of banks' assets. In the second step, we show that substantial capital injections are required to restore the stability of the banking system to an acceptable level after shocks to the CDX and iTraxx indices. Our empirical evidence thus informs the relevant regulatory authorities on the magnitude of banking systemic risk jointly posed by CDS markets.

Key Words distance to default, credit derivatives, credit default swap index, financial stability

JEL Classification: C32, G21, G33
\end{abstract}

\footnotetext{
*University of Bath, School of Management, Bath BA2 7AY, Email: g.calice@bath.ac.uk.

†University of Bath, School of Management, Bath BA2 7AY, Email: c.ioannidis@bath.ac.uk.

${ }^{\ddagger}$ University of Aberdeen, Business School, AB24 3QY, Email: julian.williams@abdn.ac.uk, corresponding author. We would like to thank Hans Hvide, Tim Barmby, Michel Habib, Chris Martin and Stuart Hyde for their invaluable comments and the participants of the Warwick finance seminar series.
} 


\section{Introduction}

In recent months the global financial system has undergone a period of unprecedented instability. The current financial crisis has brought into sharp focus the need for robust empirical analysis of bank default prediction models. The contagion currently affecting the banking sector has its roots in traditional banking crises, i.e. inflated asset valuations and inadequate risk management. The difference, however, between past crises and that which appears to have began in earnest in August 2007 is the presence of the credit derivatives (CDs) market. The transmission of credit risk via these types of instruments appears, according to international financial regulators, to have amplified the current global financial crisis by offering a direct and unobstructed mechanism for channeling defaults among a variety of types of financial institutions.

Whilst the causes of this crisis are fairly well recognized, the mechanism of transmission of shocks between CDs markets and the banking sector is not so well understood from an empirical perspective. Particularly, much less is known about the effects of the credit default swap (CDS) market on the viability of systemically relevant financial institutions. The academic and practitioner literature have not yet reached firm conclusions on the financial stability implications of CDS. Consequently, we require much more analysis of the linkages between CDSs and systemic risk. Admittedly, the recent dramatic developments in financial markets prompt the need for a thorough re-examination of the "mechanics" of these instruments as well as their systemic implications.

This paper addresses three empirical questions. First, were the banks most affected by the current crisis identifiable under normal market measures, using the CDs market as a sensitivity factor? Second, what was the role played by CDS index markets in the destabilization of banks' balance sheets? Third, could these market measures be used to assist in the identification of other possible casualties as the crisis continues? This paper uses a contingent claims approach, which explicitly integrates forward looking market information and recursive econometric techniques to track the evolution of default risk for a sample of 16 large complex financial institutions (LCFIs). The impact of developments in the CD market on the asset volatility is captured by the evolution of the corporate investment-grade CDS indices (CDX and the iTraxx). CDX North-American is the brand-name for the family of CDS index products of a portfolio consisting of 5-year default swaps, covering equal principal amounts of debt of each of 125 named North American investment-grade

issuers. The iTraxx Europe index is composed of the most liquid 125 CDSs' referencing European investment grade and high yield corporate credit instruments. 
We adopt the classic distance to default (henceforth D-to-D) approach to the pricing of corporate debt. The model treats equity as a European call option on the value of assets, which are assumed to follow a geometric Brownian motion, and it imputes the value and volatility of assets from the equity market value and published liabilities of the firm. The relationship between the observed values and volatility of equity and the unobserved values of assets, and their volatility, is depicted as the solution to a non-linear two equation system. We solve the system and acquire the relevant imputed values. We then compute the D-to-D in terms of the number of standard deviations of assets and subsequently the implied probability to default.

Our distinctive contribution in this paper is to provide empirical evidence to illustrate the effect of fluctuations in the CDS index market on systemic risk. Specifically we contribute to the existing literature on credit risk models and measures of systemic risk by exploring the intuition that equity options prices and CD premia are univariate timely indicators of information pertinent to systemic risks. To the best of our knowledge, this paper is the first to combine the D-to-D analytical prediction of individual banking fragility with measures of CD markets instability. While applications of the D-to-D methodology have so far mostly concentrated in the option pricing literature, we show that the Merton approach can be applied to the area of CRT. Hence, we provide a readable implementable empirical application to infer default probabilities and credit risk (or other tail behavior) on individual LCFIs.

To this purpose, the study considers two approaches to computing the D-to-D, using differing recursive methods of forecasting the future volatility. First, we utilize the matched term risk structure from at-the-money options traded in the options market. Second, we utilize a multivariate ARCH model to forecast the future volatility conditioned on the co-evolution of the asset and the CDs market. The incorporation of uncertainty and asset volatility are important elements in risk analysis since uncertain changes in future asset values relative to promised payments on debt obligations ultimately drive default risk and credit spreads - important elements of credit risk analysis and, further, systemic risk (IMF, 2009). The econometric framework allows testing for the predictive contribution of developments in the CD market on the stability of the banking sector as depicted by the D-to-D of major financial institutions.

Our main finding is that systemically important financial institutions are exposed simultaneously to systematic CDs shocks. In practice, we find that the sensitivity of default risk across the banking system is highly correlated with the CDS index market and that this relationship is of positive sign. 
Hence, direct links between banks and the CDS index market matter. In particular, we have prima facia evidence to suggest that the information content of the CDS market indices would have led to predict the demise of Bear Stearns as well as the collapse of Lehman Brothers several months in advance.

Moreover, we extend the model to stress test the banking system sample in order to derive the required additional capital buffers for both the US and European LCFIs. The main insight from this model is that the ongoing government re-capitalization programmes considerably underestimate the necessary capital injections to preserve financial system stability.

All our results have several important implications both for the financial stability literature and for global banking regulators. The study offers an insight on how CRT market developments affect the individual and the systemic stability dimensions of the international banking system. Overall, our results lend support to the argument that CD markets are not effectively functioning as a mechanism of credit risk mitigation having, as a result, destabilizing effects on the financial system.

The remainder of the paper is organized as follows. $\S(2)$ discusses the related literature. $\S(3)$ provides an overview of the CDS market. $\S(4)$ outlines the D-to-D approach and the econometric testing methodology. $\S(5)$ describes the data. The results are presented in $\S(6)$ and $\S(7)$ concludes.

\section{Related Literature}

\subsection{Credit Derivatives and Financial Stability}

In this section we review the papers which we regard as the most representative contributions in the area. Allen and Gale (2006) [3] develop a model of banking and insurance and show that, with complete markets and contracts, inter-sectoral transfers are desirable. However, with incomplete markets and contracts, CRT can occur as the result of regulatory arbitrage and this can increase systemic risk.

Using a model with banking and insurance sectors, Allen and Carletti (2006) [2] document that the transfer between the banking sector and the insurance sector can lead to damaging contagion of systemic risk from the insurance to the banking sector as the CRT induces insurance companies to hold the same assets as banks. If there is a crisis in the insurance sector, insurance companies will have to sell these assets, forcing down the price, which implies the possibility of contagion of systemic risk to the banking sector since banks use these assets to hedge their idiosyncratic liquidity risk. 
Morrison (2005) [29] shows that a market for CDs can destroy the signalling role of bank debt and lead to an overall reduction in welfare as a result. He suggests that disclosure requirements for CDs can help offset this effect.

Bystrom (2005) [7] investigates the relationship between the European iTraxx index market and the stock market. CDS spreads have a strong tendency to widen when stock prices fall and vice versa. Stock price volatility is also found to be significantly correlated with CDS spreads and the spreads are found to increase (decrease) with increasing (decreasing) stock price volatilities. The other interesting finding in this paper is the significant positive autocorrelation present in all the studied iTraxx indices.

Building upon a structural credit risk model (CreditGrades), Bystrom (2006) [8] reinforces this argument through a comparative evaluation of the theoretical and the observed market prices of eight iTraxx sub-indices. The paper's main insight is the significant autocorrelation between theoretical and empirical CDS spreads changes. Hence, this finding proves to be consistent with the hypothesis that the CDS market and the stock market are closely interrelated.

Arping (2004) [4] shows how CDs can facilitate the banks' quest for a more effective lending relationship. He argues that CDs can have ambiguous effects on financial stability, and that disclosure requirements can strengthen the efficacy of the CDs market. Instefjord (2005) [23] analyses risk taking by a bank that has access to CDs for risk management purposes. He finds that innovations in CDs markets lead to increased risk taking because of enhanced risk management opportunities. The paper, however, does not focus on the net stability impact. In particular, since the author considers a dynamic risk management problem with infinitesimal small shocks, there are no banking defaults in equilibrium and hence the banking sector turns out to be perfectly stable.

Wagner and Marsh (2004) [35] study the impact of CRT on the stability and the efficiency of a financial system in a model with endogenous intermediation and production. These authors demonstrate that the CRT market, under certain conditions, is generally welfare enhancing. However, Wagner (2005) [34] shows that the increased portfolio diversification opportunities introduced by CRT can increase the probability of liquidity-based crises. The reason is that the increased diversification leads banks to reduce the amount of liquid assets they hold and increase the amount of risky assets.

Rajan (2005) [32] has suggested that the hedging opportunities afforded by CDs and other risk management techniques have transformed the banking industry. Banks have begun shedding ordinary risks such as interest rate risk in order to focus on more complex, borrower specific risk that they 
have a particular advantage in assessing and monitoring. This could bring important benefits, such as more focused monitoring of corporate borrowers.

An argument against CRT by banks, particularly in the case of collateralized loan obligations (CLOs), is that it leads to greater retention by banks of "toxic waste" - assets that are particularly illiquid and vulnerable to macroeconomic performance. Further, a bank that has transferred a significant fraction of its exposure to a borrower's default has lessened its incentive to monitor the borrower, to control the borrower's risk taking and to exit the lending relationship in a timely manner. As a result, CRT could raise the total amount of credit risk in the financial system to inefficient levels, and could lead to inefficient economic activities by borrowers.

It has also been suggested, for example by Acharya and Johnson (2007) [1], that because a bank typically has inside information regarding a borrower's credit quality, the bank could use CRT to exploit sellers of credit protection.

Partnoy and Skeel (2006) [25] advocate that collateralized debt obligations (CDOs) are overly complex and that the transaction costs are high with questionable benefits. They conclude that CDOs are being used to transform existing debt instruments that are accurately priced into new ones that are overvalued. Fecht and Wagner (2007) [15] show that financial innovations, designed to make banks' assets more liquid, can have two opposing effects on banking stability. By mitigating the hold-up problem between bank managers and shareholders, the role of a bank's capital structure in disciplining the bank's management becomes less important. On the other hand, as bank managers can extract smaller rents from their bank, incentives to properly monitor the bank's borrowers are reduced.

Wagner (2006) [34] argues that new CDs instruments would improve the banks' ability to sell their loans making them less vulnerable to liquidity shocks. However, this again might encourage banks to take on new risks because a higher liquidity of loans enables them to liquidate them more easily in a crisis. This effect would offset the initial positive impact on financial stability.

Wagner and Marsh (2006) [36] on the other hand, argue that especially the transfer of credit risk from banks to non-banks would be beneficial for financial stability, as it would allow for the shedding of aggregate risk that would otherwise remain within the relatively more fragile banking sector.

Duffie (2008) [13] discusses the costs and benefits of CRT instruments for the efficiency and the stability of the financial system. The argument is that if CRT leads to a more efficient use of lender capital, then the cost of credit is lowered, presumably leading to general macroeconomic benefits 
such as greater long-run economic growth. CRT could also raise the total amount of credit risk in the financial system to inefficient levels, and this could lead to inefficient economic activities by borrowers.

\subsection{Bank Default Risk and Equity Market Indicators}

Crosbie and Bohn (2003) [11] demonstrate that the co-incidence of extreme shocks to bank D-to-Ds, as measured by the Merton (1974) [28] approach, are highly demonstrable and indicative of the risk vectors associated with the Merton approach, asset quality, leverage and asset volatility being conditionally correlated and subject to extreme co-movement. Brasili and Vulpes (2005) [6] utilize the Merton approach to model the stability of large European banks. Their results are indicative of common sensitivity to broad shocks that affect financial institutions across the European Union.

Gropp et al (2005) [19] empirically test the default risk of European banks using the Merton approach coupled with a multinomial ordered logit model to model transitions. They find that the Merton approach is a useful mechanism for forecasting potential distress up to 18 months before any crisis is fully realized.

Gropp et al (2006) [19] show that the D-to-D may be a particularly suitable way to measure bank risk, avoiding problems of other measures, such as subordinated debt spreads. Chan-Lau et al (2004) [9] measure bank vulnerability in emerging markets using the D-to-D. The indicator is estimated using equity prices and balance-sheet data for 38 banks in 14 emerging market countries. They find that the D-to-D can predict a bank's credit deterioration up to nine months in advance and it may prove useful for supervisory core purposes. Gropp et al. (2004) [20] employ Merton's model of credit risk to derive equity-based indicators for banking soundness for a sample of European banks. They find that the Merton style equity-based indicator is efficient and unbiased as monitoring device. Furthermore, the equity-based indicator is forward looking and can pre-warn of a crisis 12 to 18 months ahead of time. The D-to-D is able to predict banks' downgrades in developed and emerging market countries.

Lehar (2005) [26] proposes a new method to measure and monitor banking systemic risk. This author proposes an index, based on the Merton model, which tracks the probability of observing a systemic crisis - defined as a given number of simultaneous bank defaults - in the banking sector at a given point in time. The method proposed allows regulators to keep track of the systemic risk within

their banking sector on an ongoing basis. It allows comparing the risk over time as well as between countries. For a sample of North American and Japanese banks (at the time of the Asian crisis in 
1997/98) Lehar (2005) [26] finds evidence of a dramatic increase in the probability of a simultaneous default of the Japanese banks whilst this decreases over time for the North American banks.

Tudela and Young (2003) [33] employ a model of the D-to-Ds and probabilitie of default (PD)s for individual banks to assess their level of risk. Finding that by adding the Merton structural credit model to a model based on financial ratios significantly improves the performance of that particular model. De Nicolo' et al (2004) [12] proposes a measure of systemic risk using aggregate measures of default risk, namely the portfolio $D$-to- $D$. This can be viewed as a collective risk profile measure tracking the evolution of the joint risks of failure of the firms composing a portfolio. Lower (higher) levels of the D-to-D imply a higher (lower) probability of firms' joint failure. Since variations in the individual firms' D-to-Ds are allowed to offset each other, the D-to-D of a portfolio is always higher than the (weighted) sum of the D-to-Ds of the individual firms. As a result, the probability of failure associated with the portfolio D-to-D is always lower than that associated with the actual

probability of joint failures of sets of firms in the portfolio. For a set of publicly traded European financial institutions (both banks and insurance companies) during 1991-2003, the key finding of the paper is that the risk profiles of these institutions have indeed converged, but not to lower risk levels. Convergence has likely been driven by increased exposures to common financial shocks.

\section{Credit Risk Transfer}

Techniques for transferring credit risk, such as financial guarantees and credit insurance, have been a long-standing feature of financial markets. In the past few years, however, the range of CRT instruments and the circumstances in which they are used have widened considerably. CD instruments in their most benign state are designed to provide a mechanism to spread and dilute potential default risks to a point where large default events cannot cluster in specific institutions thereby lessening the total system-wide risk. Tables 1 and 2 illustrate the astonishing growth and the composition of market participants in the CDs market.

CDSs represent the most common technique for credit risk mitigation that has emerged over the last decade. Their growth in such period has been surprisingly high, despite they are a niche product within the context of the wide segmentation of the over the counter (OTC) derivatives market. CDSs are contracts that allow to transfer credit risk from a debt holder to another counterparty. This has permitted the creation of forms of loans or synthetic investments with structured risk profiles. The principal function of CDSs is to allow the holder of the asset to separate the debt obligation from 
Table 1: Size of Global and UK CDs Market, Source: Fitch Ratings

\begin{tabular}{l|llll} 
Market & 2002 & 2004 & 2006 & 2008 est. \\
\hline Global Market & $\$ 1,952 \mathrm{~B}$ & $\$ 5,021 \mathrm{~B}$ & $\$ 20,207 \mathrm{~B}$ & $\$ 33,120 \mathrm{~B}$ \\
London Market & $\$ 1,036 \mathrm{~B}$ & $\$ 2,450 \mathrm{~B}$ & $\$ 8,083 \mathrm{~B}$ &
\end{tabular}

the risk of default or quality downgrading in exchange for the payment of a premium or spread.

\subsection{Credit Default Swap Indices}

Indices for CDSs were properly introduced in 2003, when JP Morgan and Morgan Stanley launched the market's first index, known as Trac-X. Afterwards, in June 2004, a harmonized global family of CDS indices was launched, namely iTraxx in Europe and Asia and CDX in North America and emerging markets.

The introduction of this credit index family has revolutionized the trading of credit risk due to its liquidity, flexibility and standardization. Essentially, a CDS index is a CD used to hedge credit risk or to take a position on a basket of credit entities. Unlike a single-name CDS, which is an OTC $\mathrm{CD}$, a CDS index is a completely standardized credit security and may therefore be more liquid and trade at a smaller bid-offer spread. This means that it can be cheaper to hedge a portfolio of CDSs or bonds with a CDS index than it would be to buy the many CDSs required to achieve a similar effect. The indices are constructed on a rules basis with the overriding criteria being that of liquidity of the underlying CDS. The most widely traded of the indices are the CDX North American and the iTraxx Europe.

CDX is the brand-name for the family of North American CDS index products. The investmentgrade index follows a portfolio of 125 single name 5-year default swaps covering equal principal amounts of debt of each of 125 North American investment-grade issuers.

The iTraxx Europe investment-grade index is composed of the most liquid 125 CDSs referencing European investment grade credits, subject to certain sector rules as determined by the International Investment Company. The index trades with three credit events (Failure to Pay, Bankruptcy and \% Modified-Modified Restructuring). Similar to other index benchmarks, the iTraxx Europe is further segmented into sub-indices, defined by industry groups (Sector Baskets) and trading levels (HiVol Index). These indices form a large segment of the overall CDs market.

Over the last decade, the development of securitization techniques and CDs markets, along with 
Table 2: Global Participants in the CDs Market, Source: Deutsche Bank

\begin{tabular}{l|cc} 
Institution & 2002 & 2006 \\
\hline Banks & $39 \%$ & $36 \%$ \\
Investment Companies & $16 \%$ & $17 \%$ \\
Hedge Funds & $12 \%$ & $13 \%$ \\
Insurance Companies & $33 \%$ & $34 \%$
\end{tabular}

increasing interlinkages between markets and financial intermediaries, has provided new and more efficient opportunities for the allocation, diversification and mitigation of risks among the various components of the financial system [10].

In this context, the transfer of credit risk from banks' portfolios to institutional investors (such as insurance companies, pension funds, investment funds and hedge funds) has assumed particular relevance, mainly for two reasons. The attractiveness of these high-yield investments in a period of a sharp decline in interest rates and the opportunity of diversifying their portfolios by taking on risks not correlated to those of their respective core businesses. In addition, a low rate macroenvironment has encouraged financial firms to search for high-yielding securitization investments through broadening the range of instruments they were prepared to hold.

Baur and Joossens (2006) [5] demonstrate under which conditions loan securitization can increase the systemic risks in the banking sector. They use a simple model to show how securitization can reduce the individual banks' economic capital requirements by transferring risk to other market participants and demonstrate that stability risks do not decrease due to asset securitization. As a result, systemic risk can increase and impact on the financial system in two ways. First, if the risks are transferred to unregulated market participants where there is less capital in the economy to cover these risks and second if the risks are transferred to other banks, interbank linkages increase and therefore augment systemic risk. A recent study by Hu and Black (2008) [22] concludes that, thanks to the explosive growth in CDs, debt-holders such as banks and hedge funds have often more to gain if companies fail than if they survive. The study warns that the breakdown in the relationship between creditors and debtors, which traditionally worked together to keep solvent companies out of bankruptcy, lowers the system's ability to deal with a significant downward shift in the availability of credit.

The degree to which individual banking groups are large in the sense that could be a source 
of systemic risk would therefore seem to depend on the extent to which they can be a conduit for diffusing idiosyncratic and systemic shocks through a banking system.

Broadly, two types of pure shocks to a banking system can be distinguished: systemic and idiosyncratic. The focus of attention of the authorities, entrusted with the remit of financial stability, is the monitoring of the impact of shocks affecting simultaneously all the banks in the system. A common finding in the empirical literature is that the level of banks' exposure to systemic shocks tends to determine the extent and severity of a systemic crisis. However, another source of systemic risk may originate from an individual bank through either its bankruptcy or an inability to operate.

The transmission channel of the idiosyncratic shock can be direct, for example if the bank was to default on its interbank liabilities, or indirect, whereby a bank's default leads to serious liquidity problems in one or more financial markets where it was involved.

Hawkesby, Marsh and Stevens (2005) [21] provides empirical evidence on co-movements in equity returns for a set of US and European LCFIs, by using several statistical techniques amongst which a static factor model. They find a high degree of commonality between asset price developments of most LCFIs. However, their results also show that there is still significant heterogeneity between sub-groups of LCFIs, e.g. according to geography. Increased interconnectedness among banks is also found by De Nicolò and Kwast (2002) [30], who notice a significant rise in stock price correlation for a set of large US banks, which they partly attribute to consolidation in the financial sector.

\section{Empirical Methodology}

We integrate two techniques to impute the default risks of the LCFIs in our sample. First, the underlying theoretical model is the Merton approach to default risk that assumes assets follow a Geometric Brownian motion and equity is a call option on those assets. To compute the volatility of equity and hence the volatility of the asset process we utilize a vector autoregression with multivariate generalized autoregressive conditionally heteroskedastic disturbances (VAR-MV-GARCH) model of the joint evolution in mean and variance of daily equity returns for each LCFI and the CDX and iTraxx 5 year investment-grade CDS indices. To forecast the volatility of equity we utilize a Monte Carlo procedure and define the range of expected volatilities over a one year forecast horizon. Finally, we compute the curve relating the stability of of the sample institutions (measured by the D-to-D) and the magnitude of the extra capital required to ensure that this measure lies above some predetermined 'safe' threshold. 


\subsection{The Merton Approach to Default Risk}

Merton (1974) [28] proposed the D-to-D approach to the pricing of corporate debt. The model treats equity, $V_{E} \in \mathbb{R}_{+}$, as a European call option on the value of assets, which are assumed to follow a geometric Brownian motion and imputes the value, $V_{A} \in \mathbb{R}_{+}$, and volatility, $\sigma_{A}$, of assets from the equity market value and liabilities as they appear in the balance sheet, $V_{L} \in \mathbb{R}_{+}$, of the firm. Therefore, the asset value process is assumed to be

$$
d V_{A}=V_{A}\left(\mu_{A} d t+\sigma_{A} d W_{t}\right)
$$

where $\mu_{A}$ is the drift parameter assumed to be the expected return on assets, under risk neutral pricing, $\mu_{A} \rightarrow r_{t, T}$, where $r_{t, T}$ is the expected return on risk-free instrument (such as a government bond or equivalent), from $t$ to some future date $T<t$ and $W_{t}$ is a standard Weiner process

$$
W_{t+\Delta t}-W_{t} \sim \mathcal{N}(0, \Delta t)
$$

This assumes that the assets and equity are drawn from a log-normal distribution. The basic formulation of the expected value of equity is derived via Itôs lemma and as such the pricing of an European call option on assets is given by

$$
V_{E}=V_{A} \mathcal{N}\left(d_{1}\right)-\exp \left(-r_{t, T}\right) V_{L} \mathcal{N}\left(d_{2}\right)
$$

where

$$
\begin{aligned}
d_{1} & =\frac{\log \left(\frac{V_{A}}{V_{L}}\right)+\left(r_{t, T}+\frac{1}{2} \sigma_{A}^{2}\right)(T-t)}{\sigma_{A} \sqrt{T-t}} \\
d_{2} & =\frac{\log \left(\frac{V_{A}}{V_{L}}\right)+\left(r_{t, T}-\frac{1}{2} \sigma_{A}^{2}\right)(T-t)}{\sigma_{A} \sqrt{T-t}} \\
& =d_{1}-\sigma_{A} \sqrt{T-t}
\end{aligned}
$$

where, $\mathcal{N}(z)$ is the evaluation of the standard cumulative normal distribution at $z$ and $\mathcal{N}\left(\mu, \sigma^{2}\right)$ is the univariate normal probability density function, with mean $\mu$ and variance $\sigma^{2}$. Equation 3 has two unknowns, $V_{A}$, and $\sigma_{A}$, which must be jointly imputed. Merton (1974a) derives the volatility of equity, $\sigma_{E}$, using the following expression

$$
\sigma_{E}=\left(\frac{V_{A}}{V_{E}}\right) \frac{\partial V_{E}}{\partial V_{A}} \sigma_{A}
$$

This is effectively the delta of equity

$$
\frac{\partial V_{E}}{\partial V_{A}} \equiv \mathcal{N}\left(d_{1}\right)
$$


Therefore, the volatility of equity can be computed as: $\sigma_{E}=\left(\frac{V_{A}}{V_{E}}\right) \mathcal{N}\left(d_{1}\right) \sigma_{A}$. Rearranging and combining this into a system of non-linear equations

$$
f=\left[\begin{array}{l}
V_{A} \mathcal{N}\left(d_{1}\right)-\exp \left(-r_{t, T}\right) V_{L} \mathcal{N}\left(d_{2}\right)-V_{E} \\
\left(\frac{V_{A}}{V_{E}}\right) \mathcal{N}\left(d_{1}\right) \sigma_{A}-\sigma_{E}
\end{array}\right]
$$

and setting $f=\mathbf{0}$, then both the estimated value $\hat{V}_{A}$ and the volatility $\hat{\sigma}_{A}$ of assets can be computed using quadratic optimization or similar technique ${ }^{1}$ parameters

$$
f\left(\hat{V}_{A}, \hat{\sigma}_{A}\right)=\min _{V_{A}, \sigma_{A}}\left[e^{\prime} f f^{\prime} e \mid V_{A}, \sigma_{A}\right]
$$

where $e$ identifies a 2-element unit vector. The expected number of standard deviations, $\eta_{t, T}$, from insolvency, over the period, $t \rightarrow T$, is the $d_{2}$ of the call option of the value of the assets over the value of the liabilities, i.e. the distance that this option is away from being out-of-the-money at the maturity date

$$
\eta_{t, T}=\frac{\log \left(\frac{\hat{V}_{A}}{V_{L}}\right)+\left(\mu-\frac{1}{2} \hat{\sigma}_{A}^{2}\right)(T-t)}{\hat{\sigma}_{A} \sqrt{T-t}}
$$

The market clearing probability of default, of the $i^{\text {th }}$ institution is, therefore

$$
p_{i, t}=p\left(\eta_{t, T}\right)=\mathcal{N}\left(-\eta_{t, T}\right)
$$

Table 3 illustrates the common sources of the variables required to impute the D-to-D, $\eta_{t, T}$.

\subsection{Forecasting Equity Volatility via VAR-MV-GARCH modelling}

We consider a VAR-MV-GARCH framework to model the co-evolution of equity and CDS spreads. The two CDS indices represent the condition of the global credit market and are designed to capture potential information that describes the valuation and volatility of assets. The basic model framework is an unrestricted VAR with MV-GARCH disturbances which treats the equity return process as a multivariate Brownian motion, sampled at daily intervals. The VAR-MV-GARCH framework has the advantage of treating the instantaneous and lagged covariation as fully endogenous, with the system undergoing structural shocks, from each of the three elements in the stochastic vector.

Appendix A outlines the recursive structure of the parameter stability tests and presents the model parameters for the equilibrium model. For computational reasons we assume a VAR(1)-MVGARCH(1,1) specification for the recursive model. Appendix C illustrates the results in impulse

\footnotetext{
${ }^{1}$ The FSOLVE algorithm in Matlab is used to solve for $\hat{V}_{A}$ and $\hat{\sigma}_{A}$.
} 
Table 3: Variables required to infer the $\mathrm{D}$-to- $\mathrm{D}, \eta_{t, T}$. The codes included here are the Thomson Reuters DataStream ${ }^{\mathrm{TM}}$ data-type and instrument codes used to build the dataset. The full processed data-set in MatLab format is available from the University of Aberdeen website.

\begin{tabular}{|c|c|c|c|}
\hline Variable & Description & Notes & Code (Datastream) \\
\hline \multirow{2}{*}{$V_{L}$} & \multirow{2}{*}{ Value of Liabilities } & Balance Sheet $\$$ US & \multirow{2}{*}{ (WC03351) $\tilde{\mathrm{U}} \$$} \\
\hline & & Quarterly Frequency & \\
\hline$V_{E}$ & Value of Equity & Market Capitalization (\$ US) & $(\mathrm{MV}) \tilde{\mathrm{U}} \$$ \\
\hline$\sigma_{E}$ & Volatility of Equity & $\begin{array}{l}\text { VAR - MV - GARCH computed } \\
\text { using dividend adjusted return } \\
\text { index and CDS indices. }\end{array}$ & $(\mathrm{RI}) \tilde{\mathrm{U}} \$$ \\
\hline$r$ & Risk-Free Rate & $\begin{array}{l}\text { Term Structure from } \\
\text { US - Zero Curve }\end{array}$ & US00Y01 - US00Y12 \\
\hline$C D X$ & Indicator CDS index US & $\begin{array}{l}C D X \text { index of } \\
5 \mathrm{Y} \text { Investment-Grade (basis points) }\end{array}$ & CDX5YIG \\
\hline$i \operatorname{Trax} x$ & Indicator CDS index Europe & $\begin{array}{l}i \operatorname{Trax} x \text { index of } \\
5 \mathrm{Y} \text { Investment-Grade (basis points) }\end{array}$ & ITX5YIG \\
\hline
\end{tabular}

response framework utilizing a Cholesky decomposition approach. The vector process that describes the contemporaneous evolution of equity returns is

$$
\mathbf{y}_{t}=\left[\Delta \log \left(V_{E, t}\right), \Delta \log \left(C D X_{t}\right), \Delta \log \left(i \operatorname{Trax} x_{t}\right)\right]^{\prime}
$$

The in-mean model is an unrestricted VAR model of order $r$

$$
\mathbf{Y}=\mathbf{X} \Pi+\mathbf{U}
$$

where:

$$
\mathbf{Y}=\left[\begin{array}{c}
\mathbf{y}_{t=r+1}^{\prime} \\
\vdots \\
\mathbf{y}_{t=\tau}^{\prime}
\end{array}\right], \quad \mathbf{X}=\left[\begin{array}{ccccc}
\mathbf{y}_{t=r} & \mathbf{y}_{t=r-1} & \cdots & \mathbf{y}_{t=1} & 1 \\
\vdots & \vdots & \ddots & \vdots & \vdots \\
\mathbf{y}_{t=\tau-1} & \mathbf{y}_{t=\tau-1} & \cdots & \mathbf{y}_{t=\tau-r} & 1
\end{array}\right]
$$

with matrix of parameters

$$
\boldsymbol{\Pi}=\left[\begin{array}{llll}
\pi_{1,1} & \pi_{1,1} & \cdots & \pi_{1,3 r} \\
\pi_{2,1} & \pi_{2,1} & \cdots & \pi_{2,3 r} \\
\pi_{3,1} & \pi_{3,1} & \cdots & \pi_{3,3 r}
\end{array}\right]^{\prime}
$$

and disturbances

$$
\mathbf{U}=\left[\begin{array}{c}
\mathbf{u}_{t=r}^{\prime} \\
\vdots \\
\mathbf{u}_{t=\tau}^{\prime}
\end{array}\right], \quad \mathbf{u}_{t}=\left[u_{E, t}, u_{C D X, t}, u_{i \operatorname{Trax} x, t}\right]^{\prime}
$$


The volatility of equity may then be modeled as a multivariate ARCH type model

$$
\begin{aligned}
\mathbb{E}\left(\mathbf{u}_{t} \mathbf{u}_{t}^{\prime}\right) & =\boldsymbol{\Sigma}_{t} \\
\boldsymbol{\Sigma}_{t} & =\mathbf{K} \mathbf{K}^{\prime}+\mathbf{A}^{\prime} \mathbf{u}_{t-1} \mathbf{u}_{t-1}^{\prime} \mathbf{A}+\mathbf{B}^{\prime} \boldsymbol{\Sigma}_{t-1} \mathbf{B}
\end{aligned}
$$

where $\left\{\mathbf{A} \in \mathbb{R}^{3 \times 3}, \mathbf{B} \in \mathbb{R}^{3 \times 3}\right\}$ are matrices of autoregressive parameters and $\mathbf{K}$ is a $3 \times 3$ lower diagonal matrix of intercept parameters. We utilize the BEKK representation of Engle and Kroner (1994) [14] as this guarantees a positive semi-definite conditional covariance matrix. This condition is required by the Cholesky factorization that is used for computing the impulse responses in mean, variance and correlation and the covariance forecasts used to estimate capital shortfalls. Maximum likelihood estimation is used to find the optimal parameter vector $\hat{\theta}$. Consequently, the log likelihood function $\mathfrak{F}($.$) is defined as follows$

$$
\mathfrak{F}(\theta)=-\frac{1}{2}\left(n \tau \log (2 \pi)+\sum_{t=1}^{\tau} \log \left|\boldsymbol{\Sigma}_{t}\right|+\left(\mathbf{y}_{t}-\mu_{t}\right)^{\prime} \boldsymbol{\Sigma}_{t}\left(\mathbf{y}_{t}-\mu_{t}\right)\right)
$$

The implied asset volatility $\sigma_{A, t}$ is, therefore, a function of the implied covariation $\sigma_{A, i \operatorname{Trax} / C D X, t}$ from the MV-ARCH structure.

$$
\sigma_{A, t}=\sigma_{E, t}\left(\frac{V_{A, t}}{V_{E, t}}\right)^{-1} \mathcal{N}\left(d_{1, t}\right)^{-1}
$$

The model ascribes the contemporaneous and lagged dynamics of the credit indices endogenously within the volatility structure.

\subsection{Estimation and Model Stability}

The model is fitted using maximum likelihood estimation (MLE). We utilize the SQL routine in MatLab to jointly estimate the in-mean VAR and the MV-GARCH disturbance model, using OLS estimates and determinant loss functions for initial guesses for the parameter matrices

$$
\begin{aligned}
\mathbf{y}_{t} & =\boldsymbol{\Pi}_{0} \mathbf{y}_{t-1}+\mathbf{\Pi}_{1}+\mathbf{u}_{t} \\
\boldsymbol{\Sigma}_{t} & =\mathbf{K} \mathbf{K}^{\prime}+\mathbf{A} \mathbf{u}_{t-1} \mathbf{u}_{t-1}^{\prime} \mathbf{A}+\mathbf{B} \boldsymbol{\Sigma}_{t-1} \mathbf{B} \\
\left(\tilde{\mathbf{\Pi}}_{0}, \tilde{\mathbf{\Pi}}_{1}\right) & \sim O L S(\mathbf{Y}=\mathbf{X} \boldsymbol{\Pi}+\mathbf{U}) \\
(\tilde{\mathbf{K}}, \tilde{\mathbf{A}}, \tilde{\mathbf{B}}) & \sim \min \left|\tilde{\mathbf{u}}_{t} \tilde{\mathbf{u}}_{t}^{\prime}-\boldsymbol{\Sigma}_{t}\right|
\end{aligned}
$$

The analysis suggests that the degree of fit changes significantly through time. Figure 1 illustrates the normalized likelihood scores for the pre-defined group of banks. 


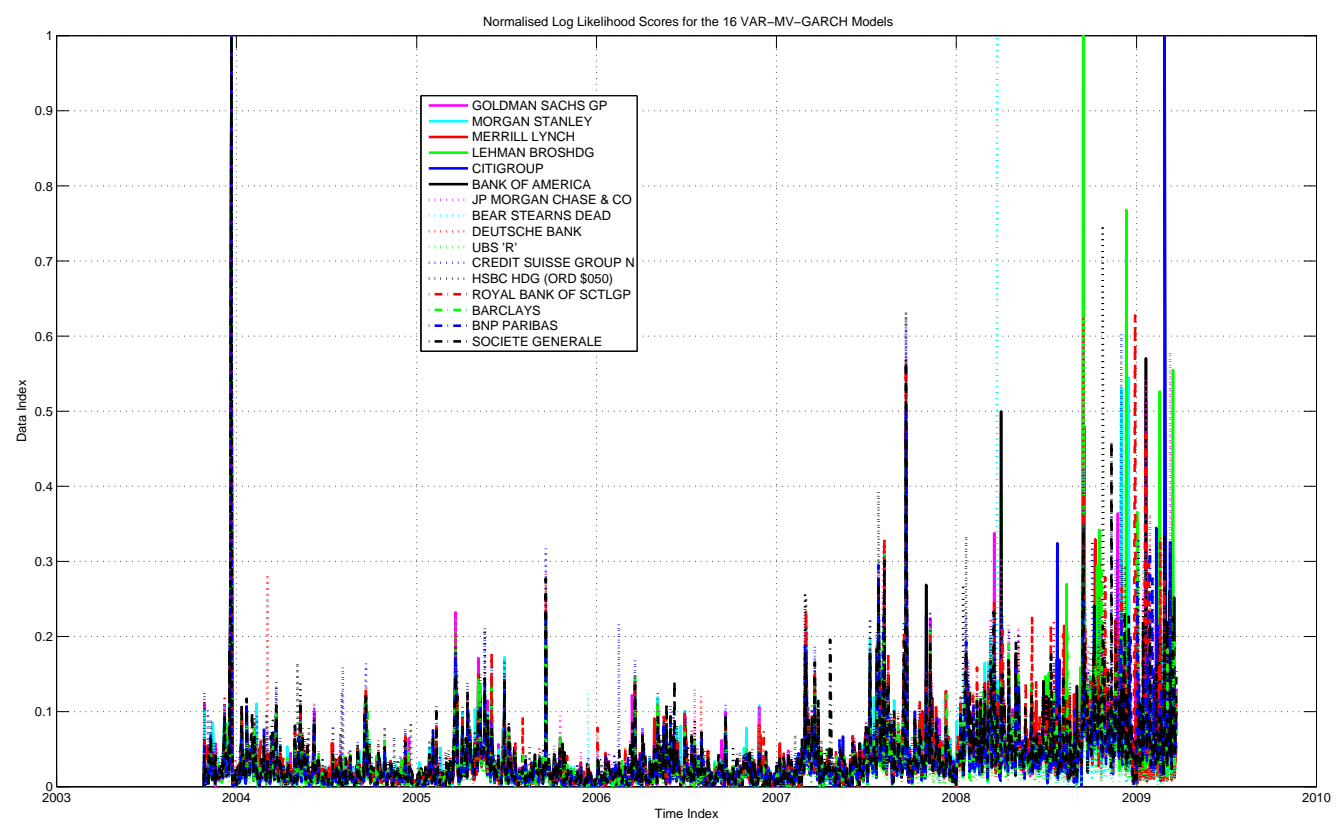

Figure 1: The normalized likelihood scores for the 16 VAR-MV-GARCH models

We utilize the ethos of the Giacomini (2002) [16] and Giacomini and White (2006) [18] approach weighting by importance the MLE fit using the initial models normalized likelihood scores. The final model parameters and estimated standard errors are reported in table A. Figure 1 plots the normalized likelihood scores for the sixteen recursive models the sixteen LCFIs in our sample. The financial crisis that began in August 2007 clearly shows up as a significant adjustment in terms of the accuracy of the models (the larger and more clustered the values the worse is the model accuracy).

\subsection{Forecasting Volatility Scenarios}

The final step is to forecast equity volatility regimes and then impute corresponding asset volatilities to stress test the banks' balance sheets. We accomplish this by Monte Carlo simulation for $s-s t e p$ ahead forecasts of the VAR model. Consider a vector draw of iid $\varepsilon_{i} \sim \mathcal{N}(0,1)$, for s-steps, then the 
first two steps of the $i^{t h} \in B$ Monte Carlo pathway are

$$
\begin{aligned}
\boldsymbol{\Sigma}_{t+1}= & \mathbf{K} \mathbf{K}^{\prime}+\mathbf{A}\left(\mathbf{y}_{t}-\hat{\mathbf{y}}_{t}\right)\left(\mathbf{y}_{t}-\hat{\mathbf{y}}_{t}\right)_{t}^{\prime} \mathbf{A}^{\prime}+\mathbf{B} \boldsymbol{\Sigma}_{t} \mathbf{B}^{\prime} \\
\mathbf{y}_{i, t+1}= & \boldsymbol{\Pi}_{0} \mathbf{y}_{t}+\boldsymbol{\Pi}_{1}+\boldsymbol{\Sigma}_{t+1}^{\frac{1}{2}} \varepsilon_{i, t+1} \\
\boldsymbol{\Sigma}_{i, t+2}= & \mathbf{K} \mathbf{K}^{\prime}+\mathbf{A}\left(\boldsymbol{\Sigma}_{t+1}^{\frac{1}{2}} \varepsilon_{i, t+1}\left(\boldsymbol{\Sigma}_{t+1}^{\frac{1}{2}} \varepsilon_{i, t+1}\right)^{\prime}\right) \mathbf{A}^{\prime} \\
& +\mathbf{B}\left(\mathbf{K} \mathbf{K}^{\prime}+\mathbf{A}\left(\mathbf{y}_{t}-\hat{\mathbf{y}}_{t}\right)\left(\mathbf{y}_{t}-\hat{\mathbf{y}}_{t}\right)_{t}^{\prime} \mathbf{A}^{\prime}+\mathbf{B} \boldsymbol{\Sigma}_{i, t} \mathbf{B}^{\prime}\right) \mathbf{B}^{\prime} \\
\mathbf{y}_{i, t+2}= & \boldsymbol{\Pi}_{0}\left(\boldsymbol{\Pi}_{0} \mathbf{y}_{t}+\boldsymbol{\Pi}_{1}+\boldsymbol{\Sigma}_{t+1}^{\frac{1}{2}} \varepsilon_{i, t+1}\right)+\boldsymbol{\Pi}_{1}+\boldsymbol{\Sigma}_{t+2}^{\frac{1}{2}} \varepsilon_{i, t+2}
\end{aligned}
$$

where $\mathbf{E}_{i} \in \mathbb{R}^{B \times 3}$, we continue for $s$-steps and for our sample we assume $s=252$ trading days. In addition, we stratify 10 volatility regimes from which we impute 10 expected annual asset volatilities. Using the Merton approach for each regime, we can derive D-to-D indicators over a continuum of asset values for each corresponding asset volatility scenarios ${ }^{2}$.

\subsection{Objective Stability Measures}

Consider a policy objective default risk probability, over some relative time horizon $T-t$, defined as $p^{*}$, such that for any systemically important institution, $p_{i, t}>p^{*}$. The probability of default at time $t$, for the $i^{\text {th }}$ institution, will be conditioned on the imputed conditional annualized volatility, $\hat{\sigma}_{A, t}$, and value of assets, $\hat{V}_{A, t}$. For any given systemically important financial institution suffering from some form of financial distress, with probability of default, $p_{i, t}<p^{*}$, the difference in probability $p^{*}-p_{i, t}$, under the assumption of conditional normality, will correspond to the difference between the objective D-to-D and the current imputed distance

$$
\delta_{i, t}=\eta\left(p^{*}\right)-\eta\left(p_{i, t}\right)
$$

If $\delta_{i, t}<0$, then we define $\delta_{i, t}$ as the distance to distress, if $\delta_{i, t}>0$, then we define $\delta_{i, t}$ as the distance to capital adequacy. Given $\delta_{i, t}>0$, the required capital injection to boost the value of assets to a point whereby $\eta\left(p^{*}\right)=\eta\left(p_{i, t}\right)$, i.e. $\gamma_{i, t}=V_{A}\left(p^{*}\right)-V_{A}\left(p_{i, t}\right)$, is defined as the capital shortfall.

\section{Data}

The data used in this paper is presented in Table 3. The sample period extends from October, 20 2003 to April, 292009 for a total of 1462 trading days. All data is obtained from Thomson Reuters,

\footnotetext{
${ }^{2}$ We assume a geometric brownian motion, therefore scale adjustments from daily to annual volatilities are as follows, if $(t+1)-t=1$ day, then for the average return over 1 day, $E_{t}\left(r_{t+1, t}\right)=x$ the annual return is $r_{t+252, t}=252 x$, whilst in standard deviations, $\sigma_{t+1, t}=\varsigma$ the annualized volatility will be $\sigma_{t+252, t}=\varsigma \frac{1}{\sqrt{\frac{1}{252}}} \approx 15.83 \varsigma$, the so called rule of 16 .
} 
Datastream. Liabilities are reported on a quarterly basis and are interpolated to daily frequency using piecewise cubic splines.

The LCFIs in this study consist of three UK banks, two French, two Swiss, one German and eight US based institutions. These financial institutions are ABN Amro/Royal Bank of Scotland, Bank of America, Barclays, BNP Paribas, Citigroup, Credit Suisse, Deutsche Bank, Goldman Sachs, HSBC Holdings, JP Morgan Chase, Lehman Brothers, Merrill Lynch, Morgan Stanley, Société Générale and UBS. In addition, we consider Bear Stearns, given its crucial role as market-maker in the global CDs market. These institutions are systemically important as the fallout from a bank failure can cause destabilizing effects. Not only does an institution's size matter for its systemic importance - its interconnectedness and the vulnerability of its business models to excess leverage or a risky funding structure matter as well. The Bank of England Financial Stability Review (2001) [31] sets out classification criteria for LCFIs. In particular, the focus is on transnational operations and the relative size of these operations compared to their banking peers. Marsh, Stevens and Hawkesby (2003) [27] present the empirical evidence for the justification of the LCFI classification list. To join the group of LCFIs studied, a financial institution must feature in at least two of six global rankings on a variety of operational activities (these are set out in table 4). We stick to the 2003 rankings and information so that the systemically important institutions prior to the recent financial crisis are included.

Appendix $\mathrm{G}$ reports on the empirical work we have undertaken in analyzing the various indices available to measure credit risk. Figures 15 to 26 depict the evolution of the variables used in the econometric model over the sample period, in addition to several other CDS benchmarks that we have examined in the data analysis stage of this research. These indices are broad investment-grade barometers of investment grade risk and preliminary studies suggest that these offer a reasonable benchmark of the corporate credit environment.

Figures 20 and 21 display the evolution of the credit indices, whilst figures 15 to 18 show the financial data collected for each firm. All values are converted in US\$ and stock prices are dividend adjusted, in the standard manner

$$
R I_{t}=R I_{t-1} \frac{P I_{t}}{P I_{t-1}}\left(1+\frac{D Y_{t}}{100} \times \frac{1}{N}\right)
$$

where $R I_{t}$ is the dividend adjusted return index, $P I_{t}$ is the price process, $D Y_{t}$ is the reported annualized dividend yield, $N$ is the annual number of trading days, usually between 252 and 260 and $t$ is the discrete time index. Dividend adjusted returns are then computed using $r_{t, t-1}=$ 
Table 4: LCFI Inclusion Criteria, Source: Marsh, Stephens and Hawkesby (2003), page 94

1. Ten largest equity bookrunners world-wide

2. Ten largest bond bookrunners world-wide

3. Ten largest syndicated loans bookrunners world-wide

4. Ten largest interest rate derivatives outstanding world-wide

5. Ten highest FX revenues world-wide

6. Ten largest holders of custody assets world-wide.

$\log \left(R I_{t}\right)-\log \left(R I_{t-1}\right)$

\section{Empirical Analysis}

The objective of our analysis is to forecast the asset volatility and its conditional quadratic covariation with the benchmark CDS indices. The VAR-MV-GARCH model captures time varying dependency in both direction and variation of the dynamic equations of interest (in this case equity, CDX and iTraxx). The results from VAR-MV-GARCH models are presented in appendix A. We also present Wold representations (impulse responses) in mean and variance in appendix C. The vast majority of the estimated coefficients are statistically significant and there is no evidence of statistical misidentification. From the estimated coefficients we calculate the time evolution of the conditional volatilities and associated correlation coefficients.

The impulse response analysis illustrates the magnitude and significance of the interrelationships between the CD indices and the equity of the LCFIs. We can see that, both in mean and variance, the transmission of shocks between the various banks equity returns and the log-difference of the CDS indices is highly significant in a variety of directions. Furthermore, the dynamic correlation analysis suggests significant adjustments in the structural correlations between the equity returns and the log-differences of the CDS indices. Some of the correlation adjustments post-crisis are quite striking. For instance, Bank of America and Citigroup show significant directional adjustments to the correlation structure with the CDS indices.

The employment of the VAR-MV-GARCH models allows for the estimation of volatility transmission between the elements entering the VAR. The results indicate a strong negative correlation between both indices and institutional equity and more importantly when the correlation between the indices increases, there is a marked rise in the negative correlation between equity returns and the indices. The average correlation between the indices increases from approximately .4 to a value in excess of .6, whilst the correlation between the indices and equity returns becomes more pronounced 
with an average value of -.6 compared to -.25. Such patterns are observed uniformly across all the banks and constitute strong evidence of detrimental volatility transmission between the evolution of the indices and the equity of all the banks included in this study. It is the uniformity of reaction, both in terms of size and direction to the same shock, that constitutes a severe threat to the stability of the banking system. Impulse response analysis in mean, standard deviation and correlation, illustrated in appendix C suggests a bidirectional relationship between equity and asset volatility and the credit indices. This seems to permeate across all banks and this response structure is evidenced in the change correlations observed over the sample.

On the basis of these estimates, we compute the value of the assets (figure 34), imputed volatility (figure 38), the D-to-D (figure 36) and the subsequent probability of default (figure 37) for the sixteen LCFIs. For ease of presentation and within country comparability, the results are disaggregated into US, UK, Swiss/German and French LCFIs. Despite the obvious similarities in the emerging patterns, there are substantial differences in the probability of default both between countries and between institutions based in the same country. For example, in the UK whilst all banks are subject to substantial increases to default probability in January 2008, for HSBC the relevant probability is just above 5\% (on an annual basis) whilst for Royal Bank of Scotland it exceeds 35\%, rendering the bank totally dependent on government support to ensure its survival.

After the announcement of in-all-but-name nationalization of the bank, the associated probability of default declines sharply to the 'safer' levels within the three banks sub-sample. For the US group, there is a relatively wide range of differences in the probability of default between the eight institutions as some of them show distinct reductions whilst for others the probability of default increases over the latest part of the period under consideration. Overall, the results indicate that systemic bank risks and CD shocks appear to be highly dependent. This likely reflects the fact that distress in the CRT market may have a detrimental impact on the state of the overall financial system, via direct or indirect links.

On the basis of the econometric evidence, we proceed by conducting a bank stress-testing exercise for given value of the liabilities to evaluate the imputed adequate bank capital requirements to ensure their financial strength and stability. Such rather strong assumption is justified in the current circumstances because their valuation is more accurate when compared to the valuation of assets. For a range of asset value volatility, as estimated from the VAR-MV-GARCH models, we compute the required equity capital injection required for a maximum tolerated default probability of $1 \%$ per 
annum. The results are presented in figures 29-31. The limiting D-to-D is denoted by the horizontal line that marks the associated D-to-D for each bank given the imposed $1 \%$ probability to default lower limit. The results reveal that there are substantial differences between the banks, given the asset volatility that have been experiencing. These figures associate the required increase in the value of the equity for any given value of volatility.

Consider Bank of America, whose asset volatility ranges from 0.019 to 0.15. If volatility increases to 0.034 , to ensure the institution's stability (that is to say its probability of default does not exceed $1 \%$ ), it would require the injection of US\$ 75 billion of additional equity capital. Interestingly, the volatility range experienced by European banks is far narrower than that of their American counterparts. This points to comparatively modest capital injections to restore them to safety as for a wide range of volatilities there is no requirements for an additional capital surcharge, whilst for the US banks the 'safe range' of volatilities is somewhat narrow.

The global financial crisis, manifested in the marked increase in bank equity volatility consequential to disturbances to the CRT market, thus results in dramatic decreases in bank capitalization. It also seems to impair profoundly the balance sheets of the major financial institutions to the point that the market adjusted valuation of their assets, via the Merton model, almost fail to exceed the increased value of their liabilities, culminating in severe multiple-institution distress and, thus, potential banking sector insolvency. The assets to liabilities ratios $\log \left(V_{A} / V_{L}\right)$ for all the sixteen banks are depicted in figure 19. After a sharp decline over 2007 and the early part of 2008, a strong reversal is observed as the banks benefited from substantial injections of capital from both government and institutional investors. However, overall the core banking system remains rather fragile compared to the conditions prevailing in 2005 and 2006.

The results of the stress-testing procedure suggest that in the presence of significant loss of asset value, the 'survival' of the institutions require considerable capital injections. Without such policies, with the notable exception of HSBC, the banks included in this study enter the 'insolvency state', albeit for rather brief periods, as the value of their liabilities tend to exceed their assets. Remaining in a high-volatility regime for long could indicate a serious threat to the stability of the banking system. Consequently, there is clear evidence that the resilience of the banking sector is conditional upon a sustained improvement to the banks' balance sheets. As a result, there remains considerable scope for further capital injections in the near future.

Some points should be made about the capital requirements computed using the D-to-D method- 


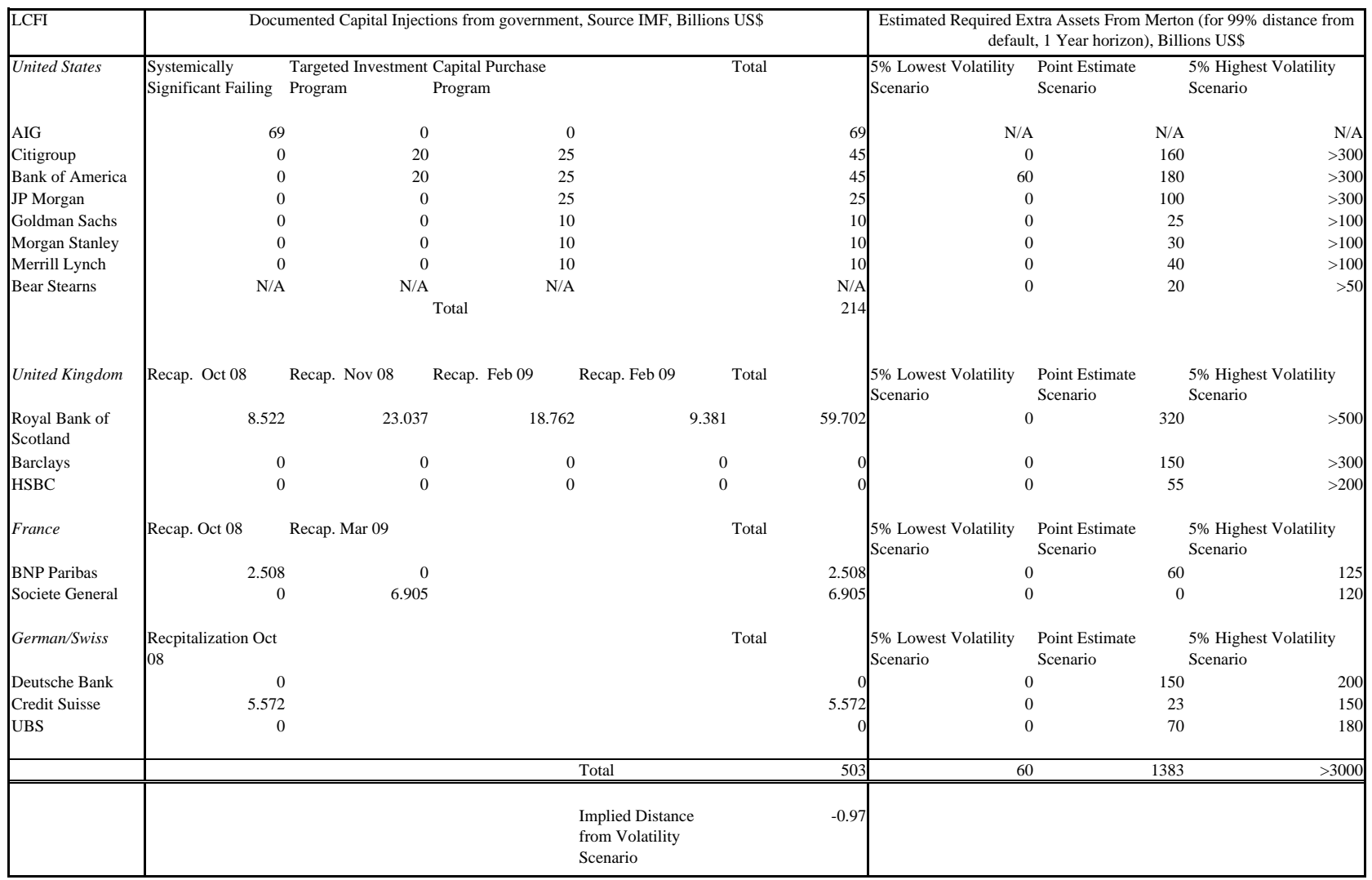

Figure 2: Capital injections comparison and Merton market measure versus actual. All projections are for 10,000 Monte Carlo paths of daily equity/asset volatilities for 1 year for the period April 2009 to April 2010, from 100 day recursive projections, original asset values held constant. 
ology. The assets are always assumed to be drawn from a pool that preserves the overall level of volatility and as such, in reality, capital injections by governments should be considered almost risk-less and, therefore, will necessarily reduce overall balance sheet risks. Nevertheless, the level of claw-back on these assets may or may not be recognized under their liabilities and this is a current point of debate in policy circles particularly in the US and the UK.

The value of this approach appears to be in normal operation, whereby the leveraging of current capital bases may be regulated by how the markets gauges the quality of a bank's balance sheets. We infer the volatility of assets via the Merton approach, however, a very simple fundamentals approach may be used to create a pricing model that aggregates total asset volatility and this may then be benchmarked against the market view.

Stress testing involves hypothesizing changes in the aggregate volatility of the banks' assets and gives a simple measure of potential risk vectors in their aggregate form. These types of measures should prevent banks from transparently leveraging themselves to a point whereby they are extremely vulnerable to changes in asset volatility, which would then require costly readjustments, possibly forcing a bank below some critical solvency thresholds. This study looks at banks sensitivities to the corporate credit risk environment, proxied by the two most closely watched CDs pricing benchmarks (CDX North America and iTraxx Europe main indices). In this sense, it is used as a common measure to all of the institutions in our sample. The VAR-MV-GARCH model endogenizes the co-evolution of equity returns and these measures of global credit risk in both directions and spread for instantaneous covariation (MV-GARCH) and auto-covariation (VAR). Estimating the model recursively does not

fully account for rapid discontinuities and these should be addressed in future work using appropriate econometric tools to test for these structures.

\section{Concluding Remarks}

Bank default risk is currently the predominant issue affecting financial practitioners and policy makers across the world. The recent failure of several LCFIs illustrates that the too big to fail paradigm predominant in analysis of the financial stability of large mainstream commercial and investment banks is no longer valid. We approach the issue of the stability of the banking sector by studying the potential effects of CDs on the statistical moments of the equity of LFCIs.

This paper offers a concrete illustration of the direct links between the global banking system and the CDS index market. We propose a set of models and empirical tests for predicting the current 
and future linkages between various CD markets and financial institutions. Specifically, we jointly model the evolution of equity returns and asset return volatility of 16 systemically important LCFIs, using a VAR-MV-GARCH model, with the evolution of the two standardized CDS indices. The conditional equity volatilities are used to impute the value and volatility of assets using a Merton type model.

The impact of developments in the CD market on the asset volatility is captured by the evolution of the investment-grade CDX North-American and the iTraxx Europe indices. We estimate a multivariate GARCH model to forecast the future volatility conditioned on the co-evolution of the equity returns and the CDs market. The econometric framework allows for testing of the predictive contribution of developments in the CD market on the stability of the banking sector as depicted by the D-to-D of major financial institutions.

The evidence of the paper suggests that the presence of a market for CDs would tend to increase the propagation of shocks and not act as a dilution mechanism. Empirically, we demonstrate that there is, in general, a substantial detrimental volatility spill-over from the CDs market to bank equity, undermining the stability of the banking system in both the USA and Europe.

In view of this evidence, we conclude that banks' equity volatility associated with significant stress in the CD market matters for systemic distress. In the presence of increasing volatility, financial institutions require fresh capital injections. Our calculations are based on the assumption that the value of liabilities is known, therefore the safety and soundness of each particular institution is a function of the market value of the assets. Future research should relax this assumption and allow for the stochastic fluctuation of the value of the liabilities and its possible relationship with the value of assets. An additional innovation could be the adoption of pareto-stable distributions in place of the normal distribution that is commonly believed to underestimate the true frequency of extreme observations. This study helps to shed more light on the CDS index market and its interaction with other markets and inform on regulatory implications. Authorities are currently implementing a diverse set of regulatory regimes to ensure an effective regulation of CD markets through enhanced transparency and disclosure of the sector. The on-going debate on CD markets regulation calls for further investigation - both theoretical and empirical - to assist policymakers and regulators to identify the most effective regulatory response. Overall, the results of this paper improve our understanding of financial innovation and add to the existing setting for analyzing the potential of CDs to affect systemic risk in the global financial system. 


\section{References}

[1] V. V. Acharya and C. T. Johnson, Insider trading in credit derivatives, Journal of Financial Economics Vol. 84, No. 1 (2007), pp. 110-141.

[2] F. Allen and E. Carletti, Credit risk transfer and contagion, Journal of Monetary Economics No. 53 (2006), 80-111.

[3] F. Allen and D. Gale, Financial contagion, Journal of Political Economy Vol. 108, No. 1 (2000), 1-33.

[4] S. Arping, Credit protection and lending relationships, University of Amsterdam Working Paper (2004).

[5] D. Baur and E. Joossens, The effect of credit risk transfer on financial stability, EUR Working Paper No. 21521 (2006).

[6] A. Brasili and G. Vulpes, Co-movements in EU banks' fragility: A dynamic factor model approach, UniCredit Group, Working Paper Series (2005).

[7] H. N. E. Bystrom, Credit default swaps and equity prices: The iTraxx CDS index market, Lund University Working Paper Series (2005).

[8] _ Creditgrades and the iTraxx CDS index market, Financial Analysts Journal Vol. 62, No. 6 (2006), pp. $65-76$.

[9] J. A. Chan-Lau, D. J. Mathieson, and Y. J. Yao, Extreme contagion in equity markets, IMF Staff Paper Series Vol. 51, No. 2 (2004), 386-408.

[10] Basel Committee, Credit risk transfer, Basel Committee on Banking Supervision, Bank for International Settlements (January, 2003).

[11] P. Crosbie and J. Bohn, Modeling default risk, Moody's KMV (2003).

[12] G. de Nicoló, G. Corker R., Tieman A., and J-W van der Vossen, European financial integration, stability and supervision, IMF Country Report 05/266 (2005), 113146.

[13] D. Duffie, Innovations in credit risk transfer: Implications for financial stability, BIS Working Paper No. 255 (2008). 
[14] R. F. Engle and K. F. Kroner, Multivariate simultaneous generalized ARCH, Econometric Theory 11 (1995), 122-150.

[15] F. Fecht and W. Wagner, The marketability of bank assets and managerial rents: implications for financial stability, Tech. report, 2007.

[16] R. Giacomini, Comparing density forecasts via weighted likelihood ratio tests: Asymptotic and bootstrap methods, Boston College Working Papers in Economics 583, Boston College Department of Economics, June 2002.

[17] R. Giacomini and B. Rossi, Detecting and predicting forecast breakdowns, SSRN eLibrary (2006) (English).

[18] R. Giacomini and H. White, Tests of conditional predictive ability, Econometrica 74 (2006), no. $6,1545-1578$.

[19] R. Gropp, M .Lo Duca, and J. Vesala, Cross-border bank contagion in Europe, ECB Working Paper Series No. 662 (2006).

[20] R. Gropp, J. Vesala, and G. Vulpes, Equity and bond market signals as leading indicators of bank fragility, Journal of Money, Credit and Banking No. 38 (2006), 399-428.

[21] C. Hawkesby, I. W Marsh, and I. Stevens, Comovements in the prices of securities issued by large complex financial institutions, Bank of England: Financial Stability Review: Dec 2003 (2003), 91-101.

[22] H. T. C. Hu and B. Black, Debt, equity, and hybrid decoupling: Governance and systemic risk implications, European Financial Management (2008).

[23] N. Instejord, Risk and hedging: Do credit derivatives increase bank risk?, Journal of Banking and Finance No. 29 (2005), 333-345.

[24] C. Ioannidis and J. M. Williams, Multivariate GARCH models with impulse responses in mean, variance and covariance, SSRN eLibrary (2008) (English).

[25] D. A. Skeel Jr and F. Partnoy, The Promise and Perils of Credit Derivatives, University of Cincinnati Law Review, Vol. 75, p. 1019, 2007 (English). 
[26] A. Lehar, Measuring systematic risk: A risk management approach, Journal of Banking and Finance No. 29 (2005), 2577-2603.

[27] I. W. Marsh, I. Stevens, and C. Hawkesby, Large complex financial institutions: Common influences on asset price behaviour?, Bank of England Working Paper Paper No. 256 (2005).

[28] R. C. Merton, On the pricing of corporate debt: The risk structure of interest rates,", Journal of Finance Vol. 29 (1974), 449-70.

[29] A. D. Morrison, Credit derivatives, disintermediation, and investment decisions, Journal of Business No. 78 (2005), pp. 621-648.

[30] G. De Nicoló and M. L. Kwast, Systemic risk and financial consolidation: Are they related?, Journal of Banking and Finance No. 26 (2002), 861-880.

[31] Bank of England, Financial stability review, Bank of England Publications No. 11 (2001), $137-159$.

[32] G. R. Rajan, Has financial development made the world riskier?, NBER Working Paper Series No. 11728 (2005).

[33] M. Tudela and G. Young G, Predicting default among uk companies: A merton approach, Bank of England: Financial Stability Review (2003), 104114.

[34] W. Wagner, The liquidity of bank assets and banking stability, Journal of Banking and Finance Vol. 31 (2007), 121-139.

[35] W. Wagner and I. Marsh, Credit risk transfer and financial sector performance, CEPR Discussion Paper No. 4265 (2004).

[36] _ Credit risk transfer and financial sector stability, Journal of Financial Stability (2006), 173-193. 


\section{A Impulse Response and Summary Statistics For Overall VAR- MV-GARCH model}

We utilize the Williams and Ioannidis (2009) [24] approach to computing the impulse responses for a general VAR-MV-GARCH model. Consider the general unrestricted stationary linear vector autoregression model of a vector process $\mathbf{y}_{t}$ with endogenous and exogenous components as well as some structural errors, the matrix form of this model is as follows

$$
\mathbf{Y}=\mathbf{X I}+\mathbf{U}
$$

where

$$
\begin{aligned}
\mathbf{Y}= & {\left[\mathbf{y}_{t=1}, \mathbf{y}_{t=2}, \ldots \mathbf{y}_{t=\tau}\right]^{\prime} } \\
\mathbf{X}= & {\left[\begin{array}{cccc}
\mathbf{y}_{-1} & \mathbf{y}_{t=1} & \cdots & \mathbf{y}_{t=\tau-1} \\
\mathbf{y}_{-2} & \mathbf{y}_{-1} & \cdots & \mathbf{y}_{t=\tau-2} \\
\vdots & \vdots & \ddots & \vdots \\
\mathbf{y}_{-r} & \mathbf{y}_{-r+1} & \cdots & \mathbf{y}_{t=\tau-r}^{\mathrm{T}} \\
\mathbf{x}_{t=1} & \mathbf{x}_{t=1} & \cdots & \mathbf{x}_{t=1}
\end{array}\right] } \\
= & {\left[\begin{array}{llll}
v e c \mathcal{Y}_{t=1} & v e c \mathcal{Y}_{t=2} & \cdots & v e c \mathcal{Y}_{t=\tau} \\
\mathbf{x}_{t=1} & \mathbf{x}_{t=2} & \cdots & \mathbf{x}_{t=\tau}
\end{array}\right]^{\prime} }
\end{aligned}
$$

and the disturbances

$$
\mathbf{U}=\left[\mathbf{u}_{t=1}, \mathbf{u}_{t=2}, \ldots, \mathbf{u}_{t=\tau}\right]
$$

The parameter matrix, $\boldsymbol{\Pi}$, is partitioned as follows

$$
\Pi=\left[\boldsymbol{\Pi}_{0}^{\prime}, \boldsymbol{\Pi}_{1}^{\prime}\right]^{\prime}
$$

Impulse response analysis focuses on the deviation from equilibrium of the elements of $\mathbf{y}_{t}$. Rewriting the multi-equation framework as an $n$ length column vector process in $\mathbb{R}^{n}$ with discrete time increments $t$, where $t \in[1,2, \ldots, \tau]$, with $\mathbf{x}$ as an $m$ length column vector process of exogenous driving variables (in this case simply the intercept), including the intercept term, $\mathbf{u}_{t}$ is a conditionally multi-normal disturbance term, $\boldsymbol{\Pi}_{0}$ and $\boldsymbol{\Pi}_{1}$ are parameter matrices, of $n r \times n$ and $n \times m$ dimensions respectively.

\section{A.1 Impulse Responses in Variance and Covariance}

To compute the impulse responses two dynamic processes must be taken into account. First the influence of the shock which is decaying relative to the dynamic structure of the mean equation. 
Second, there is an impulse on the second moment matrix (by 1 long run standard deviation) that will dissipate following the underlying MV-GARCH effects. We define the response in variance to unit shock in $\varepsilon$ as $\frac{\partial v e c h \mathbb{E}\left(\boldsymbol{\Sigma}_{t+s}\right)}{\partial \varepsilon_{t}}$. This updating will also affect the mean equations via the changing the eigenvalues of the conditional covariance matrix, $\boldsymbol{\Sigma}_{t \mid t_{2}, \ldots, t-r}{ }^{3}$. Williams and Ioannidis (2009) [24] set out the full derivation of generalized impulse responses for VAR-MV-GARCH models.

\section{A.2 Recursive Estimation and Confidence Bounds}

One of the major issues when a possible structural change occurs is to identify the manner by which the model parameters may change. Our approach to this problem involves the comparison between the model estimated over the full sample and a recursively estimated model. Consider the conditional forecasts in mean and in variance-covariance for a $\operatorname{VAR}(1)-\mathrm{MV}-\mathrm{GARCH}(1,1)$ estimated over the whole sample, $[t=1, \ldots, \tau]$, via maximum likelihood

$$
\begin{aligned}
\hat{\mathbf{y}}_{t} & =\hat{\mathbf{\Pi}} \mathbf{y}_{t-1}+\hat{\mathbf{c}} \\
\hat{\mathbf{\Sigma}}_{t} & =\hat{\mathbf{K}} \hat{\mathbf{K}}^{\prime}+\hat{\mathbf{A}}^{\prime}\left(\mathbf{y}_{t-1}-\hat{\mathbf{y}}_{t-1}\right)\left(\mathbf{y}_{t-1}-\hat{\mathbf{y}}_{t-1}\right)^{\prime} \hat{\mathbf{A}}+\hat{\mathbf{B}}^{\prime} \hat{\mathbf{\Sigma}}_{t-1} \hat{\mathbf{B}}
\end{aligned}
$$

The comparison model forecasts are estimated recursively and denoted by the superscript $r$ over a window of length $\tau^{\prime}$

$$
\begin{aligned}
\hat{\mathbf{y}}_{t}^{r} & =\hat{\mathbf{\Pi}}^{r} \mathbf{y}_{t-1}+\hat{\mathbf{c}}^{r} \\
\hat{\mathbf{\Sigma}}_{t}^{r} & =\hat{\mathbf{K}}^{r} \hat{\mathbf{K}}^{r \prime}+\hat{\mathbf{A}}^{r \prime}\left(\mathbf{y}_{t-1}-\hat{\mathbf{y}}_{t-1}^{r}\right)\left(\mathbf{y}_{t-1}-\hat{\mathbf{y}}_{t-1}^{r}\right)^{\prime} \hat{\mathbf{A}}^{r}+\hat{\mathbf{B}}^{r \prime} \hat{\mathbf{\Sigma}}_{t-1}^{r} \hat{\mathbf{B}}^{r}
\end{aligned}
$$

\footnotetext{
${ }^{3}$ where the vech operator is the column-wise stacking of the lower diagonal and above elements of a square matrix. For example

$$
\begin{aligned}
& \operatorname{vech}(\mathbf{A})=\mathbf{a} \\
& \mathbf{a}=\left[\begin{array}{c}
a_{1,1} \\
\vdots \\
a_{1, n} \\
a_{2,2} \\
\vdots \\
a_{2, n} \\
\vdots \\
a_{n-1, n-1} \\
a_{n, n-1} \\
a_{n, n}
\end{array}\right] \\
& \text { ivech }(\mathbf{a})=\left[\begin{array}{ccccc}
a_{1,1} & 0 & \cdots & 0 & 0 \\
a_{2,1} & a_{2,2} & \cdots & 0 & 0 \\
\vdots & \vdots & \ddots & \vdots & \vdots \\
a_{n-1,1} & a_{n-1,2} & \cdots & a_{n-1, n-1} & 0 \\
a_{n} & a_{n} & \cdots & a_{n, n-1} & a_{n, n}
\end{array}\right]=\mathbf{A}
\end{aligned}
$$


The local observed log-likelihoods at time $t$, are therefore respectively

$$
\begin{aligned}
\mathfrak{L}_{t}(\theta) & =-\frac{1}{2}\left(n \tau \log (2 \pi)+\left|\hat{\boldsymbol{\Sigma}}_{t}\right|+\left(\mathbf{y}_{t}-\hat{\mathbf{y}}_{t}\right)^{\prime} \hat{\boldsymbol{\Sigma}}_{t}^{-1}\left(\mathbf{y}_{t}-\hat{\mathbf{y}}_{t}\right)\right) \\
\mathfrak{L}_{t}\left(\theta^{r}\right) & =-\frac{1}{2}\left(n \tau^{\prime} \log (2 \pi)+\left|\hat{\boldsymbol{\Sigma}}_{t}^{r}\right|+\left(\mathbf{y}_{t}-\hat{\mathbf{y}}_{t}^{r}\right)^{\prime}\left(\hat{\boldsymbol{\Sigma}}_{t}^{r}\right)^{-1}\left(\mathbf{y}-\hat{\mathbf{y}}_{t}^{r}\right)\right)
\end{aligned}
$$

We adapt the local KLIC model of Giacomini and Rossi (2007) [17] to impute the local relative fit of the two models

$$
\Delta K L I C_{t}=\mathbb{E}\left(\mathfrak{L}_{t}\left(\theta_{t}\right)-\mathfrak{L}_{t}\left(\theta^{r}\right)\right)
$$

The evolution of $\Delta K L I C_{t}$ is then normalized and compared to the local fluctuation test proposed in Giacomini and Rossi (2007) [17] for multivariate cross comparison models. The Table in figure 3 illustrates the estimated parameters for the whole sample model. Whilst the local $K L I C$ does appear to favour the recursive model through the financial crisis, there is only a short period through 2008 where the local fluctuation and local variation tests suggests that this is significant for more than 8 out of 16 banks $^{4}$.

\footnotetext{
${ }^{4}$ Full local variation and local fluctuation plots are available on request.
} 
Figure 3: Full sample VAR-MV-GARCH models for each LCFI in the sample.

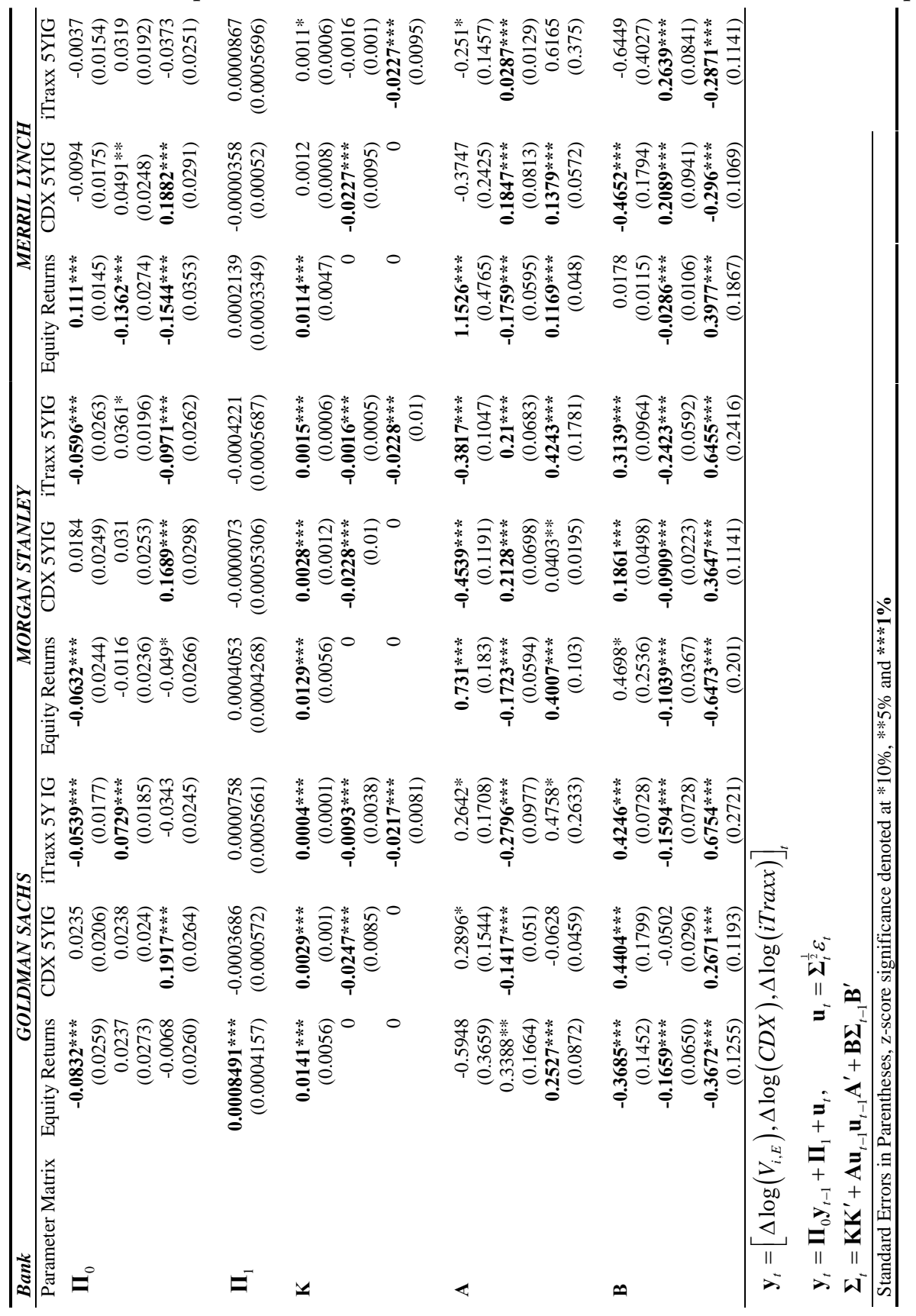




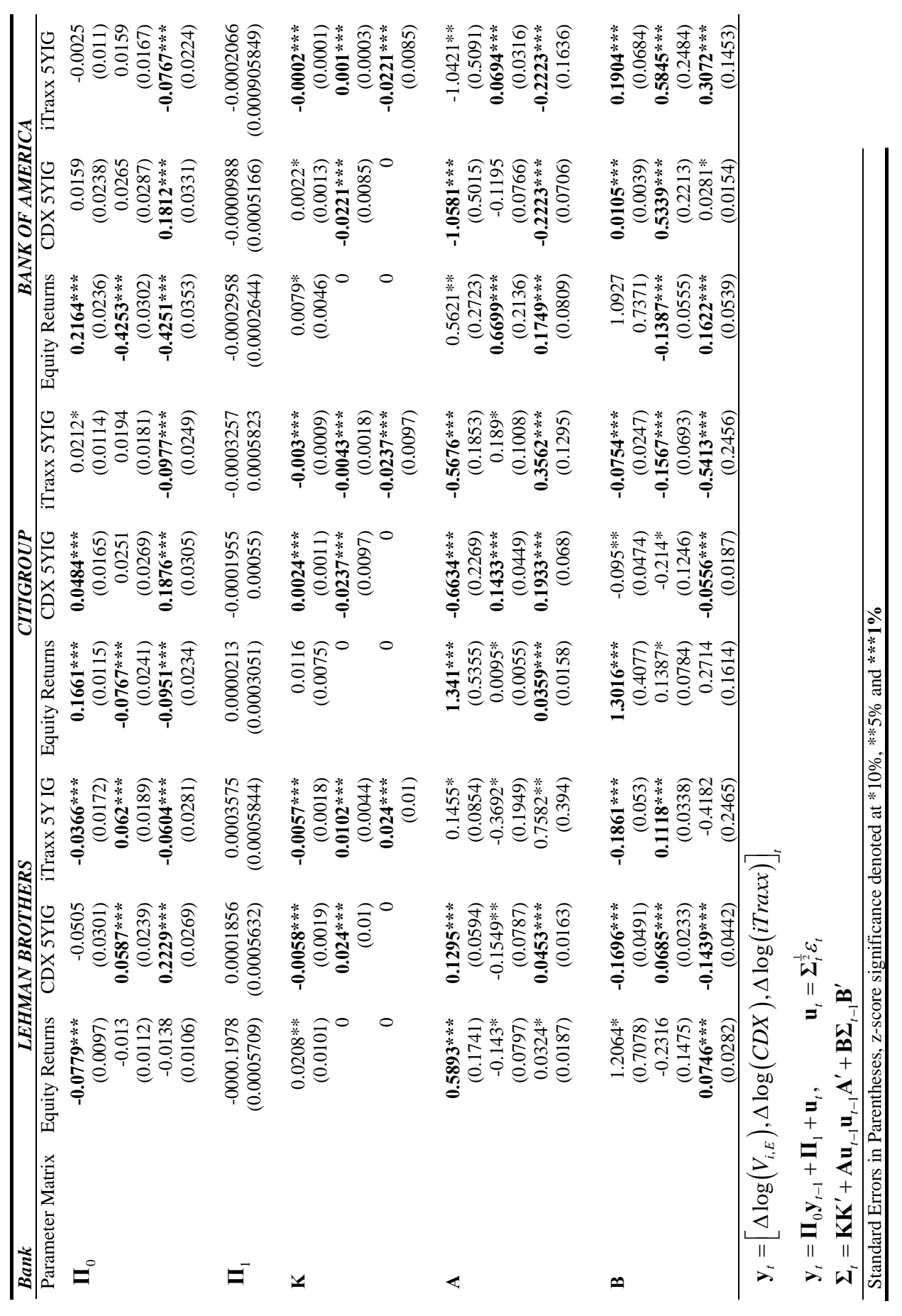




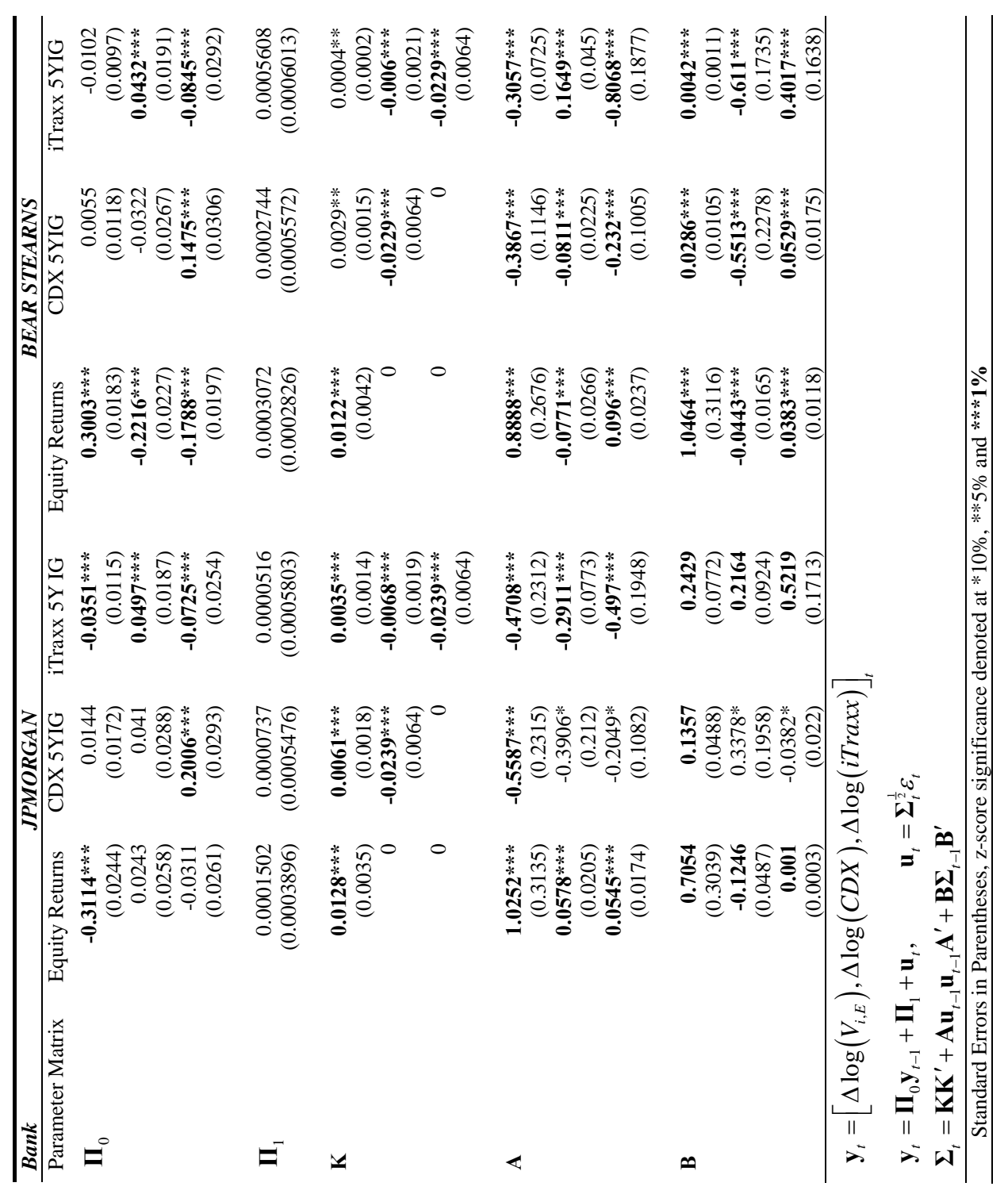




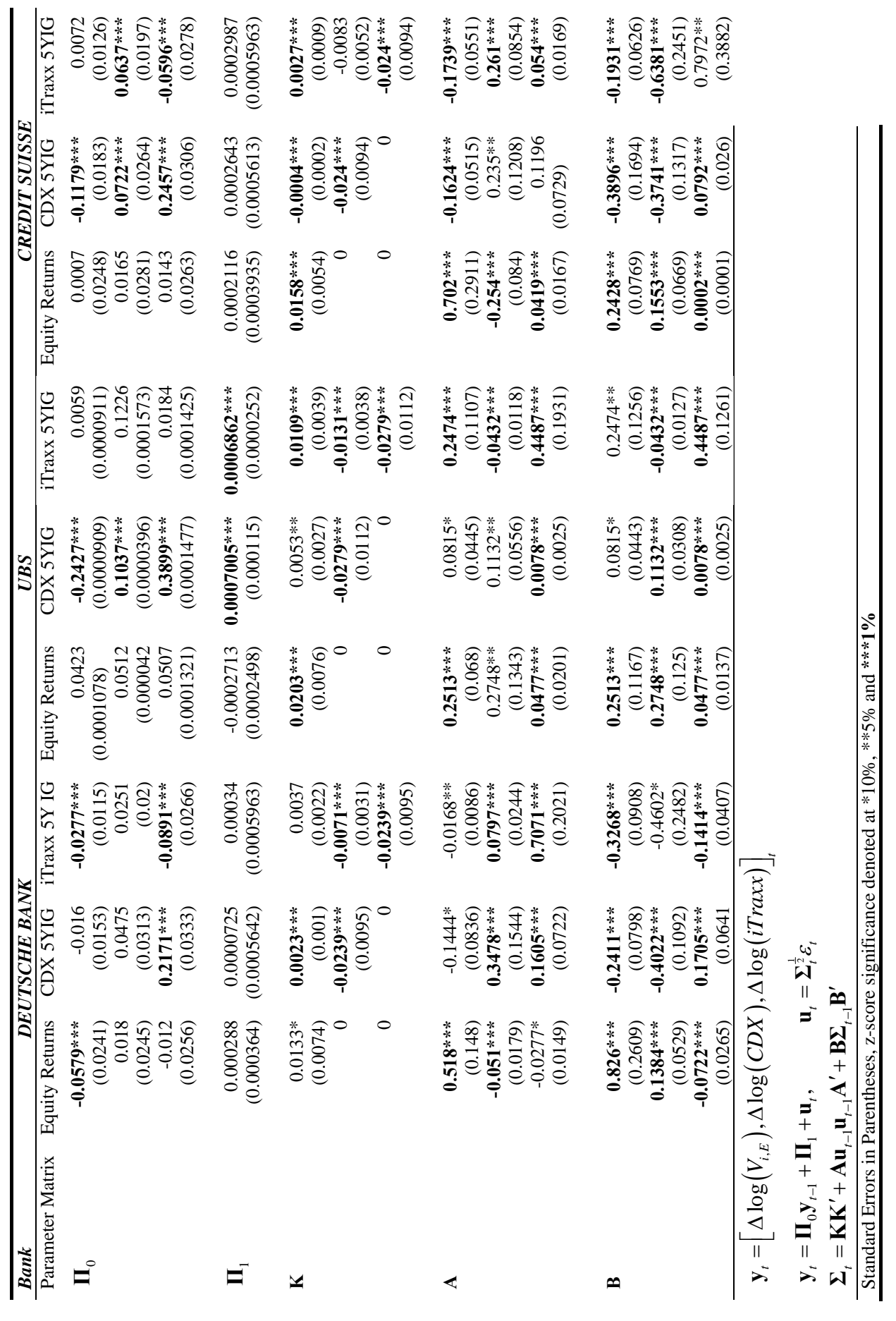




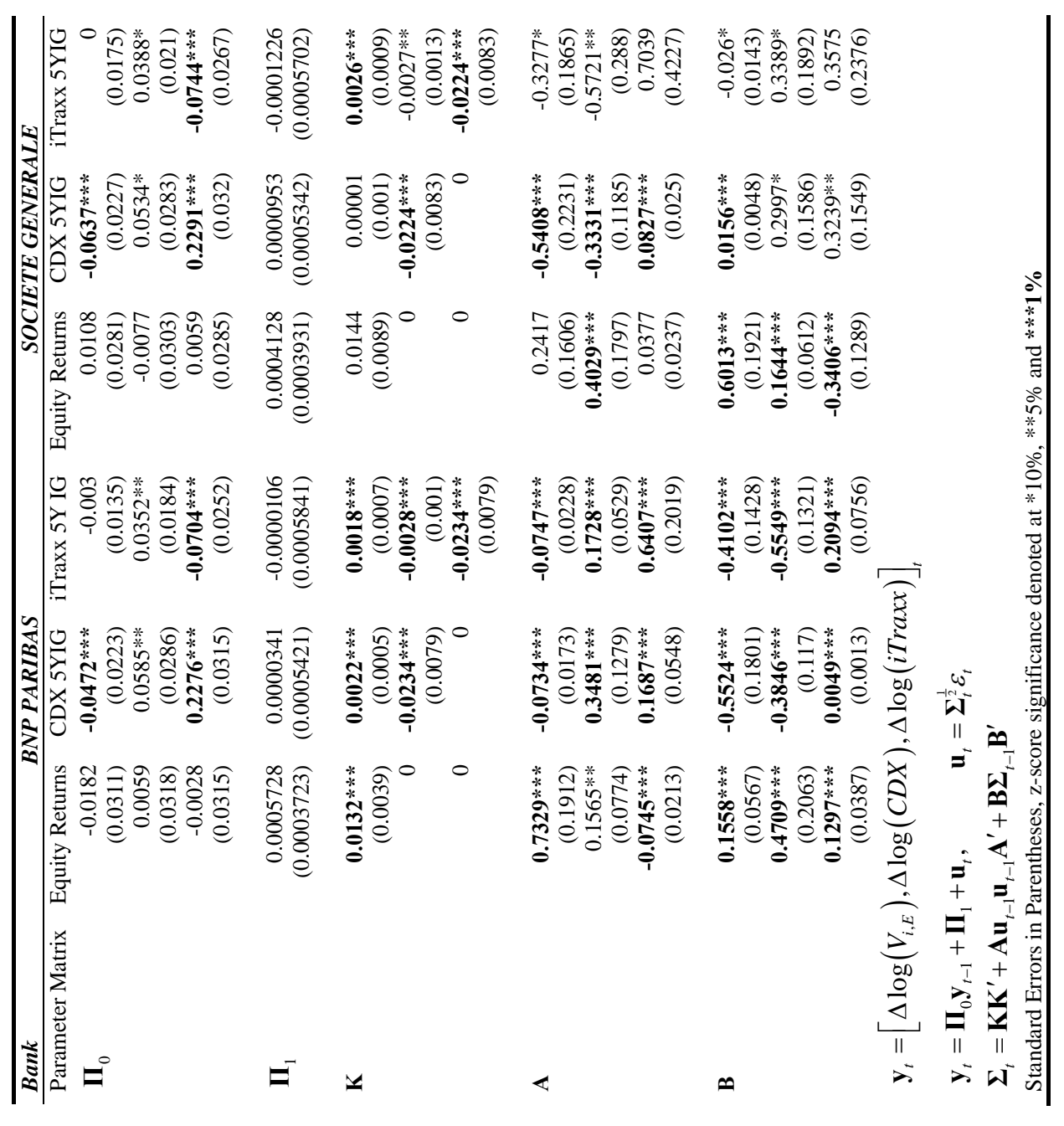




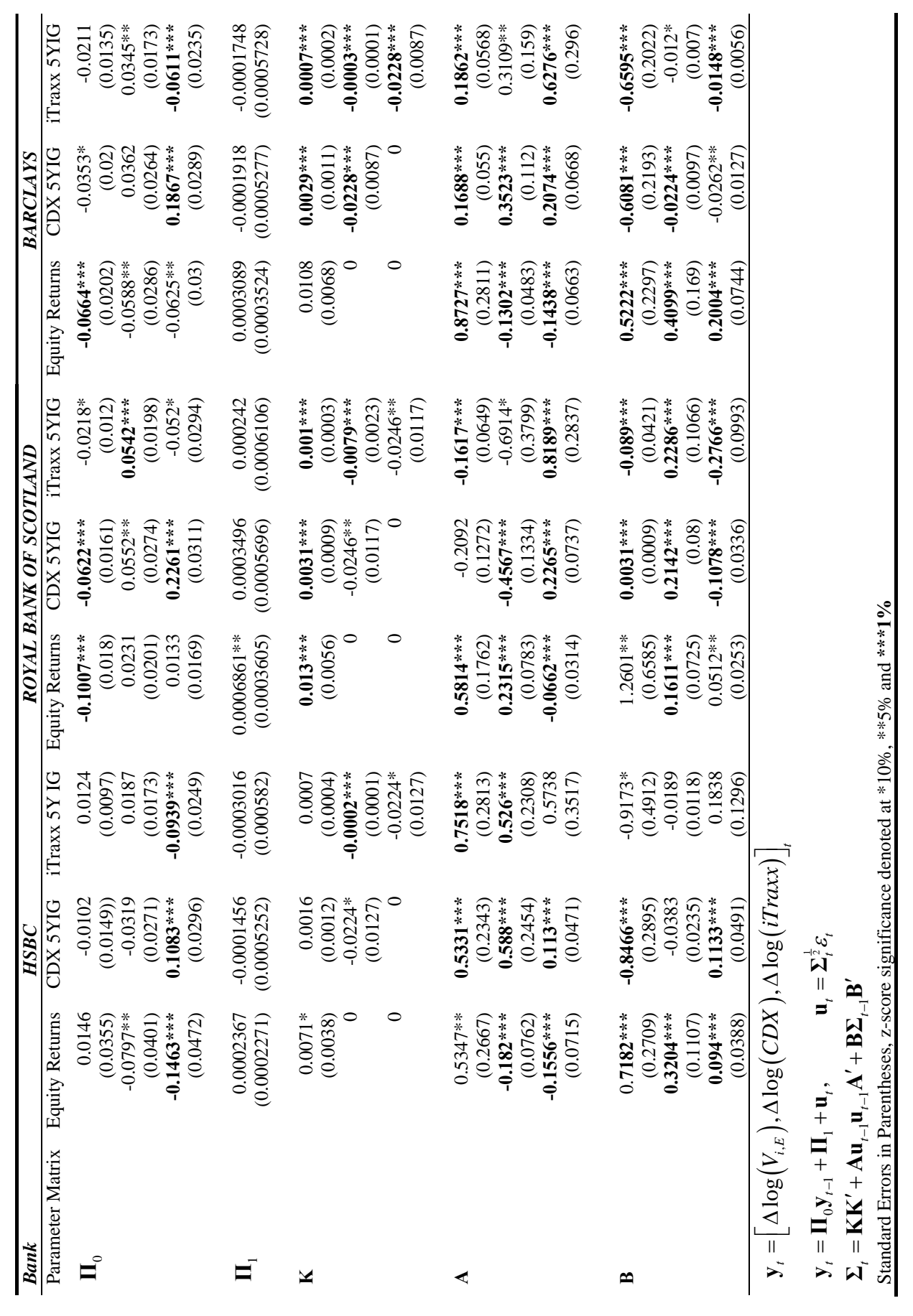




\section{B Correlations and Volatilities}
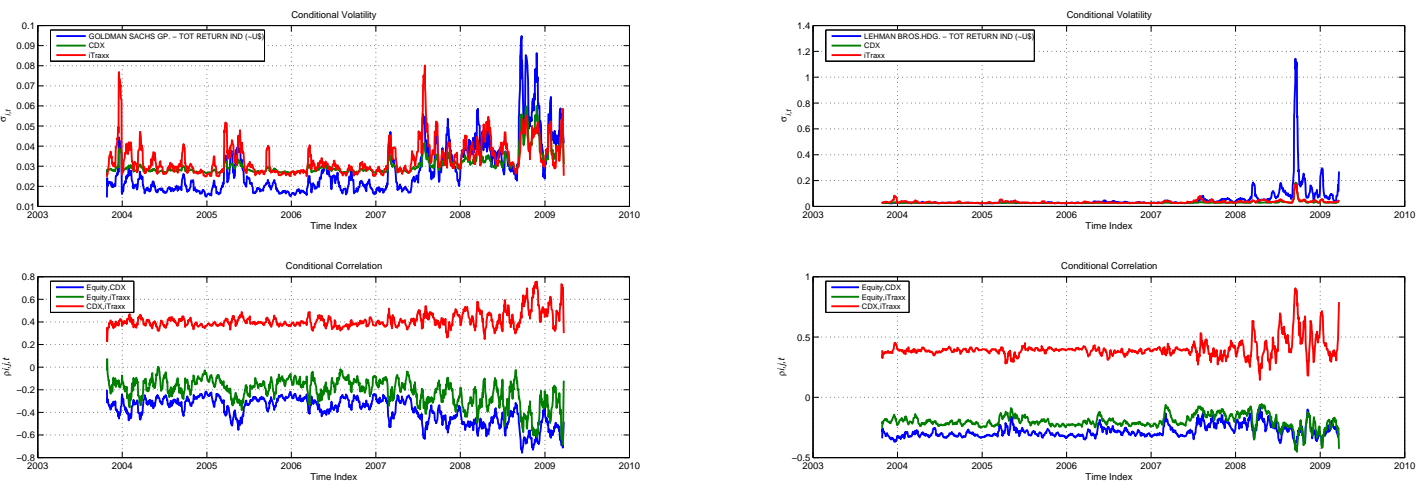

(a) Goldman Sachs

(b) Lehman Brothers
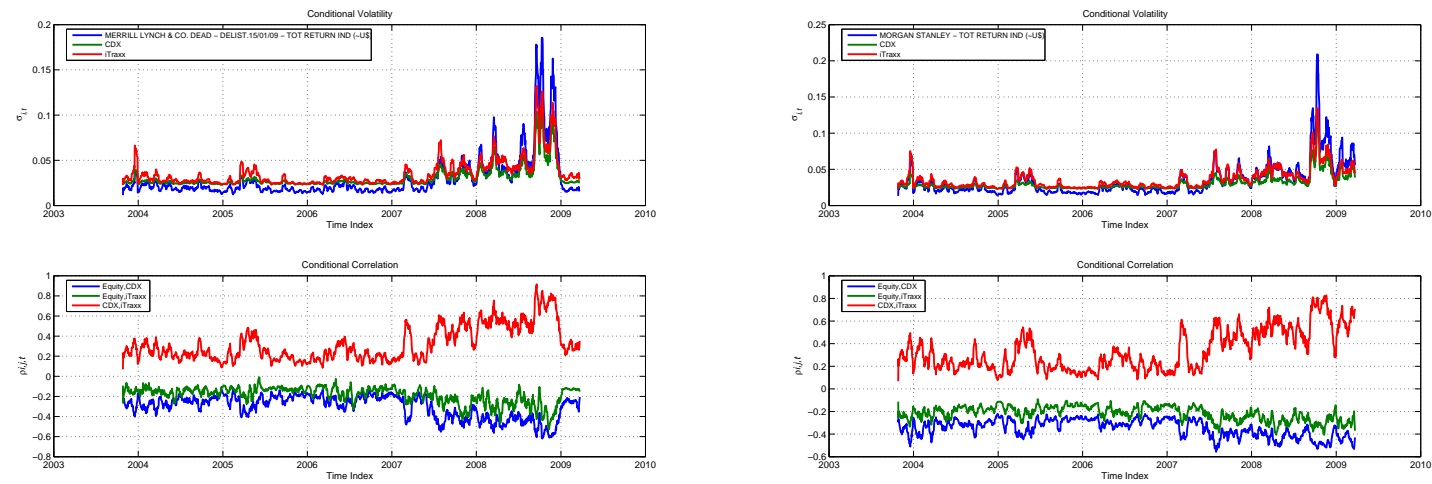

(c) Merrill Lynch

(d) Morgan Stanley

Figure 4: The conditional volatility and correlations for selected US investment banks with respect to the CDX and iTraxx 5Y Investment-Grade Index Spreads. 

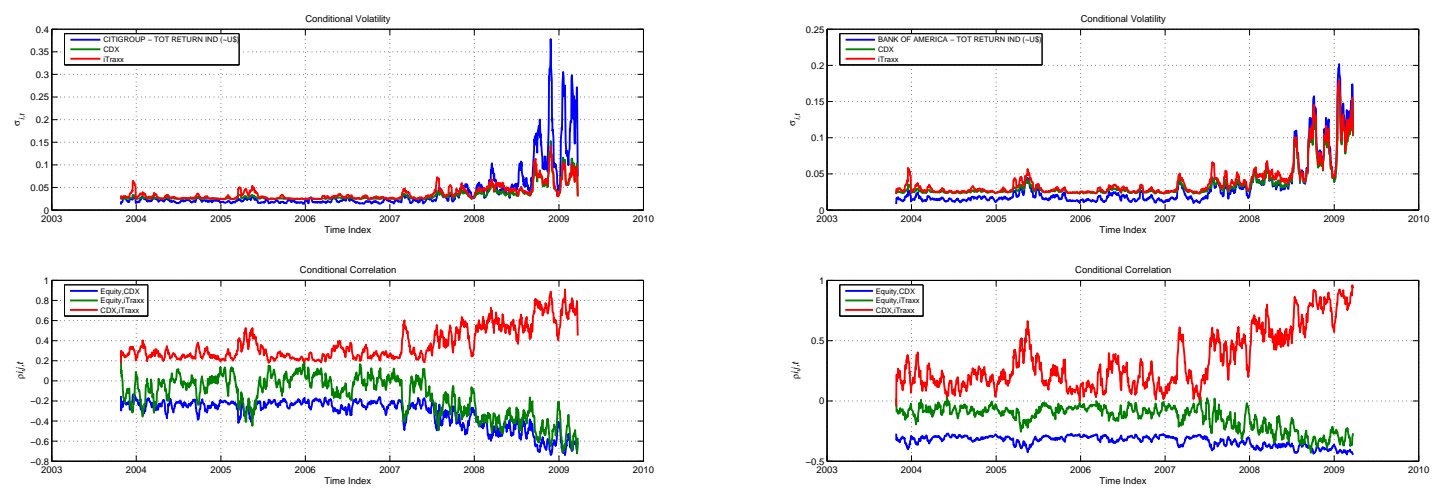

(a) Citigroup

(b) Bank of America
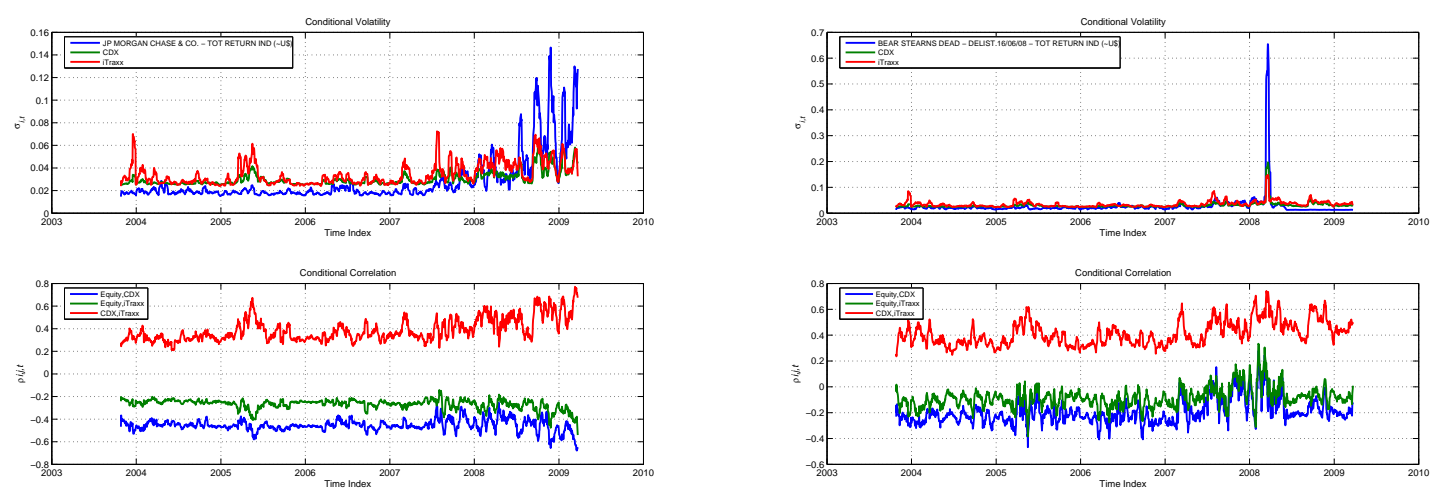

(c) JP Morgan

(d) Bear Stearns

Figure 5: The conditional volatility and correlations for selected systemically important US financial institutions with respect to the CDX and iTraxx 5Y Investment-Grade Index Spreads. 

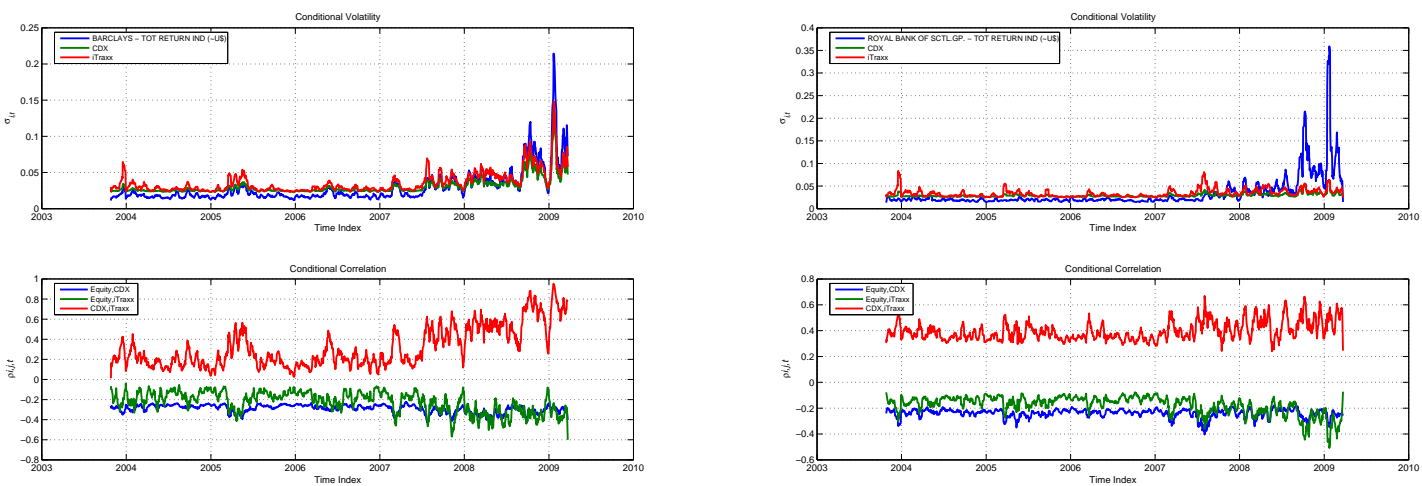

(a) Barclays

(b) Royal Bank of Scotland
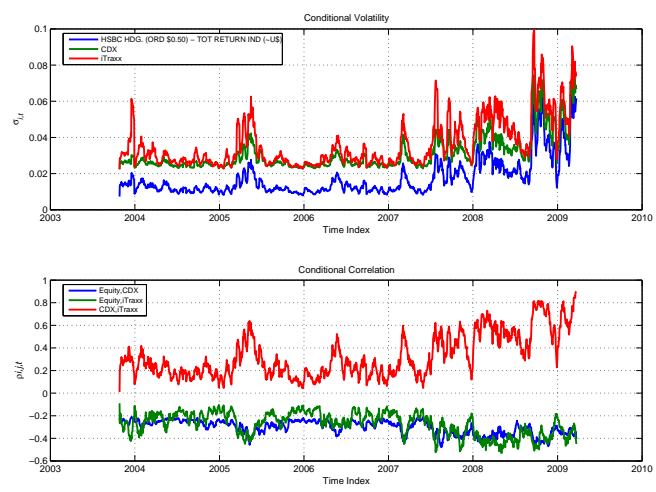

(c) HSBC Holdings

Figure 6: The conditional volatility and correlations for systemically important UK banks with respect to the CDX and iTraxx 5Y Investment-Grade Index Spreads.
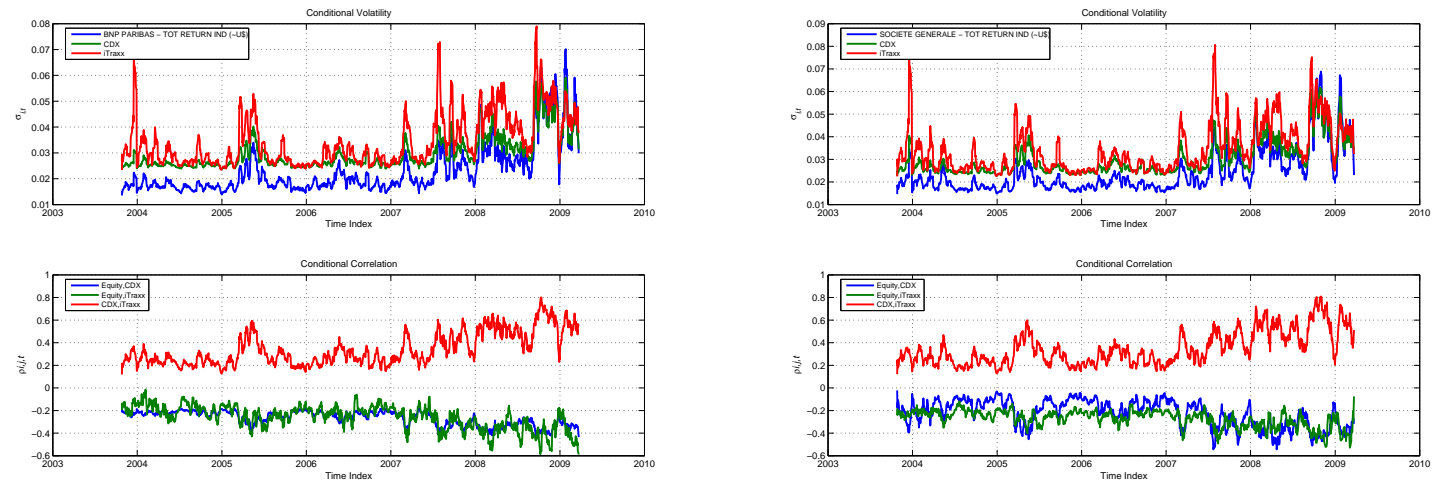

(a) BNP Paribas

(b) Scociete Generale

Figure 7: The conditional volatility and correlations for systemically important French banks with respect to the CDX and iTraxx 5Y Investment-Grade Index Spreads. 

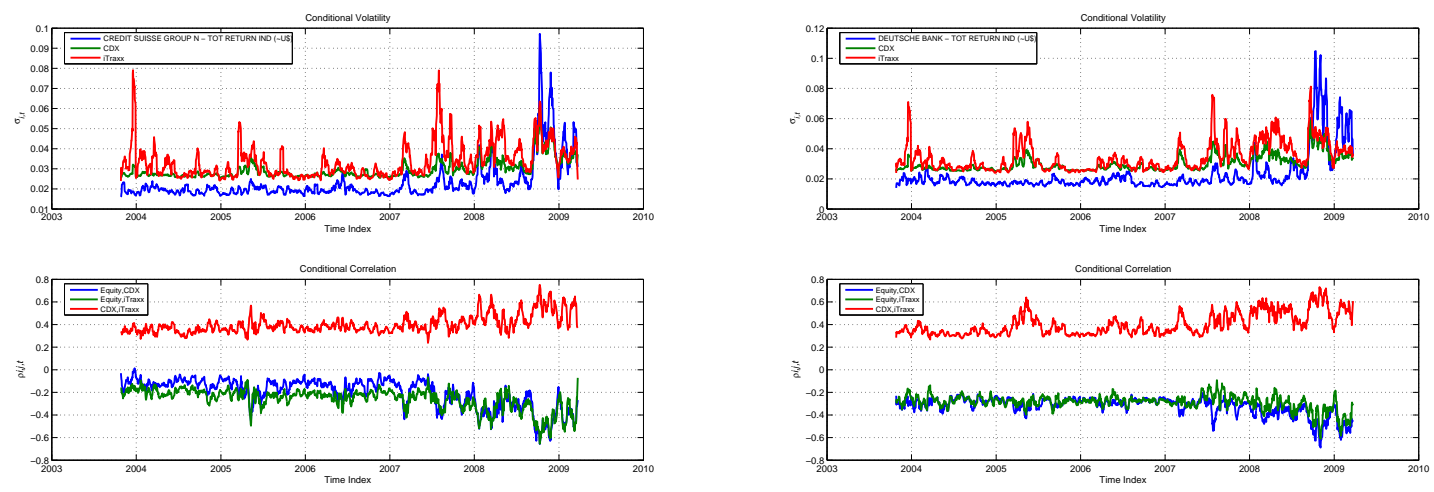

(a) Credit Suisse

(b) Deutsche Bank
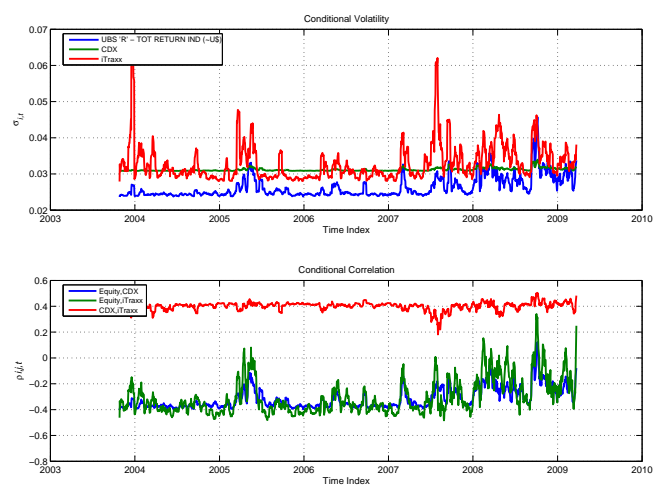

(c) UBS

Figure 8: The conditional volatility and correlations for systemically important German/Swiss banks with respect to the CDX and iTraxx 5Y Investment-Grade Index Spreads. 


\section{Impulse Response Models}

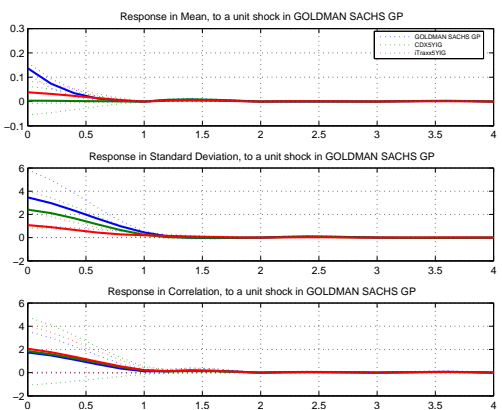

(a) Goldman Sachs

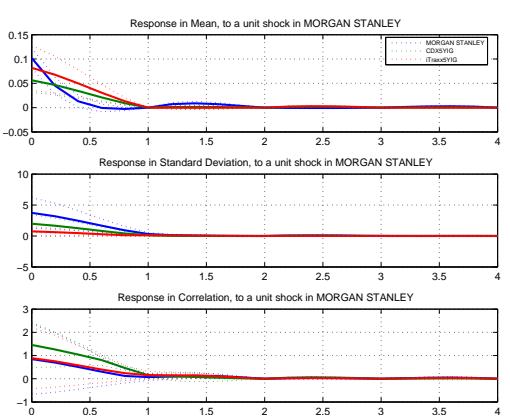

(d) Morgan Stanley

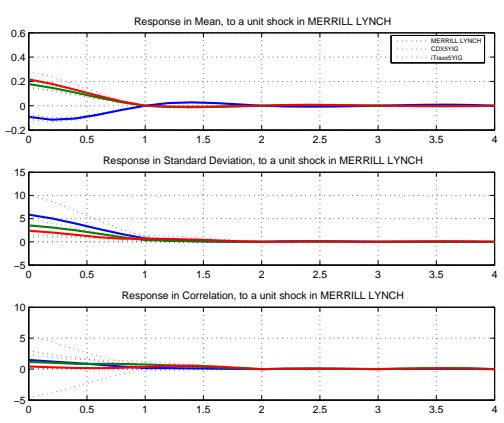

(g) Merrill Lynch

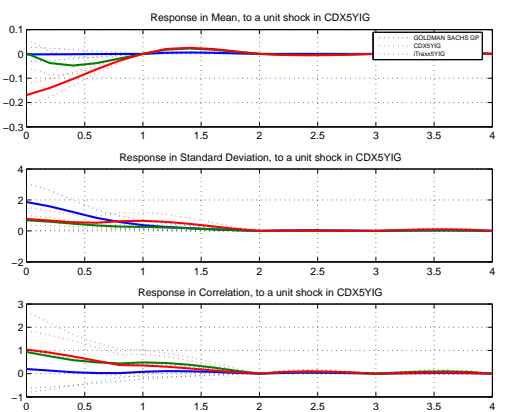

(b) CDX

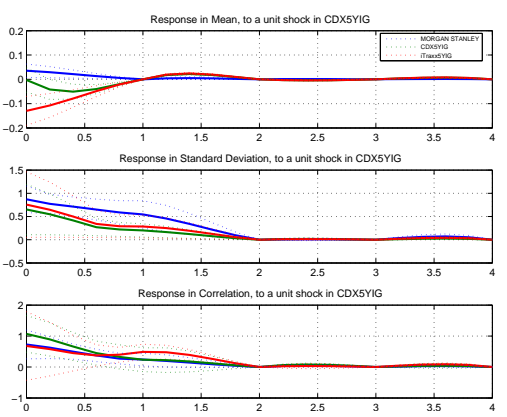

(e) CDX

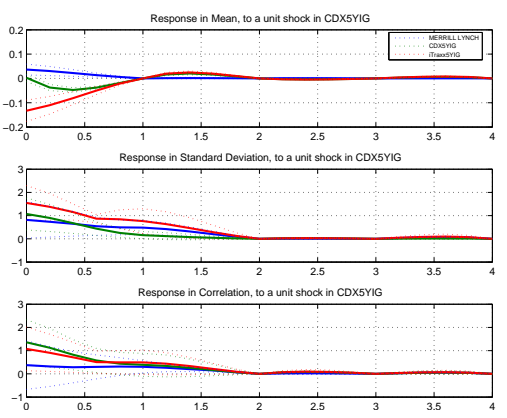

(h) CDX

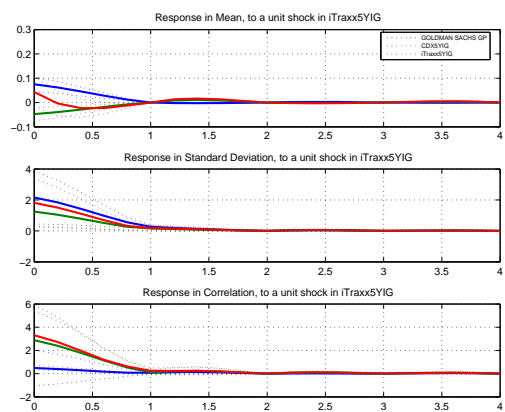

(c) iTraxx

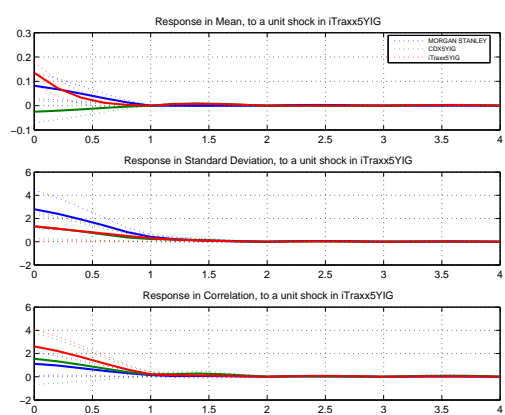

(f) $i \operatorname{Traxx}$

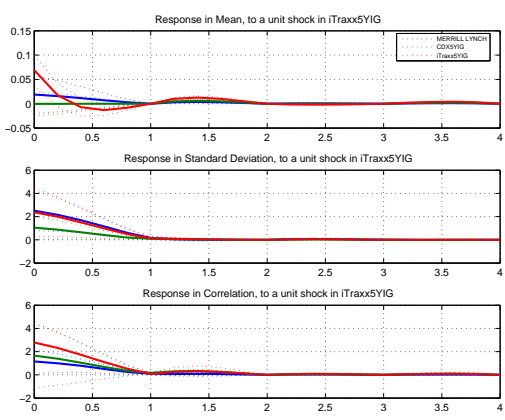

(i) iTraxx

Figure 9: Impulse response in conditional mean (top), standard deviation (middle) and correlation (bottom), from the VAR-MV-GARCH models, specification is $r=1, p=1, q=1$, Graphic a. presents the dynamic responses to equity shocks, b. presents the dynamic responses to shock to the CDX 5Y Investment-Grade spreads and c. the responses to iTraxx 5Y Investment-Grade spreads. 


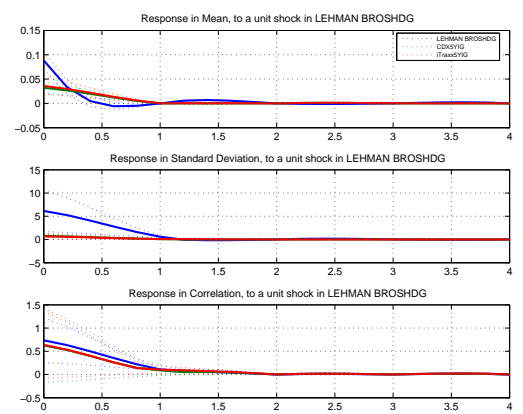

(a) Lehman Brothers

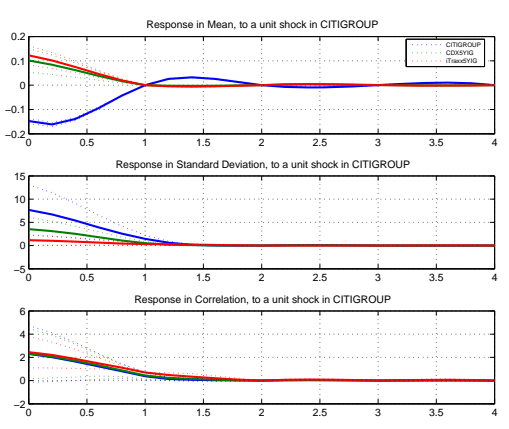

(d) Citigroup

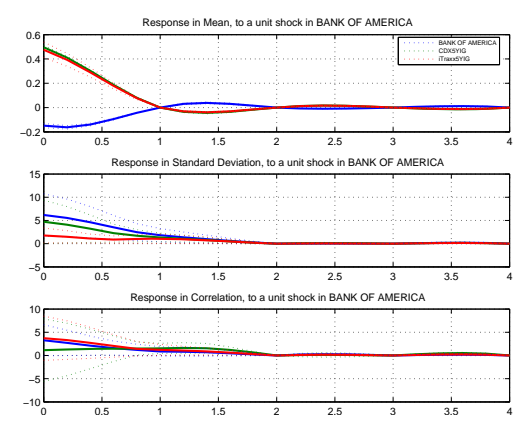

(g) Bank of America

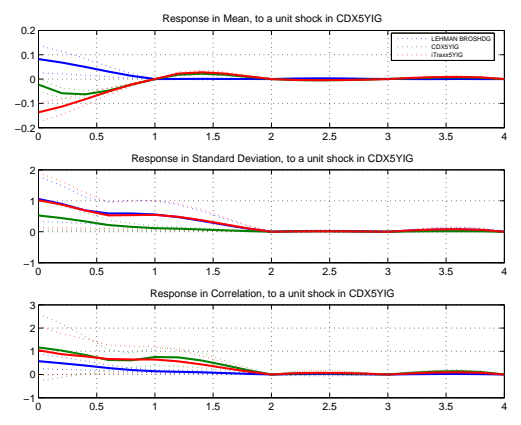

(b) CDX

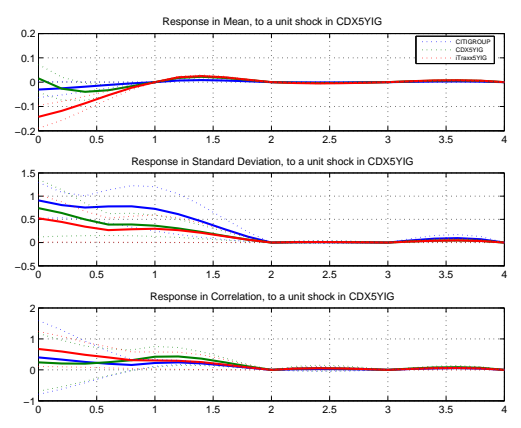

(e) CDX

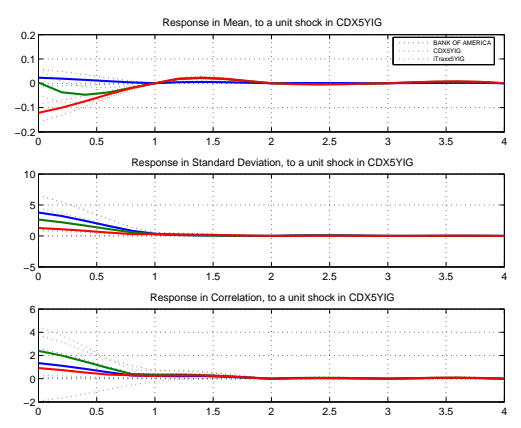

(h) CDX

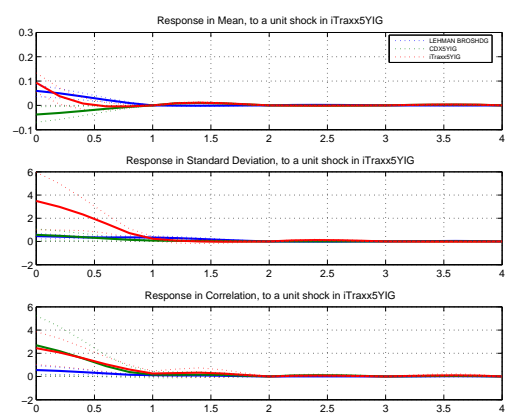

(c) iTraxx

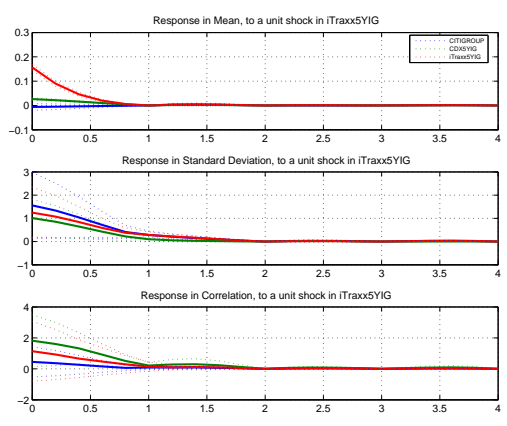

(f) iTraxx

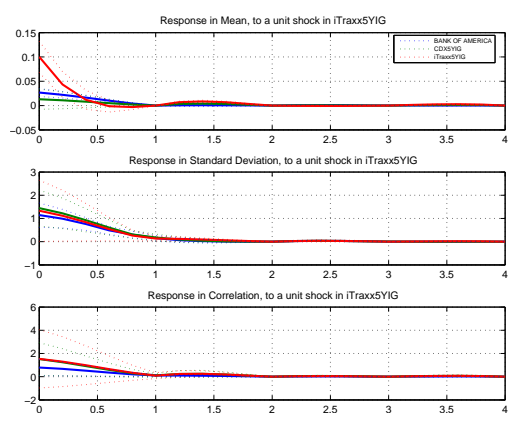

(i) $i \operatorname{Traxx}$

Figure 10: Impulse response in conditional mean (top), standard deviation (middle) and correlation (bottom), from the VAR-MV-GARCH models, specification is $r=1, p=1, q=1$, Graphic a. presents the dynamic responses to equity shocks, b. presents the dynamic responses to shock to the CDX 5 Y Investment-Grade spreads and c. the responses to iTraxx 5 Y Investment-Grade spreads. 

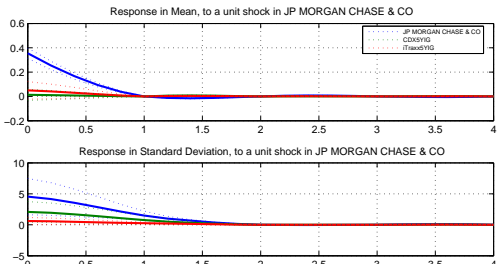

2.5 PAN 3 HASE \& CO

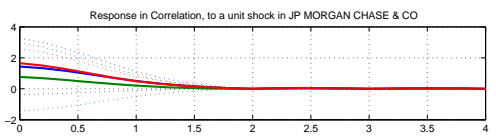

(a) JP Morgan
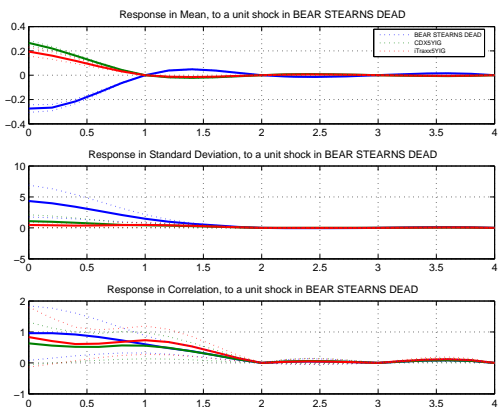

(d) Bear Stearns
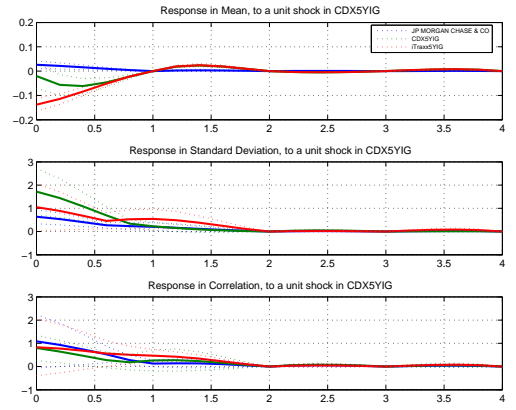

(b) CDX
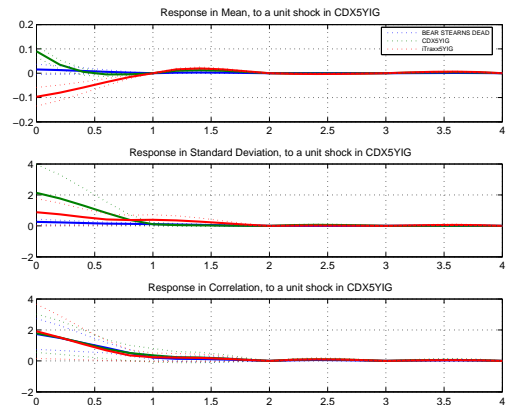

(e) CDX

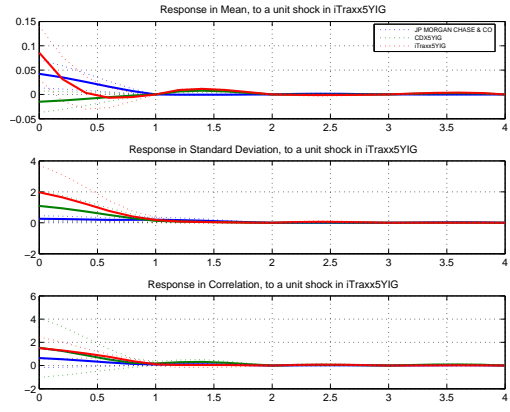

(c) iTraxx
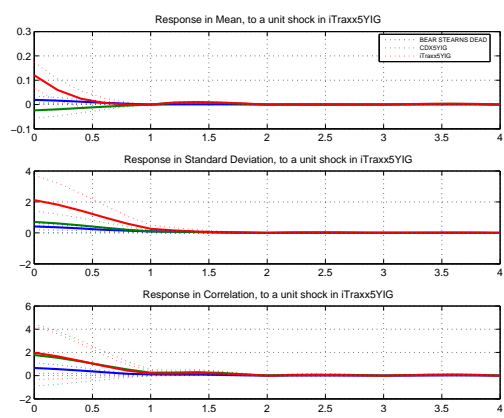

(f) iTraxx

Figure 11: Impulse response in conditional mean (top), standard deviation (middle) and correlation (bottom), from the VAR-MV-GARCH models, specification is $r=1, p=1, q=1$, Graphic a. presents the dynamic responses to equity shocks, b. presents the dynamic responses to shock to the CDX 5Y Investment-Grade spreads and c. the responses to iTraxx 5Y Investment-Grade spreads. 


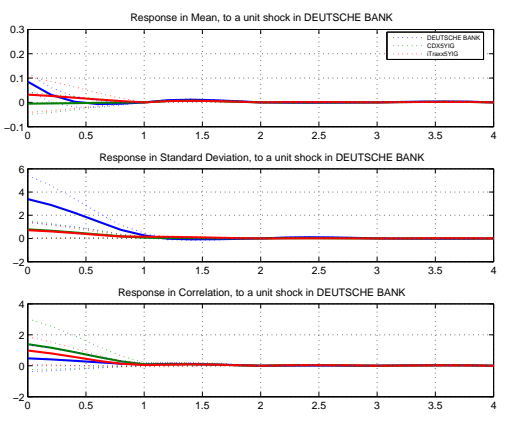

(a) Deutsche Bank

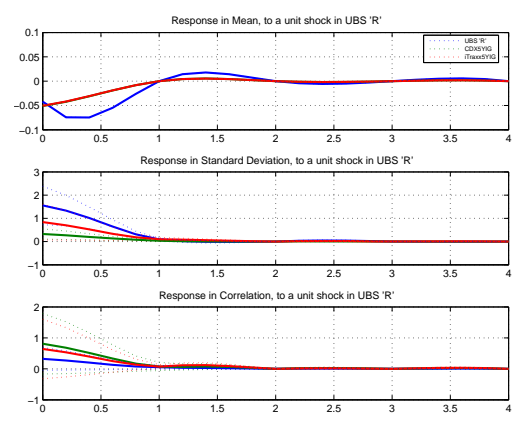

(d) UBS

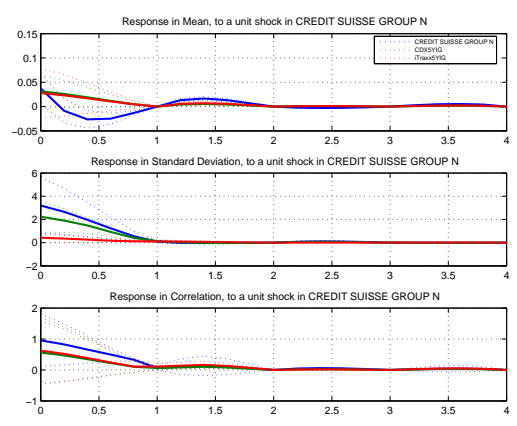

(g) Credit Suisse

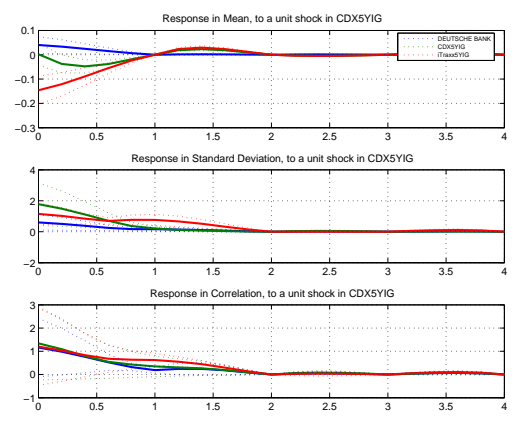

(b) CDX

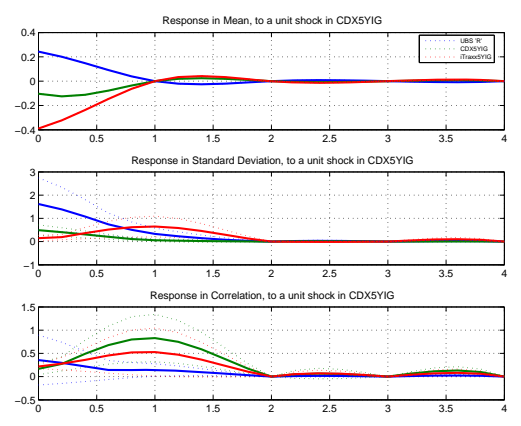

(e) CDX

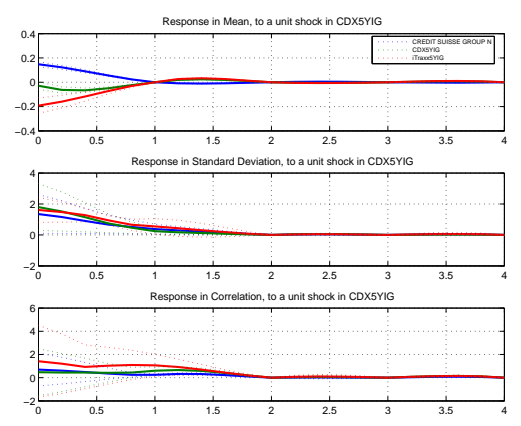

(h) CDX

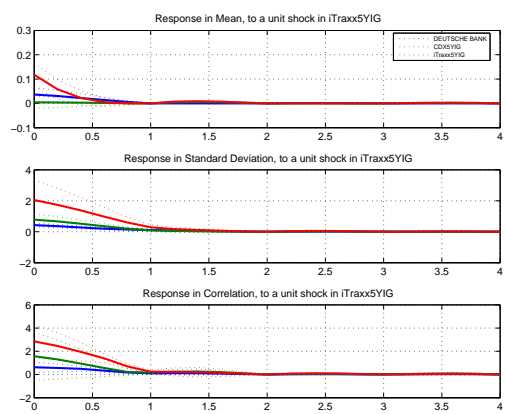

(c) iTraxx

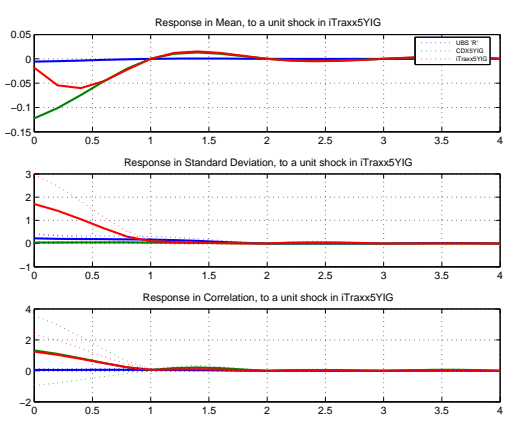

(f) iTraxx

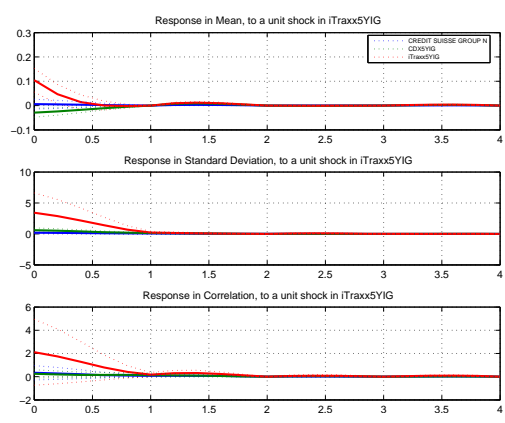

(i) $i \operatorname{Traxx}$

Figure 12: Impulse response in conditional mean (top), standard deviation (middle) and correlation (bottom), from the VAR-MV-GARCH models, specification is $r=1, p=1, q=1$, Graphic a. presents the dynamic responses to equity shocks, b. presents the dynamic responses to shock to the CDX 5 Y Investment-Grade spreads and c. the responses to iTraxx 5 Y Investment-Grade spreads. 


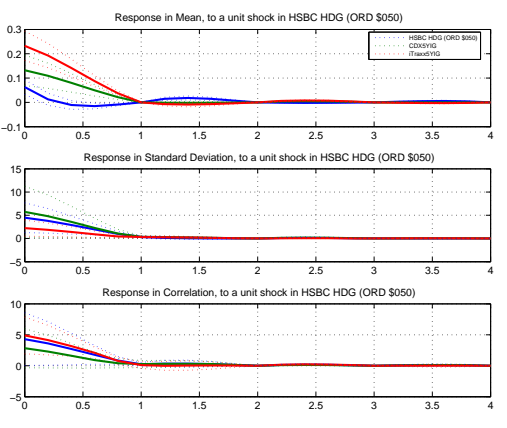

(a) HSBC

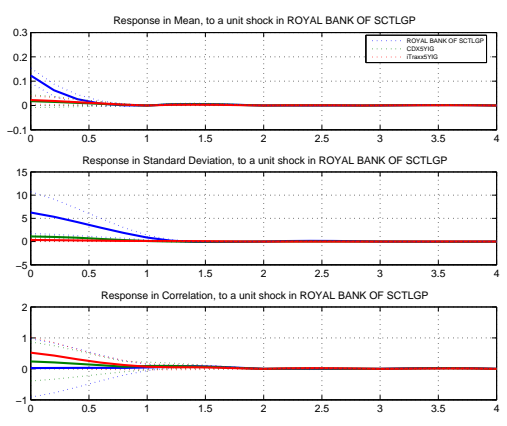

(d) Royal Bank of Scotland

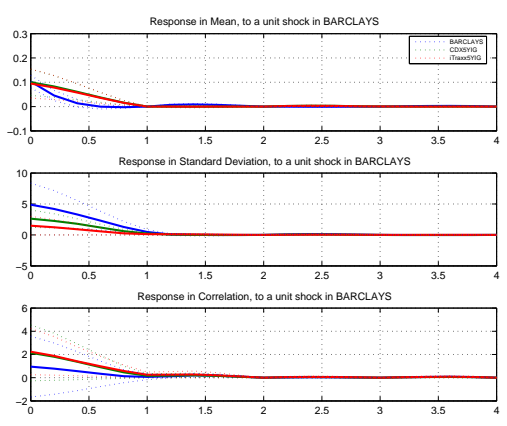

(g) Barclays

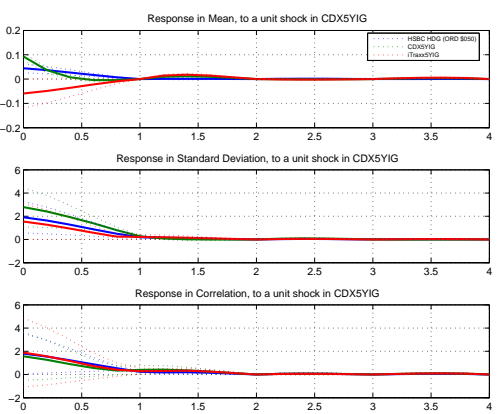

(b) CDX

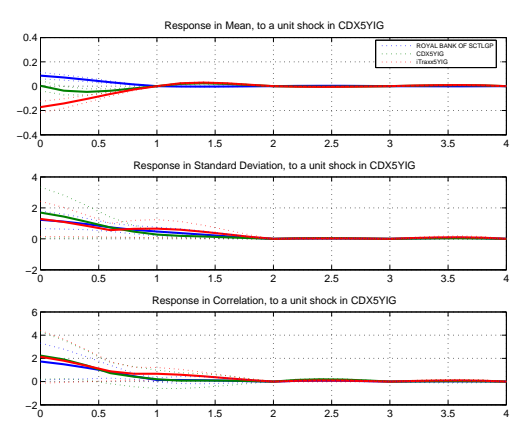

(e) CDX

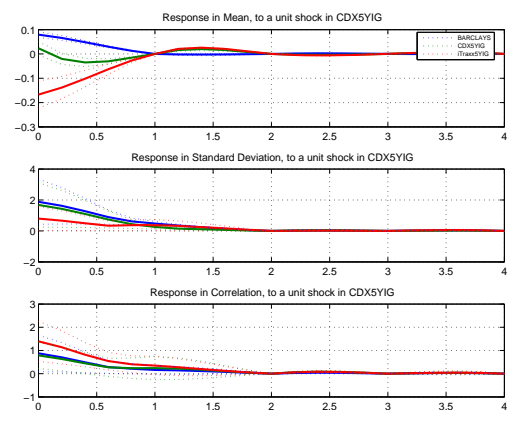

(h) CDX

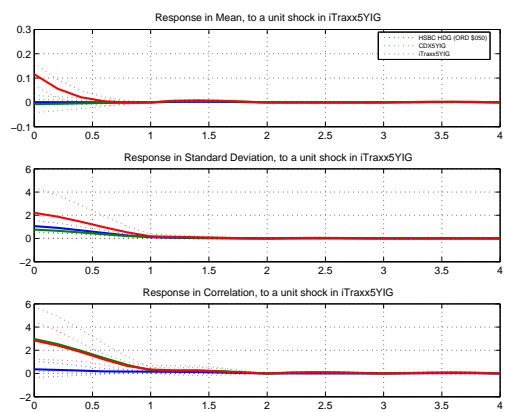

(c) iTraxx

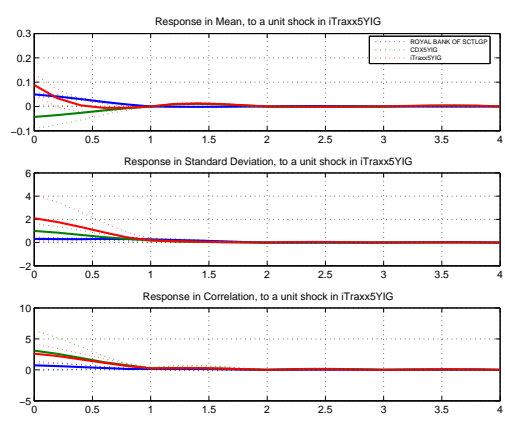

(f) iTraxx

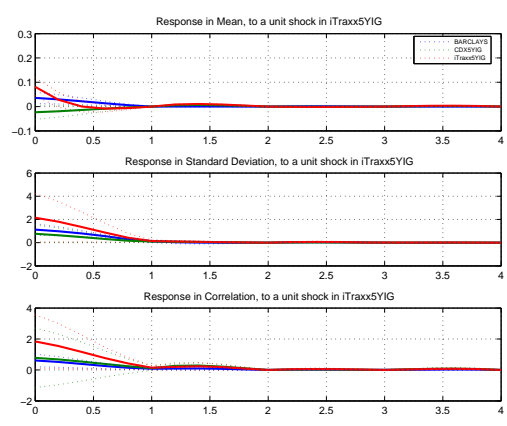

(i) iTraxx

Figure 13: Impulse response in conditional mean (top), standard deviation (middle) and correlation (bottom), from the VAR-MV-GARCH models, specification is $r=1, p=1, q=1$, Graphic a. presents the dynamic responses to equity shocks, b. presents the dynamic responses to shock to the CDX 5 Y Investment-Grade spreads and c. the responses to iTraxx 5 Y Investment-Grade spreads. 

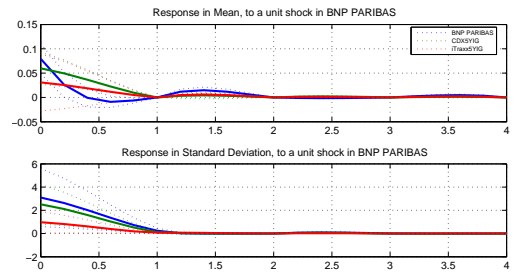

Response in Correlation, to a unit shook in BNP PARIBAS

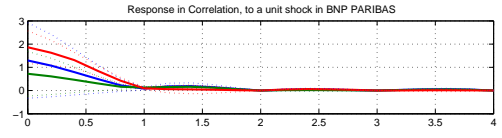

(a) BNP Paribas
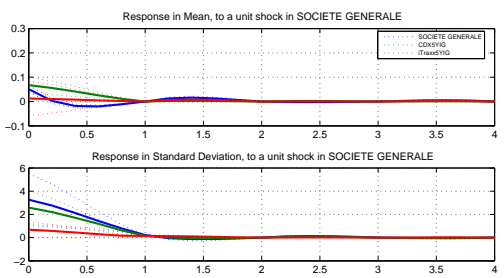

Response in Correalato, to a unit shockin SOCIETE GENERALE

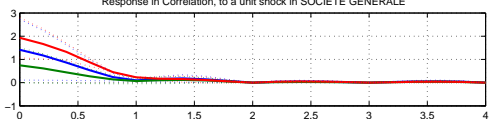

(d) Societe Generale

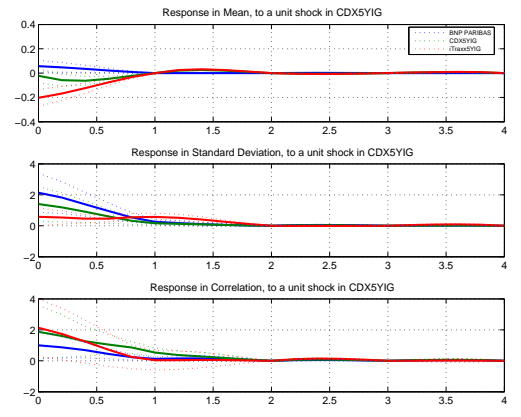

(b) CDX
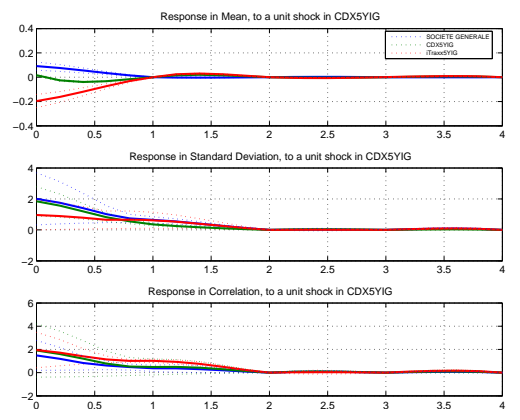

(e) CDX

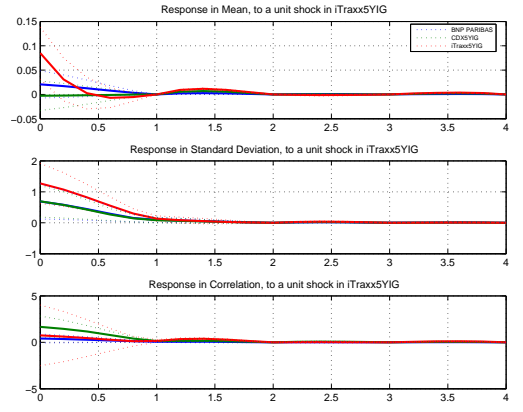

(c) $i \operatorname{Traxx}$
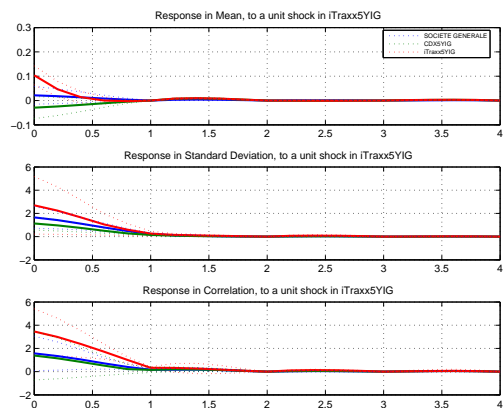

(f) iTraxx

Figure 14: Impulse response in conditional mean (top), standard deviation (middle) and correlation (bottom), from the VAR-MV-GARCH models, specification is $r=1, p=1, q=1$, Graphic a. presents the dynamic responses to equity shocks, b. presents the dynamic responses to shock to the CDX 5 Y Investment-Grade spreads and c. the responses to iTraxx 5Y Investment-Grade spreads. 


\section{Data Plots}

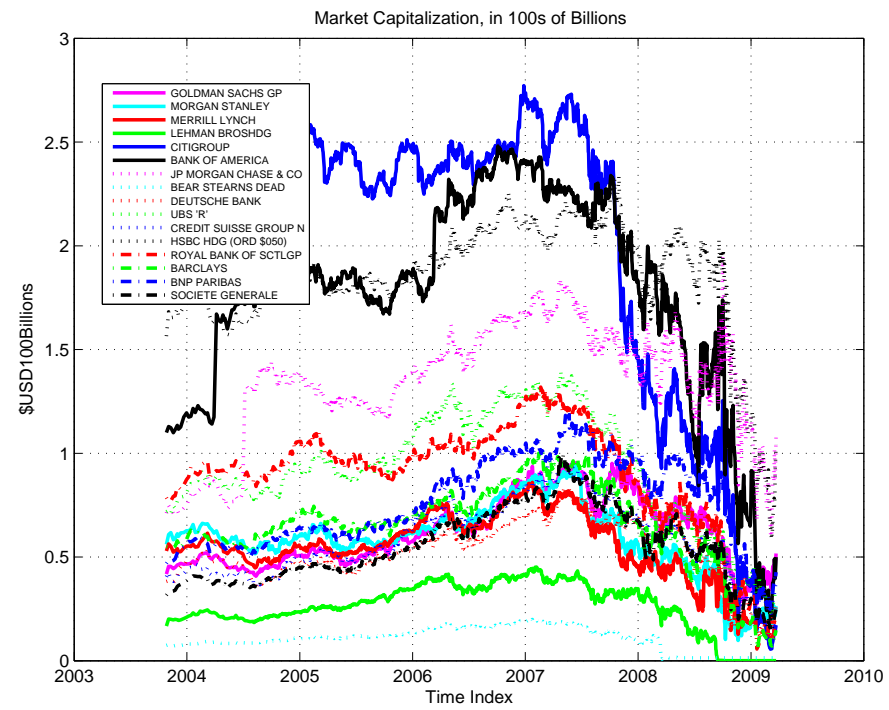

Figure 15: Market Capitalization of Sample Institutions: Source Thompson Reuters.

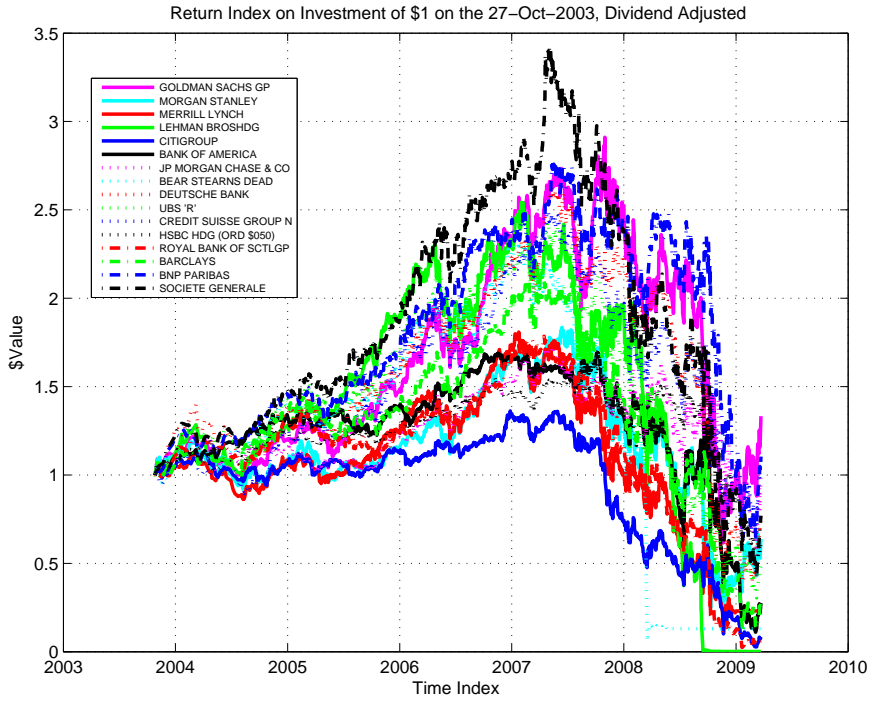

Figure 16: Return Index from beginning of time sample of \$USD1, dividend adjusted. 


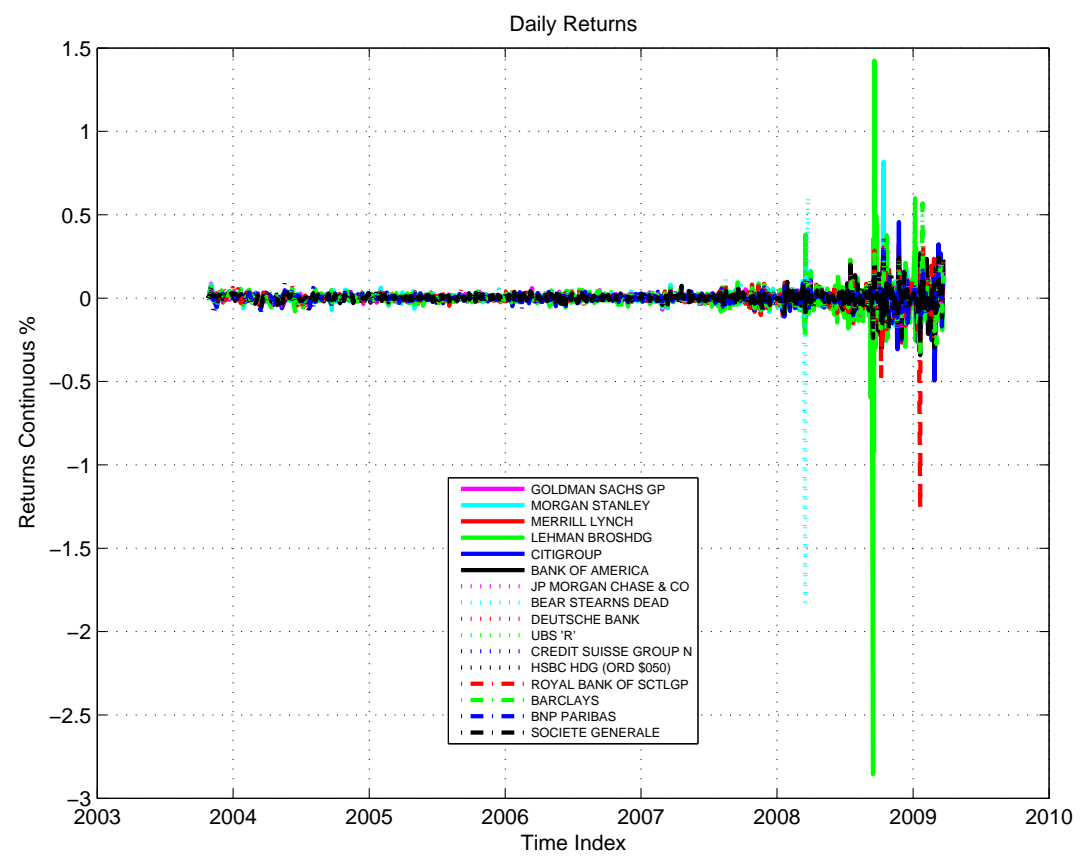

Figure 17: Dividend adjusted Returns of Sample Institutions.

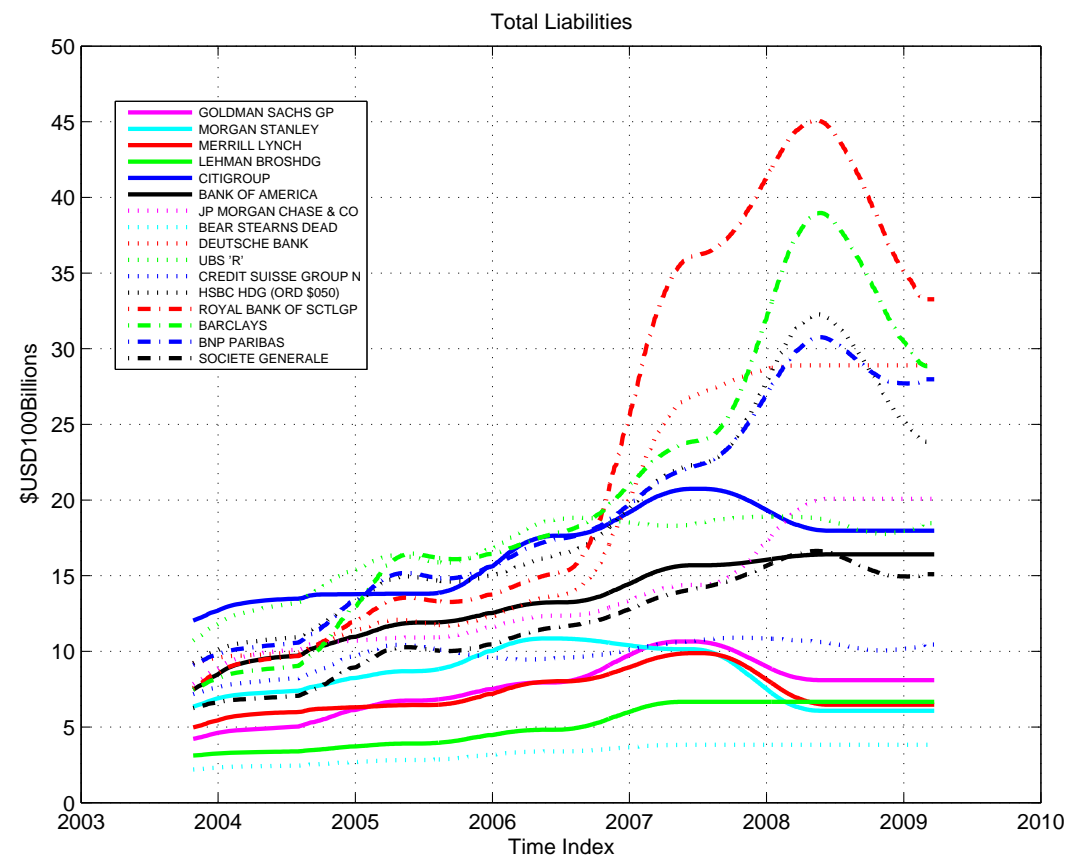

Figure 18: Total Liabilities in $\$$ US, interpolated using piecewise cubic spline to daily data from quarterly data frequency. Source Thompson Reuters. 


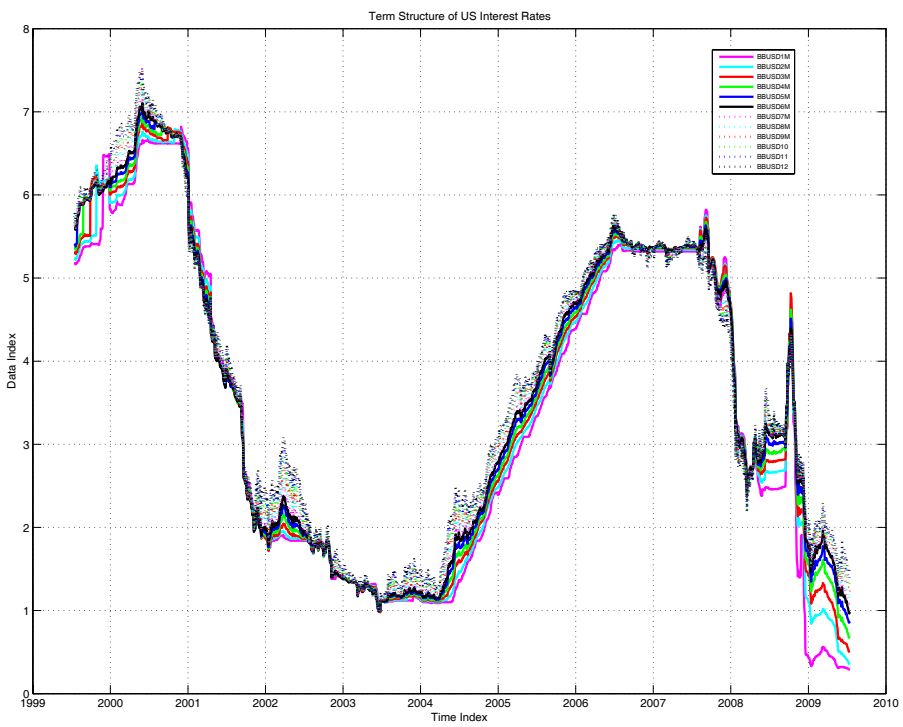

Figure 19: Term structure of short term US interest rates, using the bank offered rate. BBUSD1M is the 1 month offered rate to BBUSD12 which is the 1 year offered rate.

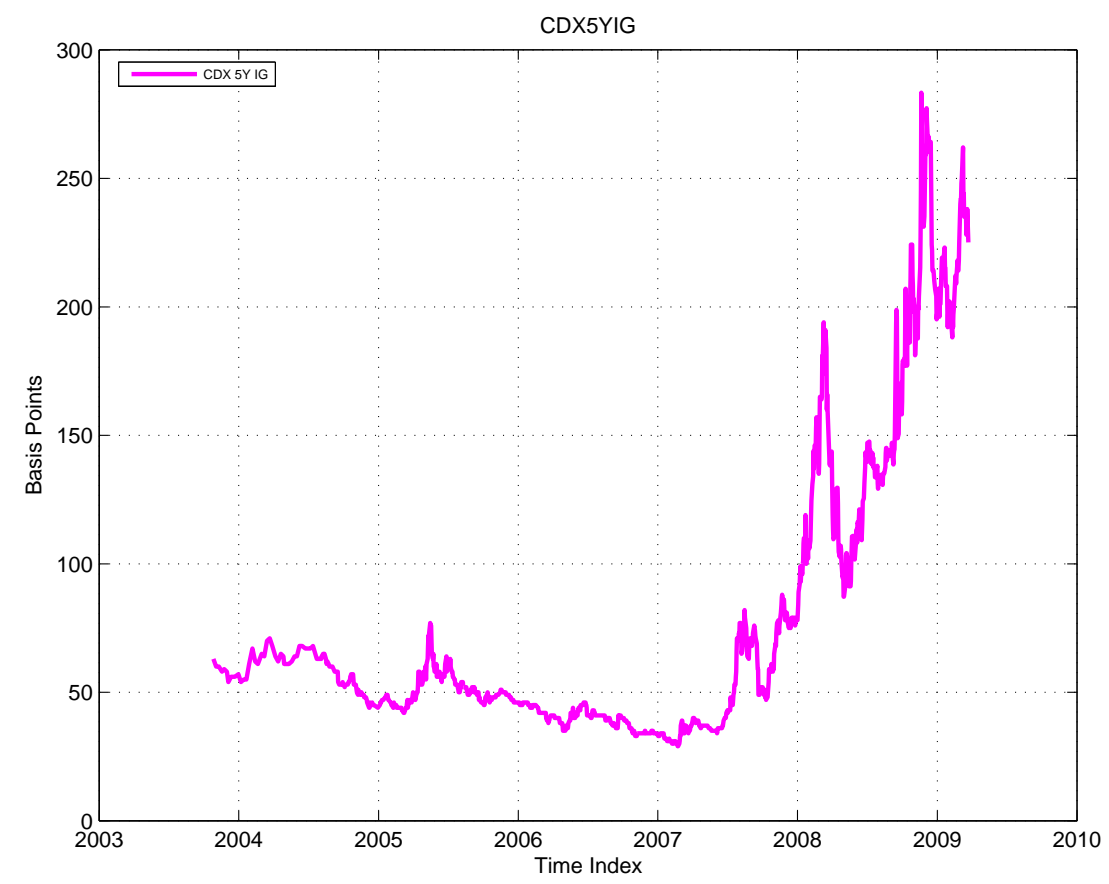

Figure 20: CDX 5Y Investment-Grade Spreads, source CMA and Thompson Reuters. 


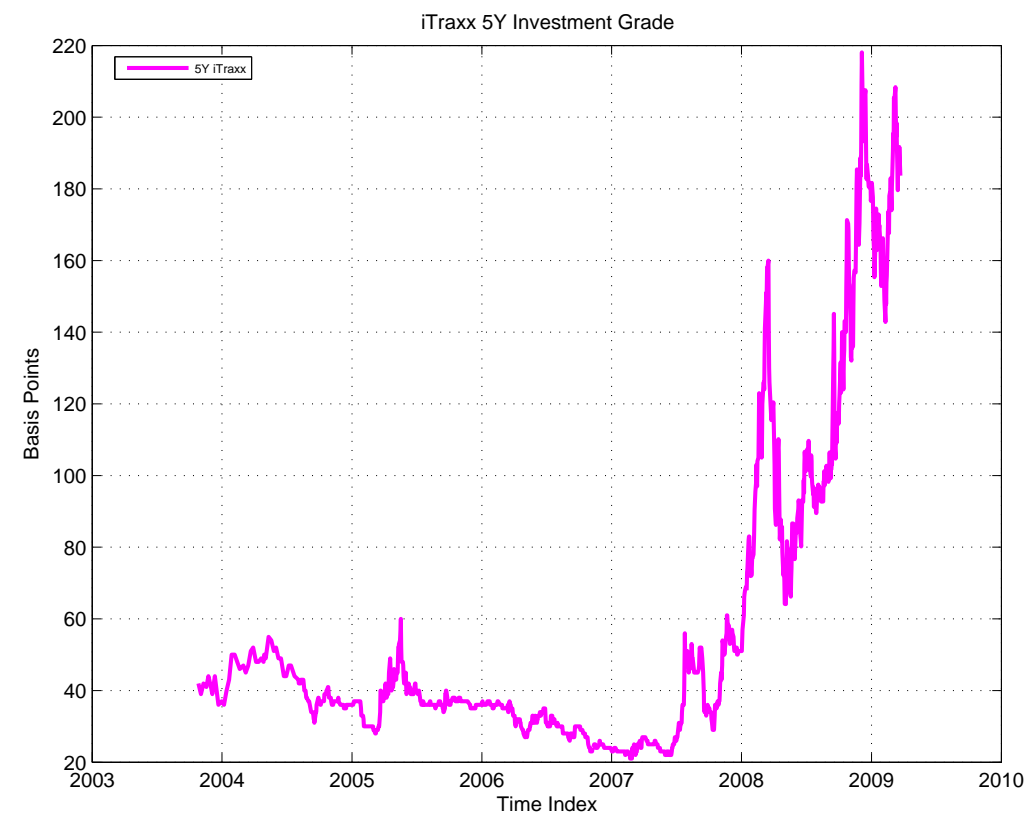

Figure 21: iTraxx 5Y Investment-Grade Spreads, source CMA and Thompson Reuters.

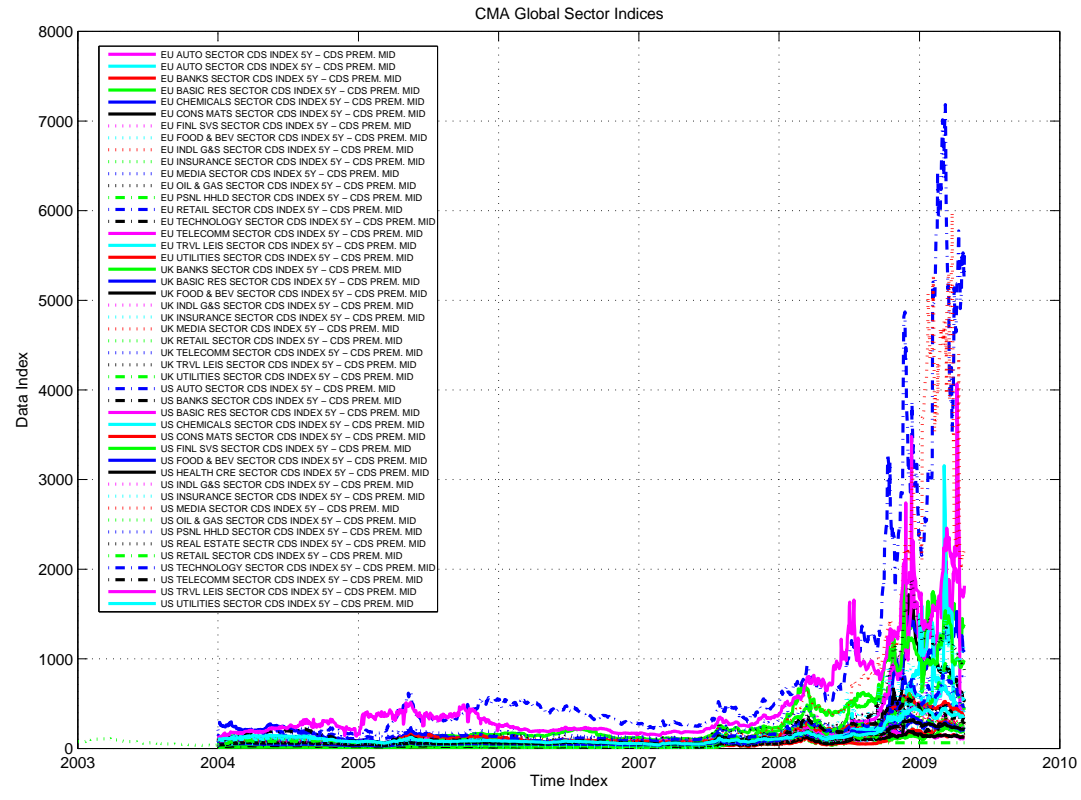

Figure 22: Thompson Reuters Datastream CDS Sector Decomposition for UK, US and Europe. 


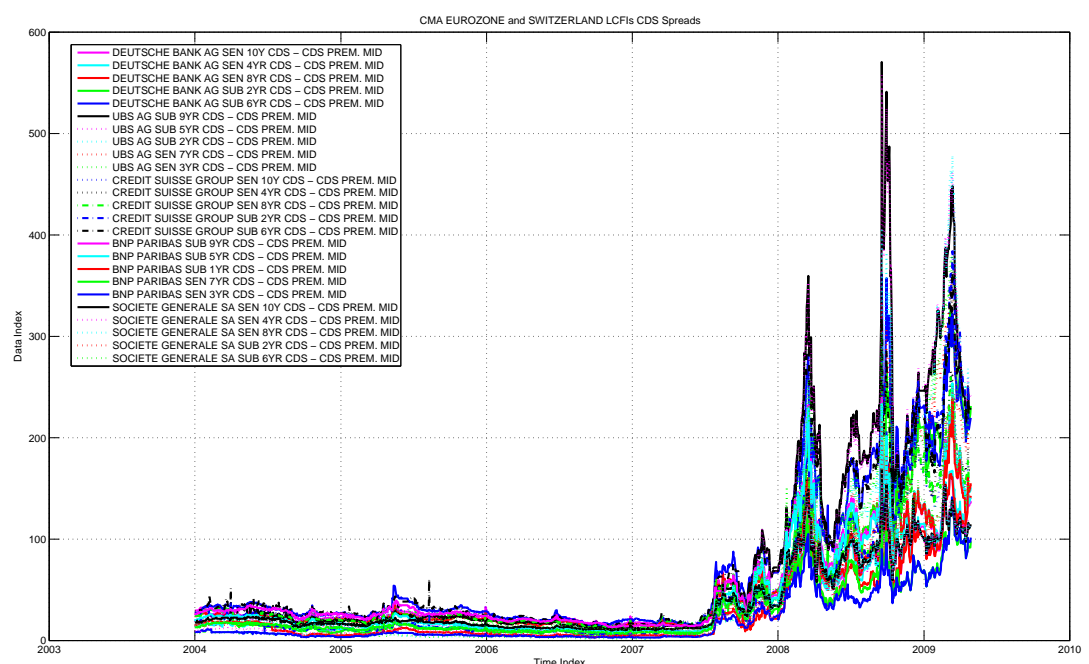

Figure 23: CMA Selected European Financial Institutions, CDS Spreads.

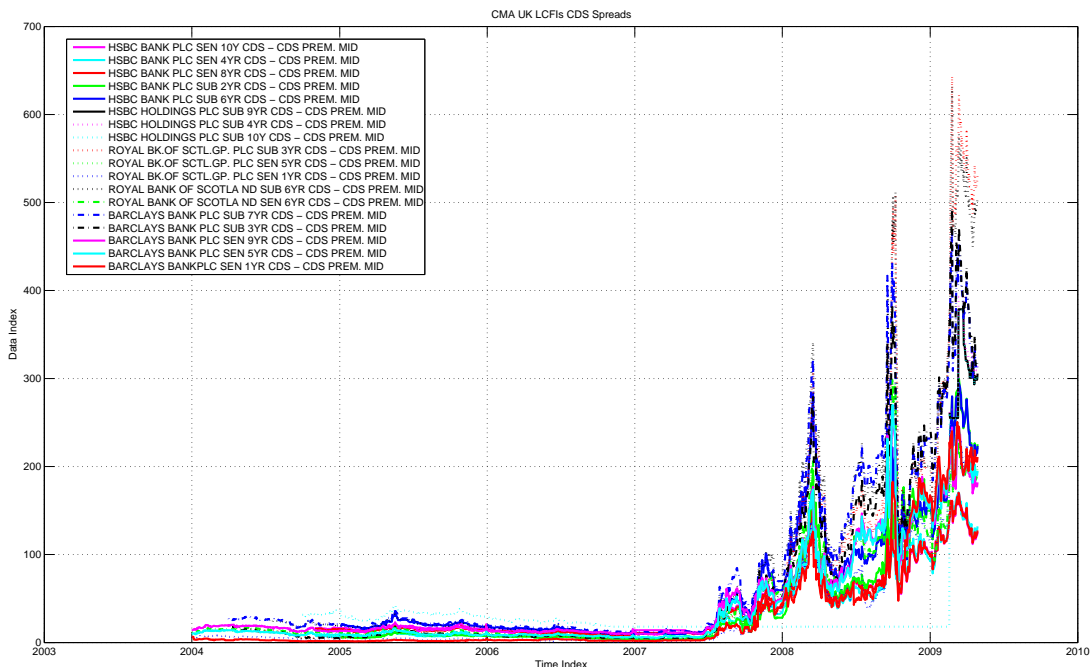

Figure 24: CMA Selected UK Financial Institutions, CDS Spreads. 


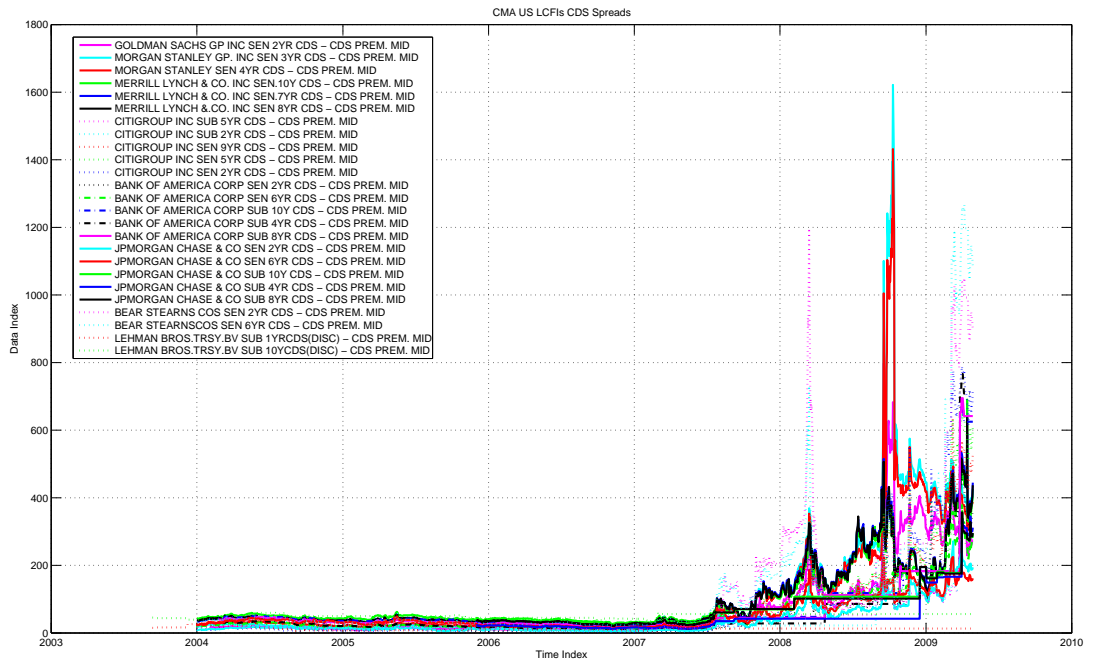

Figure 25: CMA Selected US Financial Institutions, CDS Spreads.

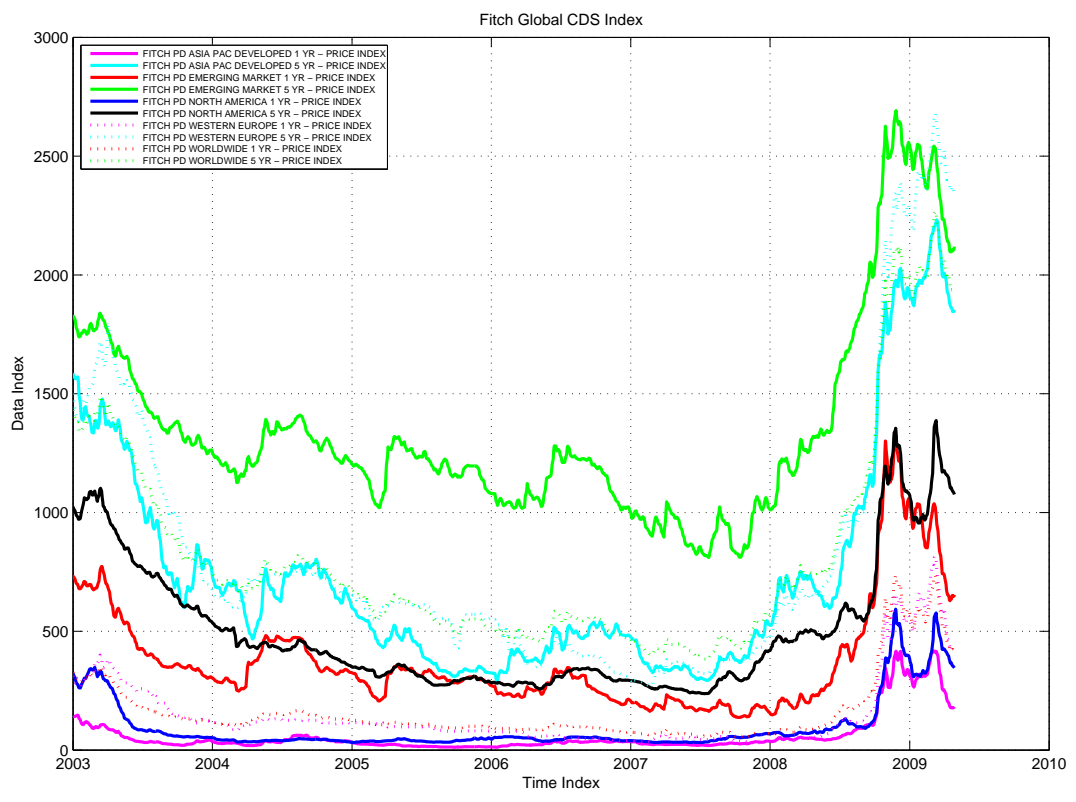

Figure 26: Fitch Ratings Regional CDS Index Spreads. 


\section{E Asset Injection Plots}

To read the capital injection plots, first set a level of default risk in terms of number of standard deviations from default, the dotted red line represents 2.3263 or $99 \%$ for a cumulative normal distribution. Each of the plot-lines represents and relationship between extra capital and default risk dependent on a level of asset volatility, we stratify the distribution of volatilities from the top $5 \%$ to the bottom $5 \%$, the unbroken red line represents the mid point volatility prediction. The asset volatilities are ordered from the lowest (top line) to the highest (bottom line), from forward looking simulations over 1 year from April 2009 to April 2010. As asset volatility increases so does the level of default (holding the average asset value over the 30 days to April 1 2009). The abscissa values are in 100s billions of US dollars, April 2009, the figures represent the total extra assets (at the particular level of volatility).

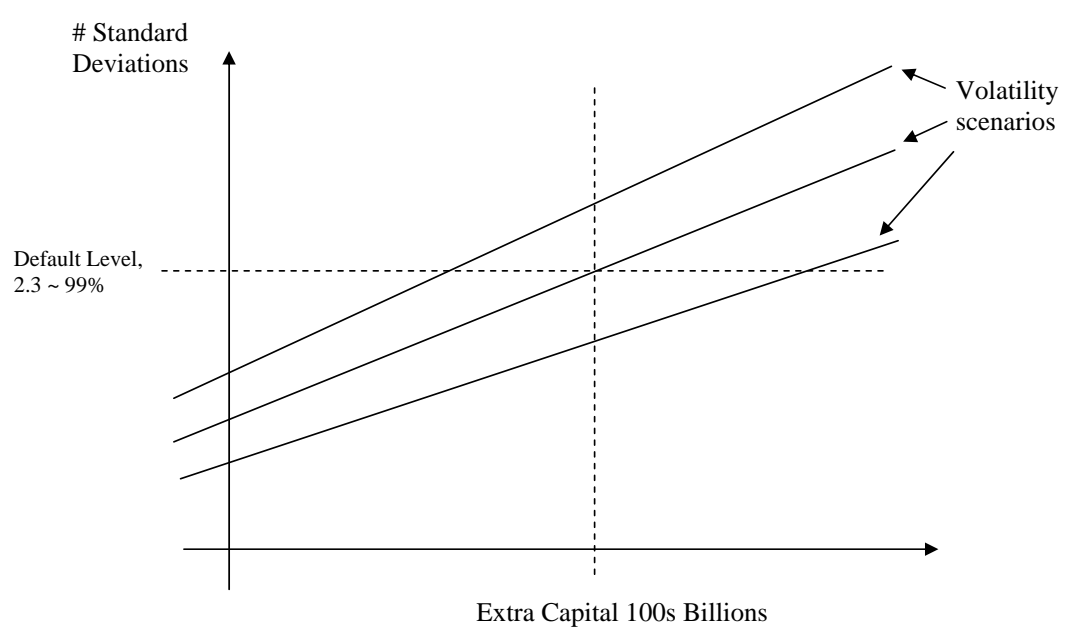

Figure 27: Diagrammatic representation of the stress test plots. 


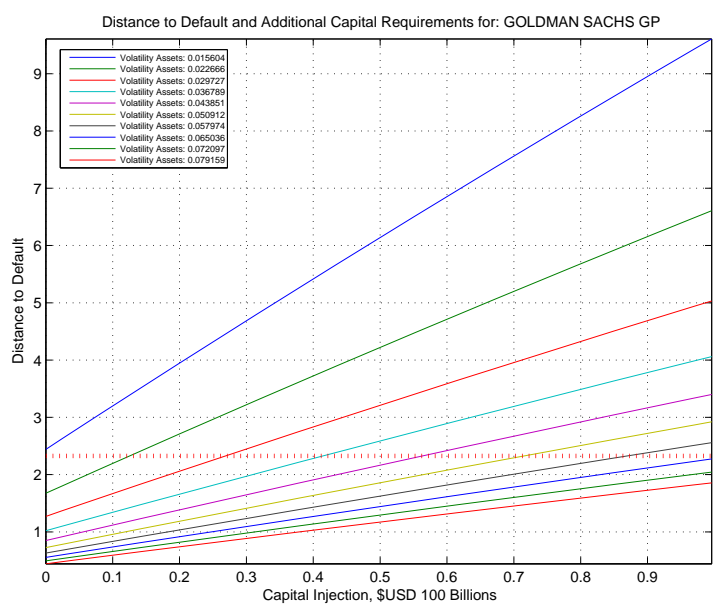

(a) Goldman Sachs

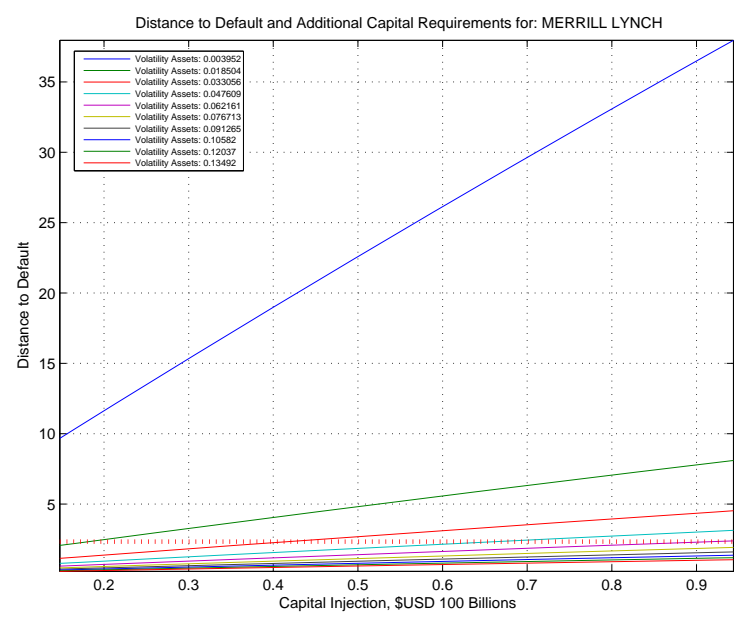

(c) Merrill Lynch

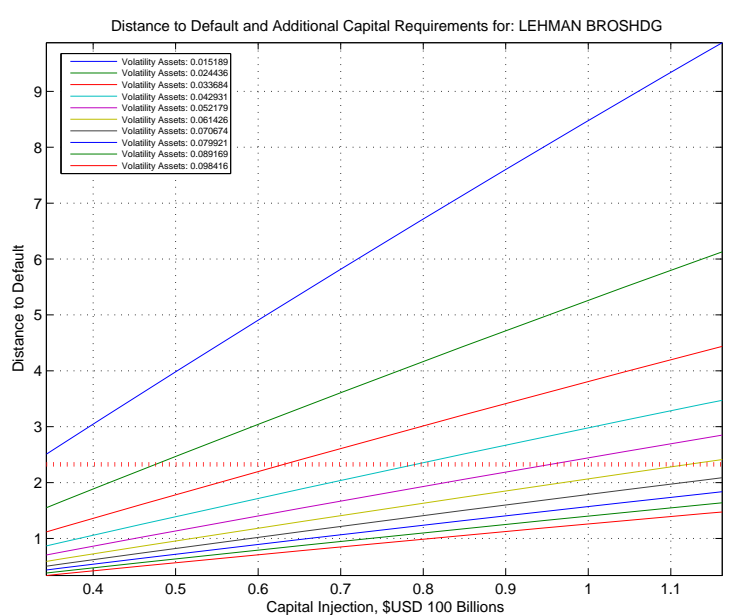

(b) Lehman Brothers

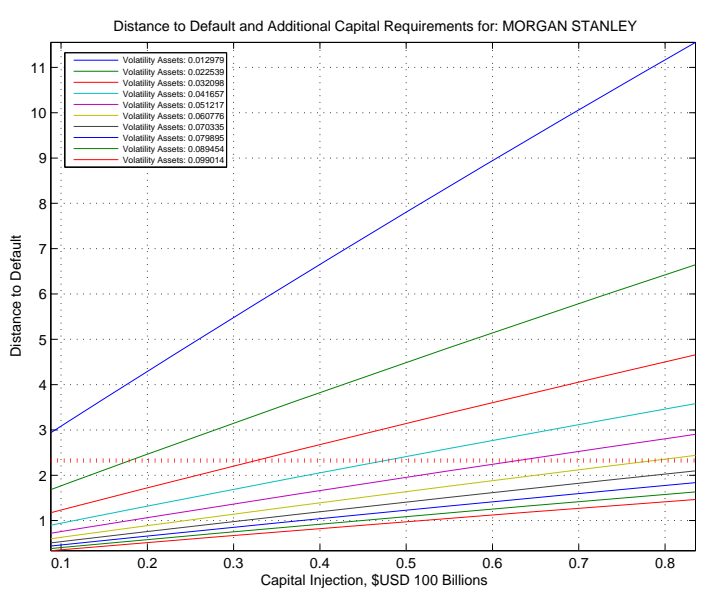

(d) Morgan Stanley

Figure 28: Default stress testing for four systemically important US financial institutions. 


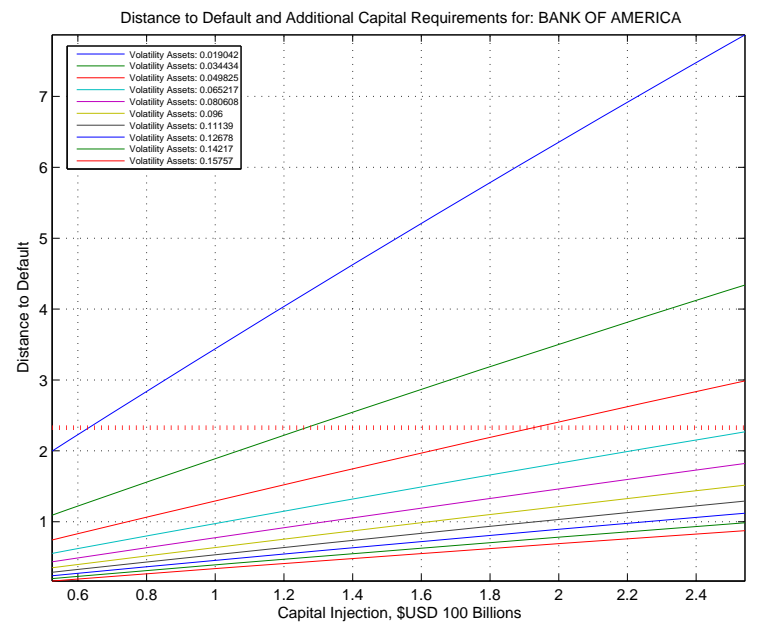

(a) Bank of America

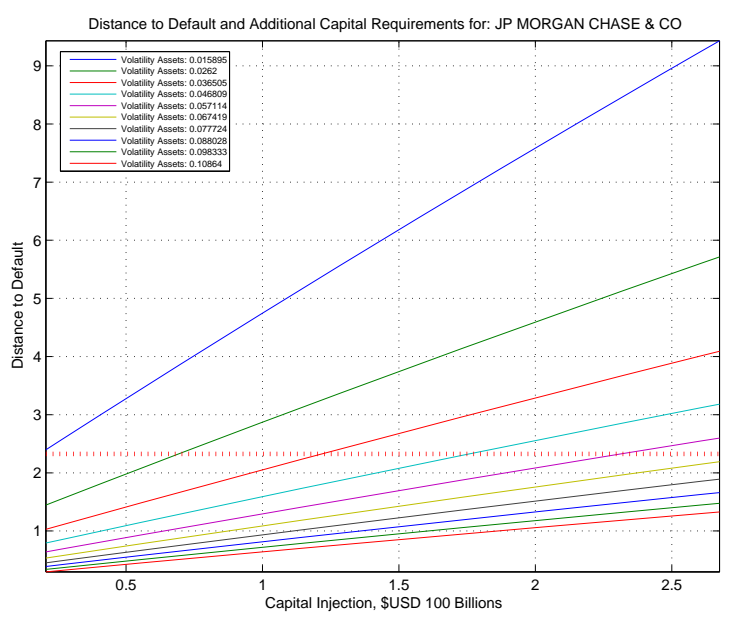

(c) JP Morgan

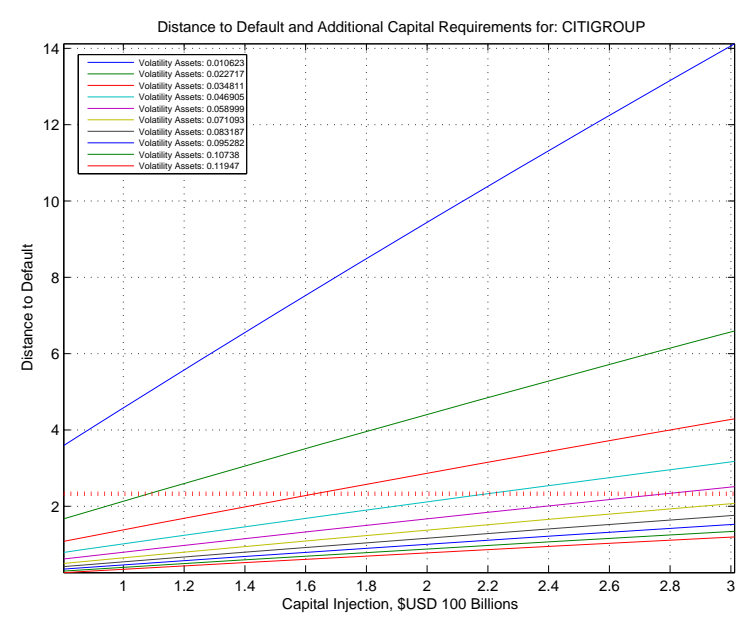

(b) Citigroup

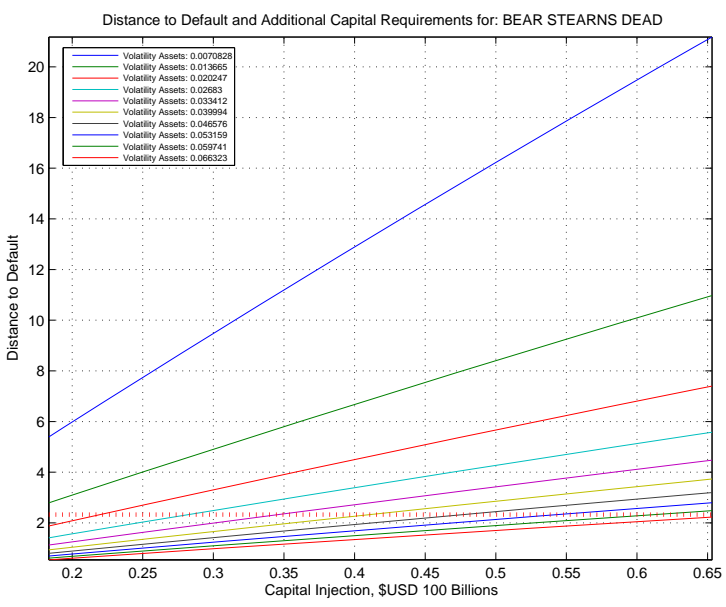

(d) Bear Stearns

Figure 29: Default stress testing for four selected systemically important US financial institutions. 


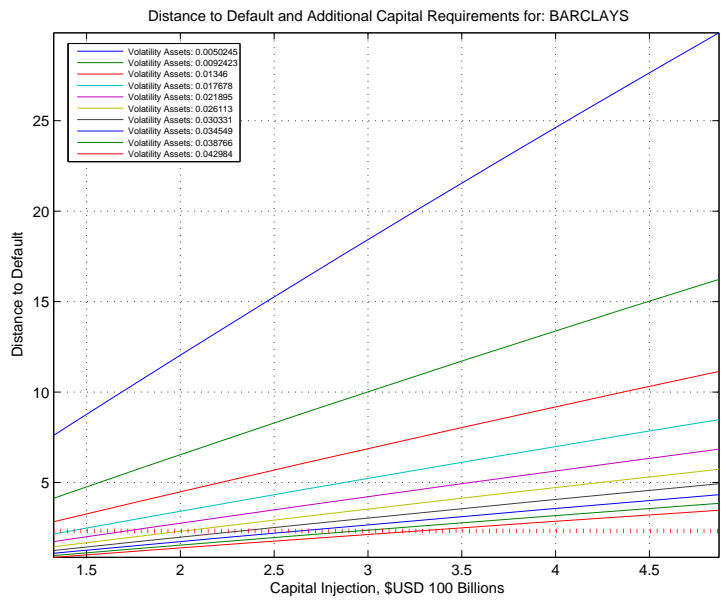

(a) Barclays

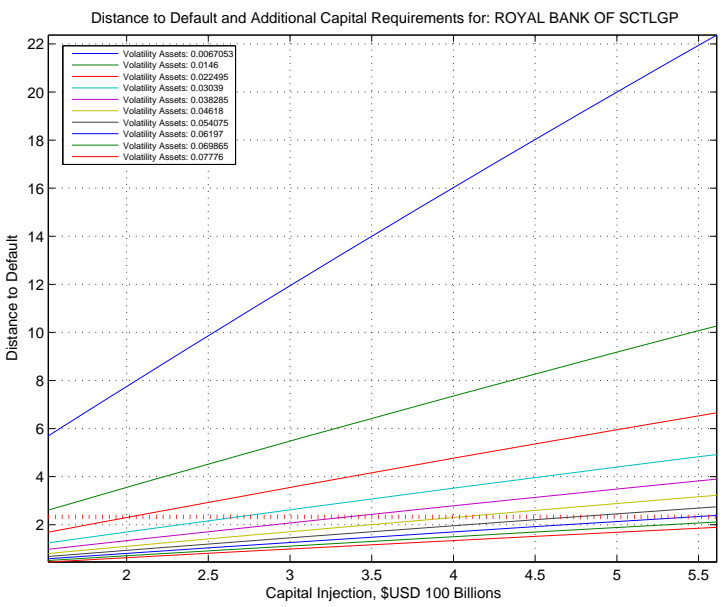

(b) Royal Bank of Scotland

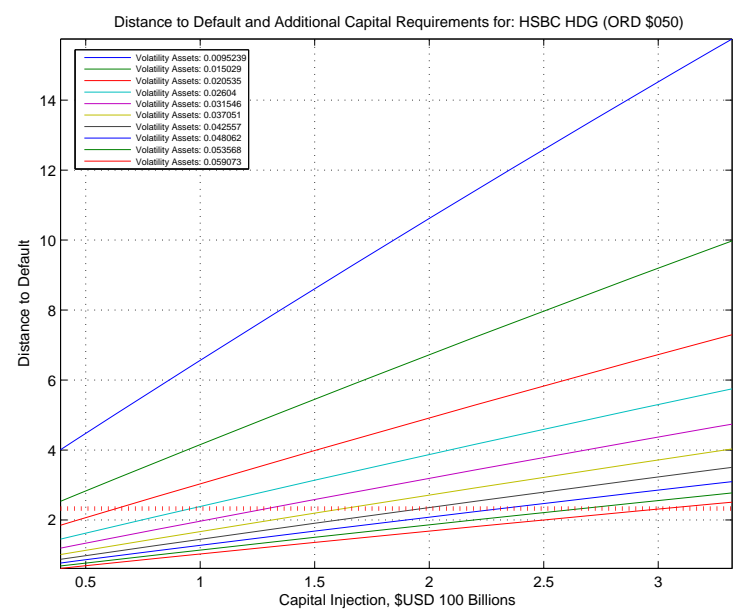

(c) HSBC Holdings

Figure 30: Default stress testing for four selected systemically important UK financial institutions. 


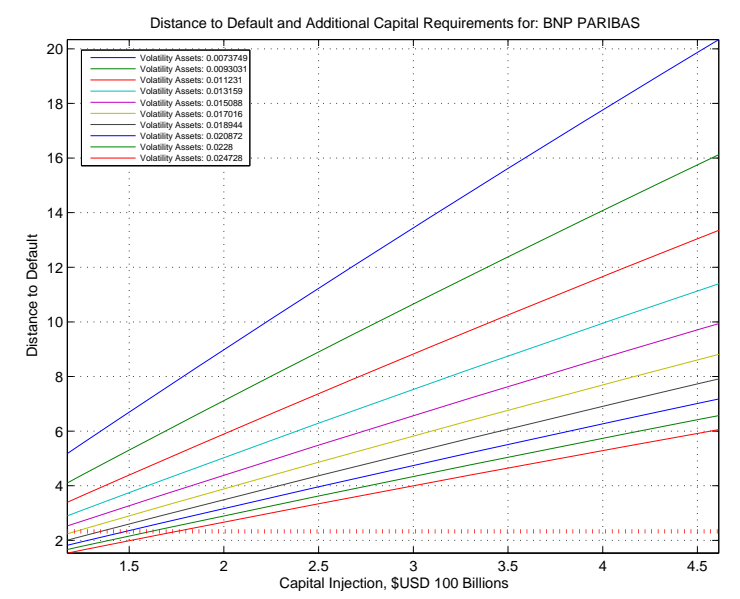

(a) BNP Paribas

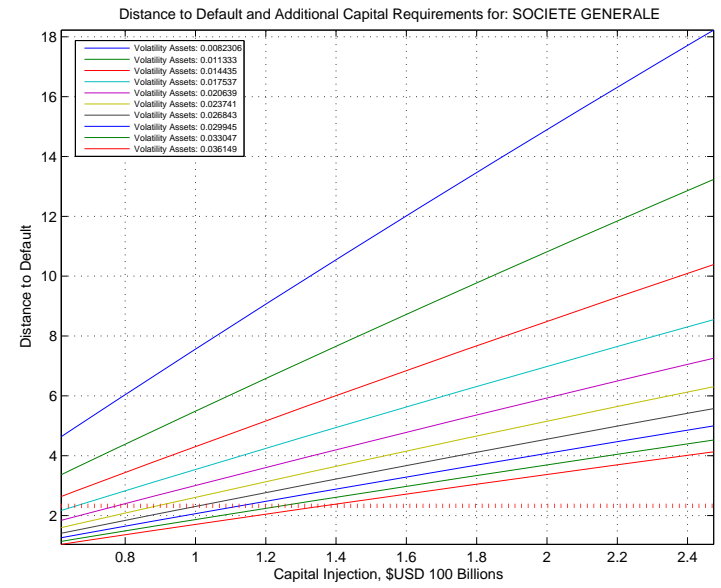

(b) Scociete Generale

Figure 31: Default stress testing for four selected systemically important French financial institutions. 


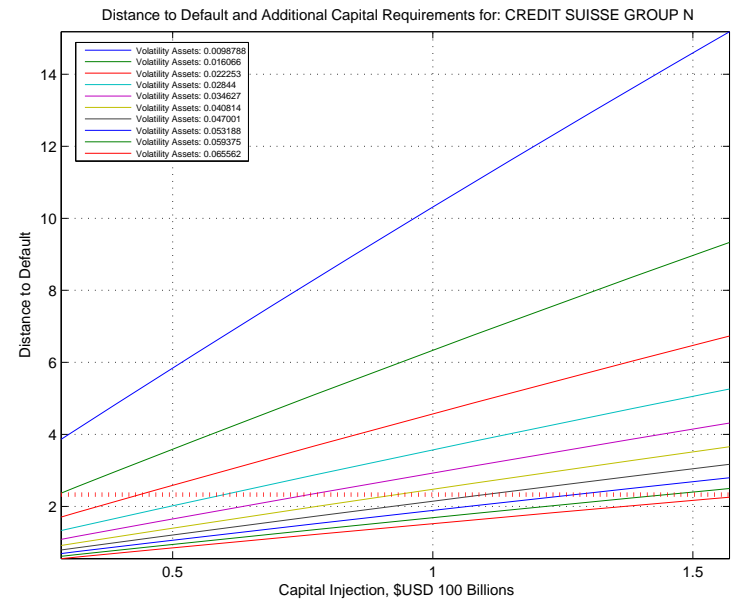

(a) Credit Suisse

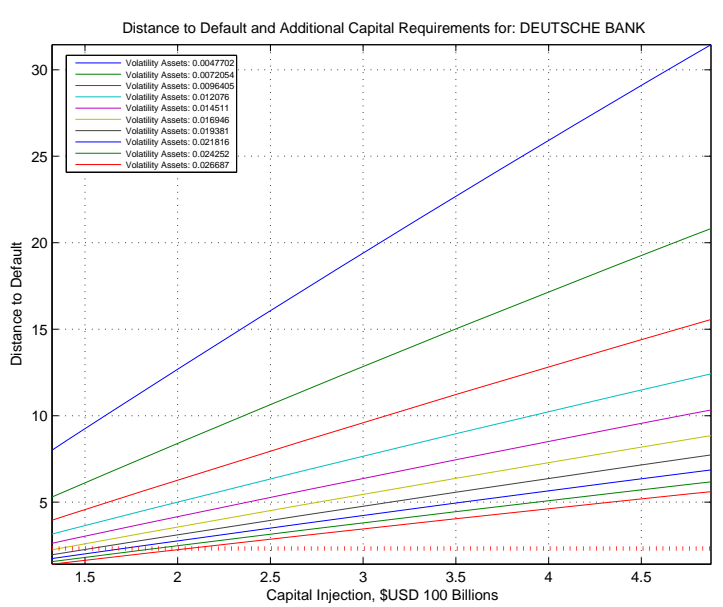

(b) Deutsche Bank

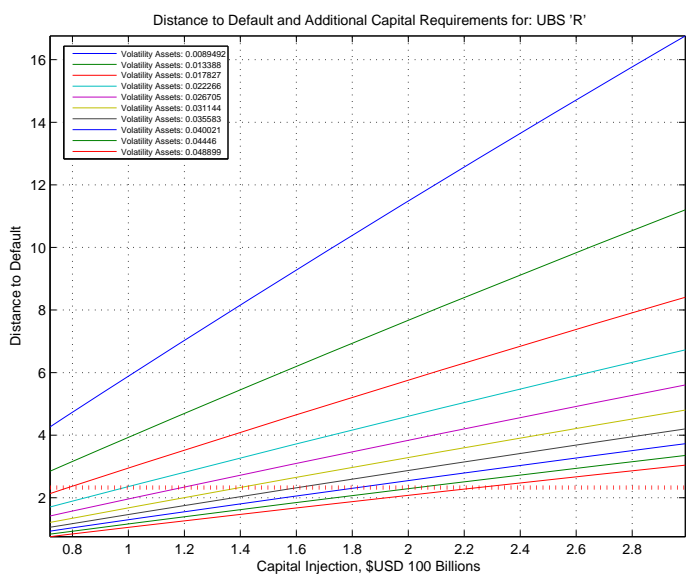

(c) UBS

Figure 32: Default stress testing for four selected systemically important German/Swiss financial institutions. 


\section{F Distance to Default}

The computed D-to-Ds derived from the VAR-MV-GARCH and Merton models are illustrated here. Figure 33 illustrates the implied asset-liability ratios for the 16 banks grouped into geographical region. Comparison can be made between the implied value of assets (figure 34) and reported liabilities (figure 35). Figure 36 outlines the predicted D-to-Ds implied for a one year model while figure 37 illustrates the implied conditional probability of default within one trading year. The model assumes 252 trading days and a geometric brownian motion underlying the stochastic evolution of the assets, therefore $\sigma_{t}^{Y}=\sigma_{t}^{D}\left(\frac{1}{252}\right)^{-\frac{1}{2}}$. Where $\sigma^{Y}$ is annualized volatility and $\sigma^{D}$ is daily volatility.

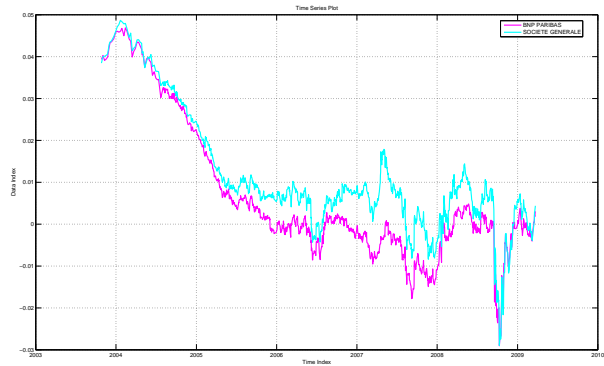

(a) French LCFIs

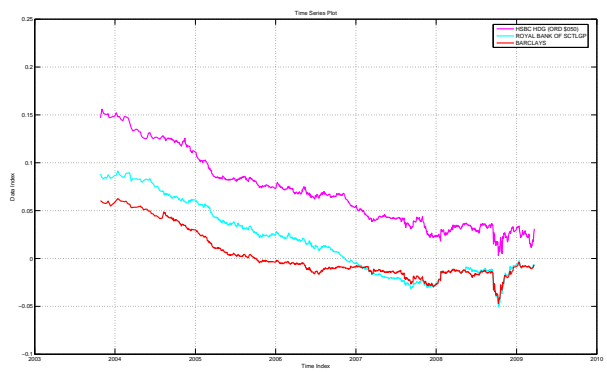

(c) UK LCFIs

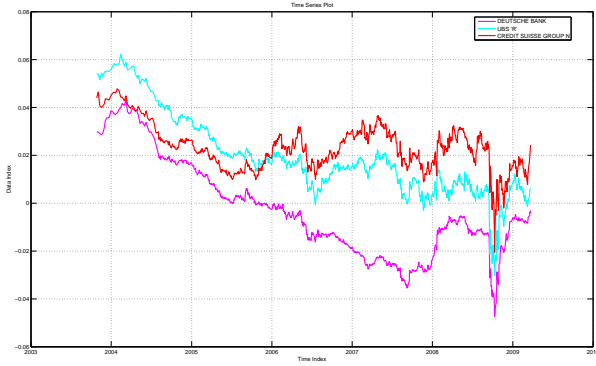

(b) German/Swiss LCFIs

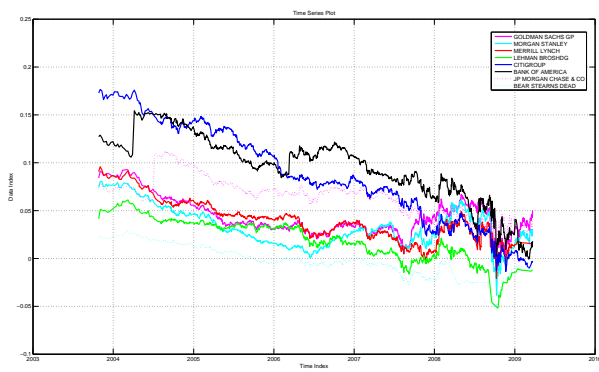

(d) US LCFIs

Figure 33: Imputed Assets to Liabilities Ratio, for US systemically important financial institutions. 


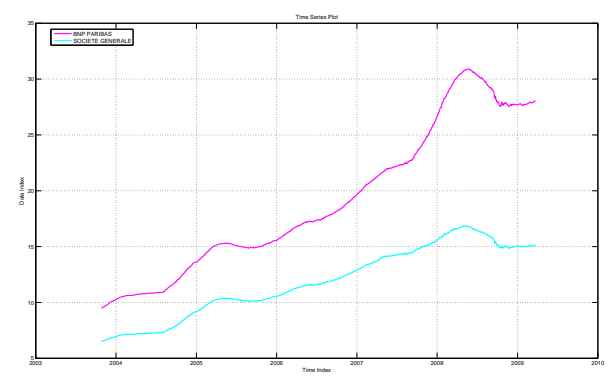

(a) French LCFIs

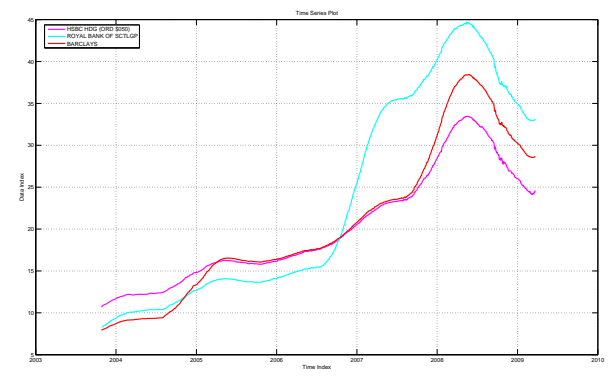

(c) UK LCFIs

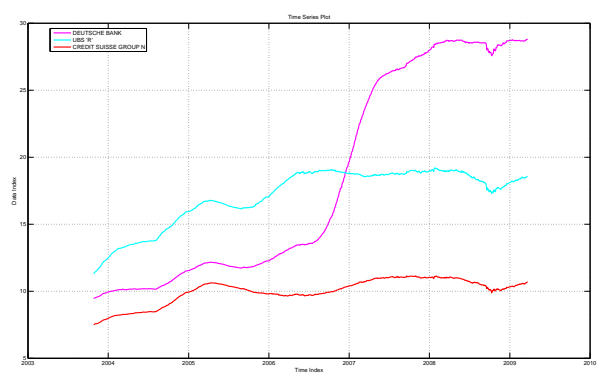

(b) German/Swiss LCFIs

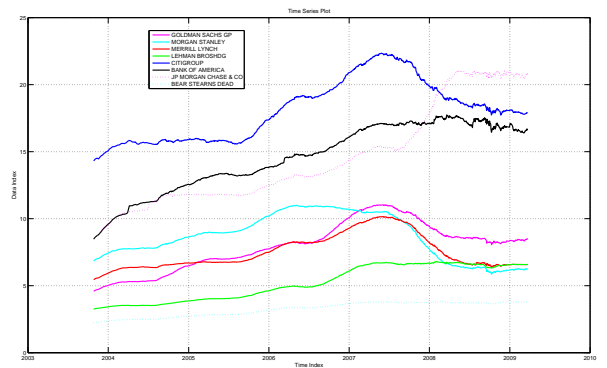

(d) US LCFIs

Figure 34: Imputed value of assets for selected systemically important financial institutions.

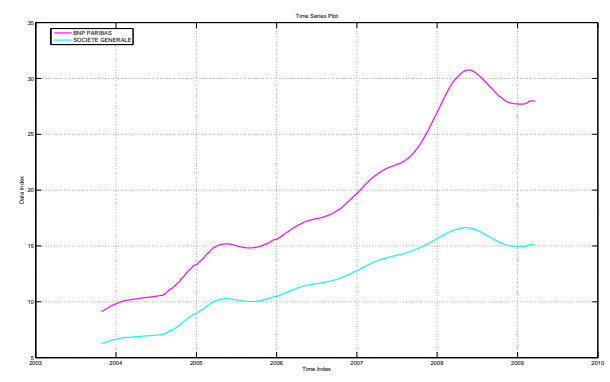

(a) French LCFIs

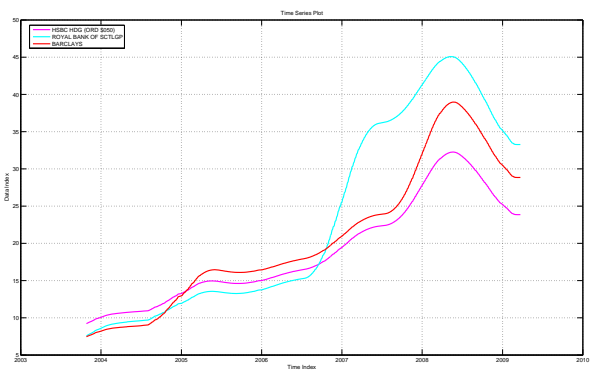

(c) UK LCFIs

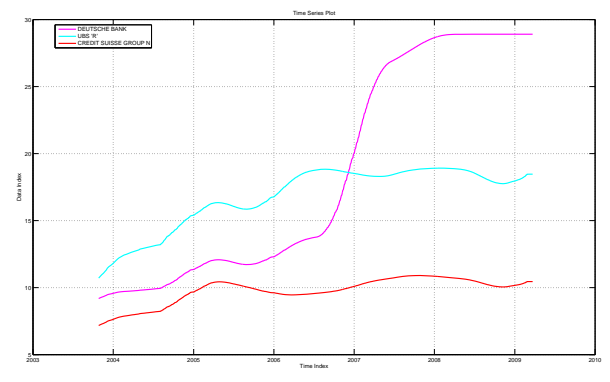

(b) German/Swiss LCFIs

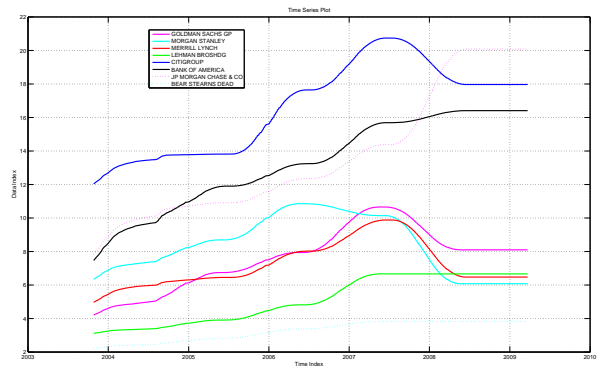

(d) US LCFIs

Figure 35: Total liabilities for selected systemically important financial institutions. 


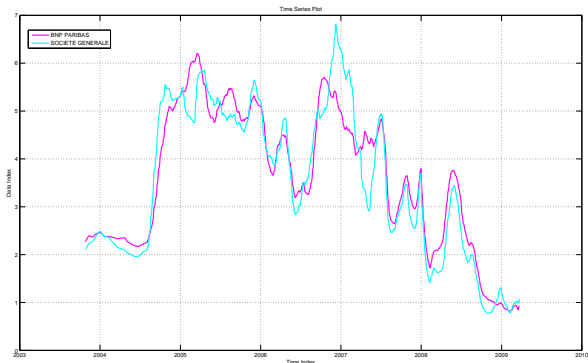

(a) French LCFIs

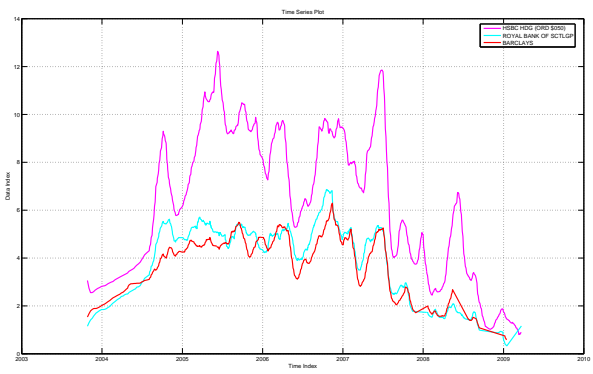

(c) UK LCFIs

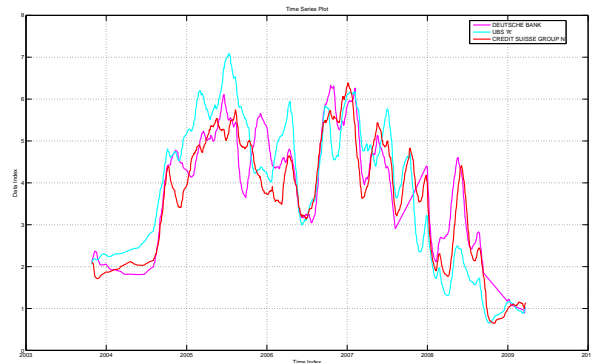

(b) German/Swiss LCFIs

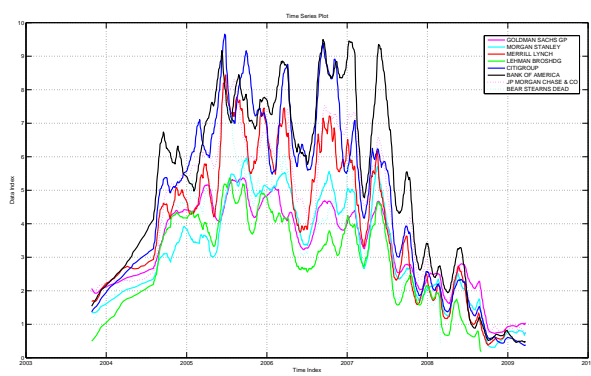

(d) US LCFIs

Figure 36: Conditional D-to-D for selected systemically important financial institutions.

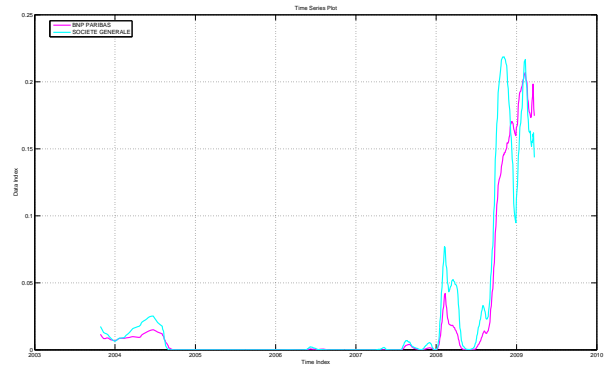

(a) French LCFIs

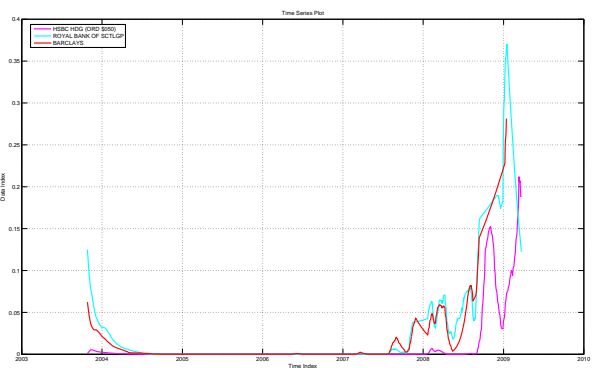

(c) UK LCFIs

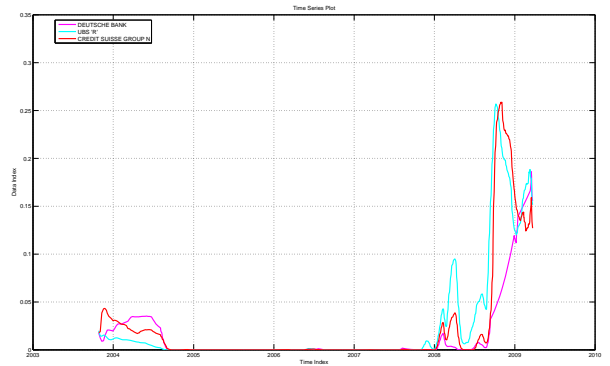

(b) German/Swiss LCFIs

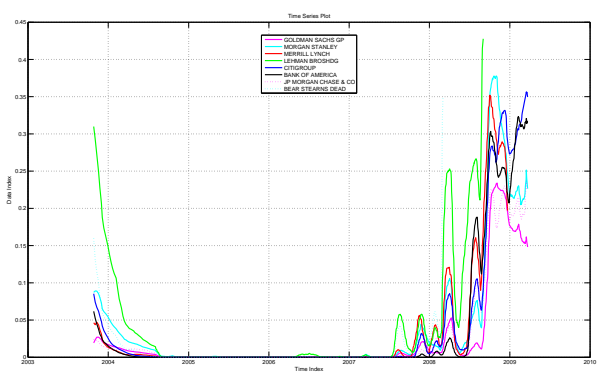

(d) US LCFIs

Figure 37: Imputed conditional probability of default for selected systemically important financial institutions. 


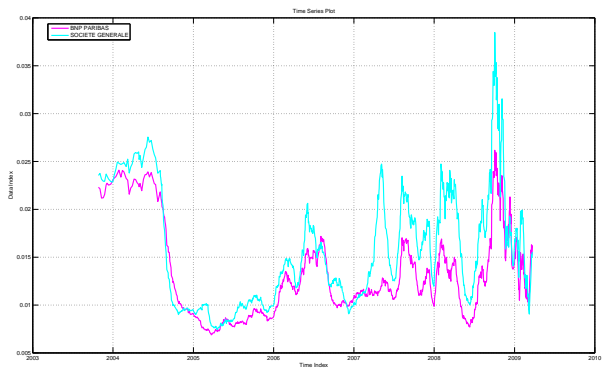

(a) French LCFIs

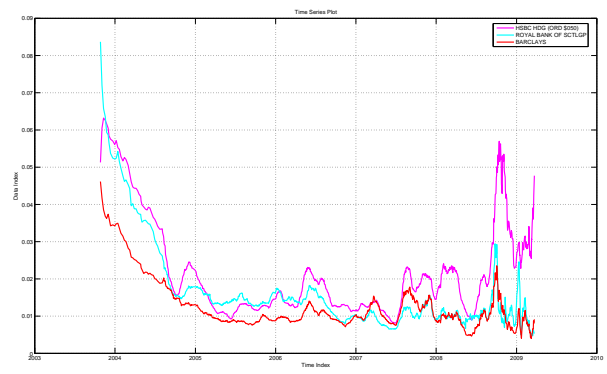

(c) UK LCFIs

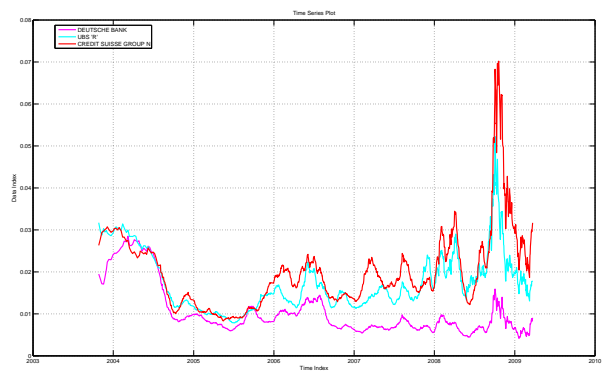

(b) German/Swiss LCFIs

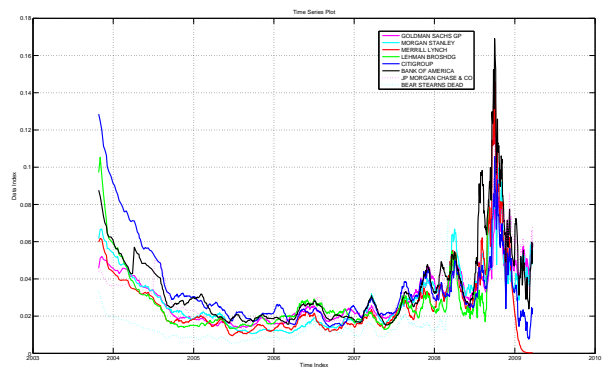

(d) US LCFIs

Figure 38: Imputed volatility of assets for selected systemically important financial institutions. 


\section{G Covariance Analysis of CDS Indices}

Principle component analysis of the various available CDS indices is detailed in the following appendix. We choose the CDX 5 year investment grade and iTraxx 5 year investment grade indices to represent the stochastic evolution of the credit conditions of the global market. This appendix illustrates some of the preliminary data analysis undertaken on the broad list of spreads available. The 5 year investment grade indices are suggested to be the most liquid and long running of the index products available from iTraxx and CDX. HiVol or High Yield indices (iTraxx and CDX respectively) are also available as benchmarks. We have collected data on 377 measures of credit risk, these are plotted in figures 22 to figure 26.

\section{G.1 Principle Components}

We consider a very broad cross section of credit indices and run a principle component analysis on the whole sample and rolling covariance of these indices. First consider a broad list of CDS indices (measures in log differences):

$$
\begin{aligned}
& \mathbf{x}_{t}=\left[x_{1, t}, x_{2, t}, \ldots, x_{N, t}\right]^{\prime} \\
& \mathbf{X}=\left[\begin{array}{c}
\mathbf{x}_{t=1} \\
\mathbf{x}_{t=2} \\
\vdots \\
\mathbf{x}_{t=\tau}
\end{array}\right]
\end{aligned}
$$

The long run covariance matrix is

$$
\boldsymbol{\Sigma}=\frac{1}{\tau} \mathbf{X}^{\prime} \mathbf{X}
$$

The eigenvalues of this matrix are $\lambda_{i} \boldsymbol{\Sigma}=\lambda_{i} \mathbf{z}, \quad i \in\{1, \ldots, N\}$ and are ranked by magnitude, the largest eigenvalue is denoted as, $\lambda_{\max }=\max \lambda_{i}$, the principle components are,

$$
\mathbf{P}=\mathbf{X W}
$$

where $\mathbf{W}$ is the matrix consisting of the concatenated eigenvectors of the $k$ largest eigenvalues of $\boldsymbol{\Sigma}$. Figure 39 illustrates the time evolution of the six largest principle components from a broad list of 377 different spreads (data from Thomson-Reuters). We truncate the eigenvalues to include only those which when normalized against the largest eigenvalue contribute cumulatively to above $95 \%$ of

the variation. Dynamic covariance analysis involves computing the fixed window rolling covariance and we then plot the largest eigenvalues, using a 50 day moving average, $\boldsymbol{\Sigma}_{\mathbf{t}}$. Figure 40 illustrates the evolution of the 6 largest eigenvalues of this rolling covariance matrix. 


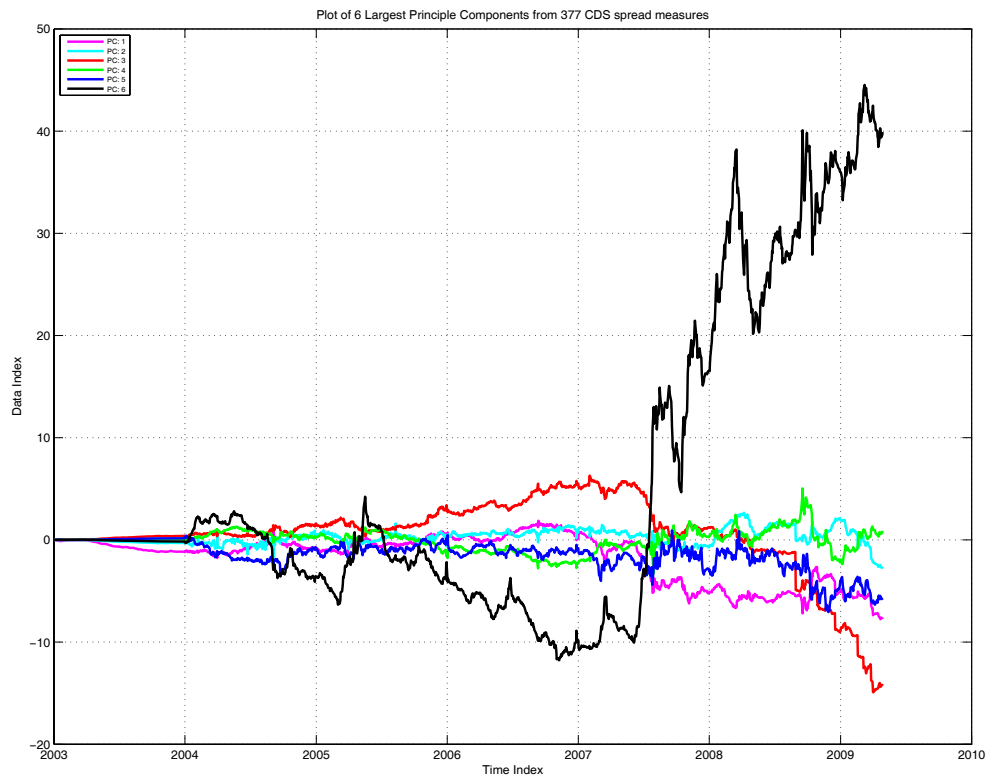

Figure 39: Evolution of the 6 largest principle components, CDS spreads in log differences.

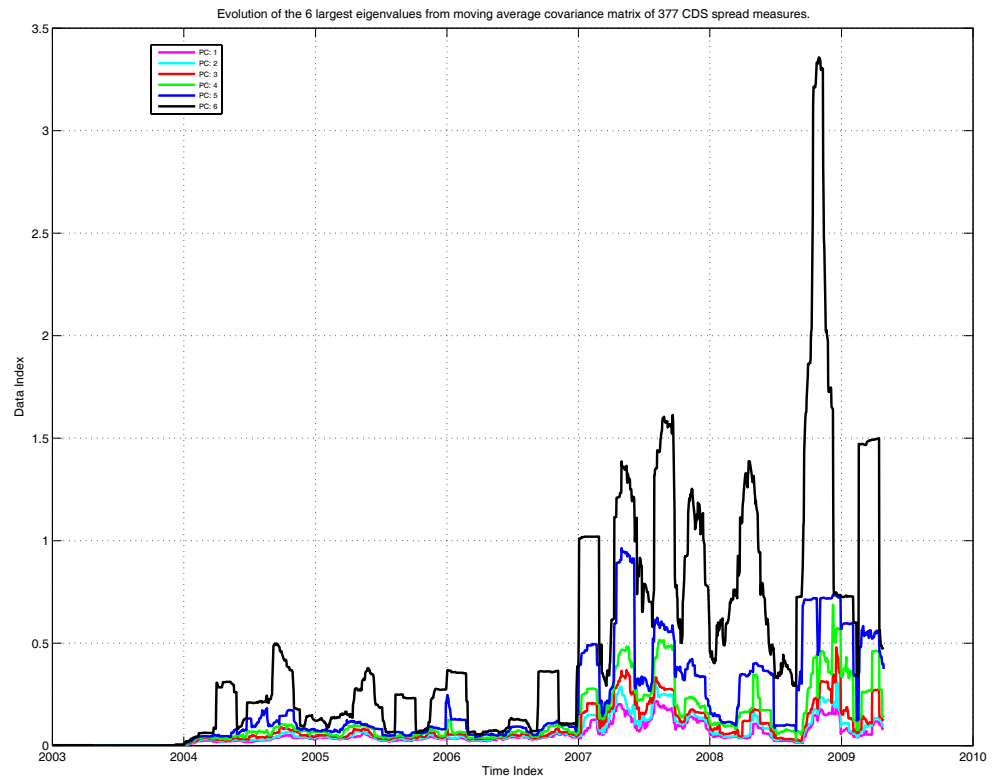

Figure 40: Plot of the evolution of the 6 largest eigenvalues of the rolling covariance matrix, $\boldsymbol{\Sigma}_{t}$. 